Raphael Schwarz

\title{
Model-Based Quantification of Pathological Voice Production
}





\title{
Model-Based Quantification of Pathological Voice Production
}

\author{
Der Technischen Fakultät der \\ Universität Erlangen-Nürnberg \\ zur Erlangung des Grades
}

\section{DOKTOR-INGENIEUR}

vorgelegt von

Dipl.-Ing. Raphael Schwarz

Erlangen - 2007 
Als Dissertation genehmigt von der Technischen Fakultät der Universität Erlangen-Nürnberg

Tag der Einreichung 10.04.2007

Tag der Promotion: 15.05 .2007

Dekan : Prof. Dr. A. Leipertz

Berichterstatter : Prof. Dr. Dr. U. Eysholdt

Prof. Dr. R. Lerch 


\title{
Modellbasierte Quantifizierung der pathologischen Stimmgebung
}

\author{
Der Technischen Fakultät der \\ Universität Erlangen-Nürnberg \\ zur Erlangung des Grades
}

\section{DOKTOR-INGENIEUR}

vorgelegt von

Dipl.-Ing. Raphael Schwarz

Erlangen - 2007 



\section{Danksagung}

Meinem Doktorvater Prof. Dr. Dr. Ulrich Eysholdt danke ich für die Aufnahme in seiner Abteilung und für die Überlassung des Themas. Sein Engagement ermöglichte interdisziplinäre Strukturen, welche eine substantielle Basis meiner Arbeit waren.

Bei Herrn Prof. Dr. Reinhard Lerch möchte ich mich für die gewährte Unterstützung und für die Übernahme des Korreferats bedanken.

Ein großer Dank geht an meine beiden Betreuer Dr. Jörg Lohscheller und PD Dr. Michael Döllinger, die sich stets Zeit für Diskussionen nahmen und viele wertvolle Anregungen zur Arbeit gaben. Insbesondere bin ich ihnen dankbar für ihre Mühen beim Durcharbeiten meiner Manuskripte und die resultierenden konstruktiven Kritiken.

Martin Burger und Tobias Wurzbacher haben den Entstehungsprozess der vorliegenden Arbeit unmittelbar miterlebt und konstruktiv unterstützt. Für die zahlreichen Diskussionen und Anregungen möchte ich mich herzlich bedanken.

Ebenso danke ich Prof. Dr. Dr. Ulrich Hoppe für die intensive Zusammenarbeit.

Weiterhin bin ich den Mitarbeitern der Abteilung für Phoniatrie und Pädaudiologie zu Dank verpflichtet. Namentlich seien hier Dr. Hikmet Toy und PD Dr. Maria Schuster für die Erstellung der Hochgeschwindigkeitsaufnahmen und für die geduldige und aufschlussreiche Beantwortung medizinischer Fragestellungen erwähnt.

Ein ganz besonderer Dank gilt meiner Familie, die meinen bisherigen Lebensweg so liebevoll unterstützt hat. Ebenso bedanke ich mich bei meiner Freundin Dorothee, die mir durch ihr Interesse an meiner Arbeit sowie ihr Verständnis und aufgebrachte Geduld während der Erstellung des Manuskripts eine wertvolle Stütze war.

Die vorliegende Arbeit wurde im Rahmen des Projekts DFG Ey15/10 der Deutschen Forschungsgemeinschaft sowie des Teilprojekts B5 des Sonderforschungsbereichs 603 "Modellierung und Visualisierung komplexer Szenen und Sensordaten" gefördert.

Erlangen, Mai 2007. 



\section{Zusammenfassung}

Heiserkeit, das primäre Symptom einer Stimmstörung, beruht auf irregulären Stimmlippenschwingungen. Der vollständige Verlust der Stimme ist wohl die extremste Form einer Stimmstörung. Die onkologische Therapie von Kehlkopfkrebs kann solch einen Stimmverlust zur Folge haben, wenn Lage und Zustand des Tumors eine vollständige Entfernung des Kehlkopfes und damit der Stimmlippen notwendig macht. Infolgedessen verliert der Patient zunächst die Fähigkeit zu sprechen. Um in solch einem Fall eine Stimmrehabilitation zu ermöglichen, wird Narbengewebe am oberen Ende der Speiseröhre (PE-Segment) zur Ersatzstimmgebung genutzt. Die Qualität sowohl von Normal- als auch Ersatzstimme hängt maßgeblich von der Anatomie und den Schwingungsmustern der stimmgebenden Elemente ab. Mittels endoskopischer Hochgeschwindigkeitsaufnahmen können die Tongeneratoren während der Stimmgebung in Echtzeit beobachtet werden. Die digitale Aufnahmetechnik ermöglicht eine rechnergestützte Auswertung der erzeugten Bilddaten.

In der vorliegenden Arbeit werden Methoden zur modellbasierten Analyse und objektiven Quantifizierung der aus den digitalen Bilddaten extrahierten Schwingungsmuster entwickelt. Prinzipiell wird die Dynamik eines biomechanischen Modells des Tongenerators an das tatsächlich beobachtete Schwingungsmuster unter Verwendung einer automatischen Parameteroptimierung angepasst. Dabei wird neben der Frequenz und Amplitude auch die spezifische Wellenform der Schwingung berücksichtigt. Die Anpassung der Modelldynamik stellt ein Optimierungsproblem mit nichtkonvexer Zielfunktion dar. Die berechneten Werte der Modellparameter liefern eine objektive Quantifizierung der Dynamik des Tongenerators. Stabilität und Zuverlässigkeit der entwickelten Optimierungsalgorithmen werden mit synthetisch generierten Schwingungsmustern nachgewiesen. Erste Studien mit klinischen Datensätzen belegen die Anwendbarkeit der entwickelten Methoden zur objektiven Quantifizierung und Klassifizierung von Schwingungsmustern der Stimmlippen und des PE-Segments. 



\section{Contents}

1 Introduction 1

2 Fundamentals 5

2.1 Functional Anatomy of the Larynx . . . . . . . . . . 6

2.2 Voice Generating Process . . . . . . . . . . . . . . . . . 12

2.3 Voice Disorders . . . . . . . . . . . . . . . . . . . . . 13

2.3.1 Organic Voice Disorders . . . . . . . . . . . . 13

2.3.2 Functional Voice Disorders . . . . . . . . . . . . . . 14

2.4 Total Laryngectomy . . . . . . . . . . . . . . . . . . . . 14

2.4.1 Laryngeal Cancer . . . . . . . . . . . . . . . 15

2.4.2 Substitute Voice Generation . . . . . . . . . 16

3 High-Speed Recordings $\quad 19$

3.1 High-Speed Imaging of the Vocal Folds . . . . . . . . . . 20

3.2 High-Speed Imaging of the PE Segment. . . . . . . . . . . 22

4 Image Processing $\quad 25$

4.1 Extraction of the Vocal Fold Dynamics . . . . . . . . . 25

4.1.1 Single-Line Trajectories . . . . . . . . . . . . 27

4.1.2 Multi-Line Trajectories . . . . . . . . . . . . . 29

4.2 Extraction of the PE Dynamics . . . . . . . . . . 30

5 Model-Based Classification 33

5.1 Two-Mass Model . . . . . . . . . . . . . . . . . 35

5.1 .1 Anchor Force . . . . . . . . . . . . . . . 37

5.1 .2 Vertical Coupling Force . . . . . . . . . . . 38

5.1 .3 Collision Force . . . . . . . . . . . . . . . . . . . 38

5.1 .4 Driving Force . . . . . . . . . . . . . . . . . 39 
5.2 Simulation of Vocal Fold Vibrations . . . . . . . . . . . 40

5.2.1 Defining Non-Standard Model Configurations . . . 41

5.2.2 Dynamics of Asymmetric Model Configurations . . 41

5.3 Objective Function . . . . . . . . . . . . . . . . 43

5.4 Automatic Parameter Optimization . . . . . . . . . . 45

5.4 .1 Initial Value Search . . . . . . . . . . . . . . 46

5.4.2 Optimization Procedure . . . . . . . . . . . . 49

5.5 Validation of the Parameter Optimization . . . . . . 50

5.6 Application to Clinical Data . . . . . . . . . . . 51

5.6 .1 Clinical Data . . . . . . . . . . . . . . 51

5.6 .2 Adaptation Results . . . . . . . . . . . . . 53

5.6.3 Interpretation of the Model-Based Classification . . 57

6 Spatio-Temporal Quantification $\quad 63$

6.1 Multi-Mass Model . . . . . . . . . . . . . . . . . 64

6.1 .1 Anchor Force . . . . . . . . . . . . . . . 68

6.1.2 Vertical Coupling Force . . . . . . . . . . . . 68

6.1.3 Longitudinal Coupling Force . . . . . . . . . . . . 68

6.1.4 Collision Force . . . . . . . . . . . . . . . . . 69

6.1.5 Driving Force . . . . . . . . . . . . . . . 70

6.2 Optimization Parameters . . . . . . . . . . . . . . 72

6.3 Objective Function . . . . . . . . . . . . . . . . . . . 72

6.4 Automatic Parameter Optimization . . . . . . . . . . 73

6.4.1 Model Initialization . . . . . . . . . . . . . . . . . 74

6.4.2 Optimization Procedure . . . . . . . . . . 75

6.5 Validation with Synthetic Data Sets . . . . . . . . . 78

6.5.1 Validation Results . . . . . . . . . . . . . 79

6.6 Application to Real Vocal Fold Oscillations . . . . . . . . . 81

6.7 Interpretation of the Clinical Results . . . . . . . . . . 89

7 Quantification of PE Segment Vibrations 93

7.1 Multi-Mass Model of the PE Segment . . . . . . . . . . . 93

7.2 Automatic Parameter Optimization . . . . . . . . . . 96

7.2.1 Optimization Parameters . . . . . . . . . . . . 96

7.2 .2 Objective Function . . . . . . . . . . . . . . 96

7.2.3 Model Initialization and Optimization Procedure . 98

7.2.4 Validation with Synthetic Data Sets . . . . . . . . 99 
7.3 Application to Real PE Segment Oscillations . . . . . . . . 101

8 Summary and Outlook 105

A PE-MMM Fitting Results 109

$\begin{array}{ll}\text { List of Abbreviations } & 113\end{array}$

$\begin{array}{ll}\text { Bibliography } & 115\end{array}$

$\begin{array}{ll}\text { List of Figures } & 129\end{array}$

$\begin{array}{ll}\text { List of Tables } & 131\end{array}$

$\begin{array}{ll}\text { Curriculum Vitae } & 133\end{array}$ 


\section{Inhaltsverzeichnis}

1 Einleitung 1

2 Grundlagen $\mathbf{5}$

2.1 Funktionelle Anatomie des Kehlkopfes $\ldots \ldots \ldots \ldots \ldots \ldots \ldots$

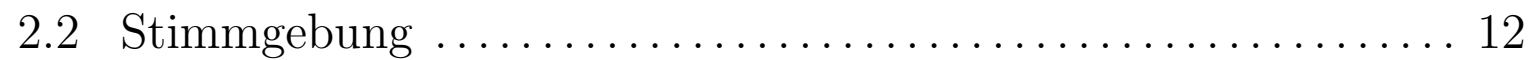

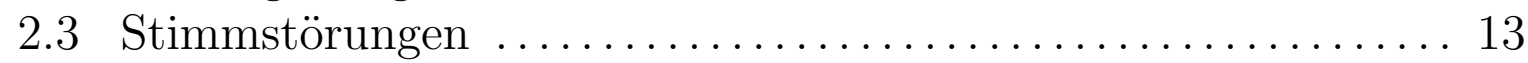

2.3.1 Organische Stimmstörungen $\ldots \ldots \ldots \ldots \ldots \ldots \ldots \ldots \ldots$

2.3.2 Funktionelle Stimmstörungen $\ldots \ldots \ldots \ldots \ldots \ldots \ldots \ldots$

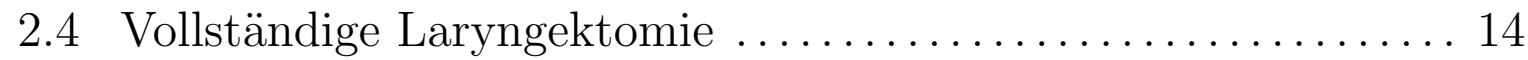

2.4 .1 Kehlkopfkrebs ............................ 15

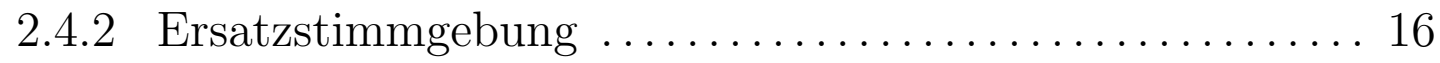

3 Hochgeschwindigkeitsaufnahmen $\quad 19$

3.1 Hochgeschwindigkeitsaufnahmen der Stimmlippen ......... 20

3.2 Hochgeschwindigkeitsaufnahmen des PE-Segments .......... 22

4 Bildverarbeitung $\quad 25$

4.1 Extraktion der Stimmlippendynamik ................. 25

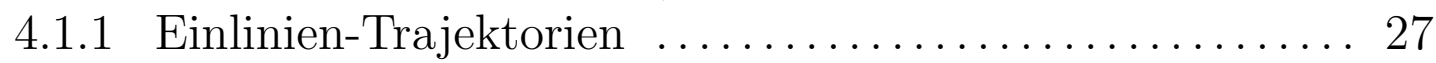

4.1.2 Mehrlinien-Trajektorien ...................... 29

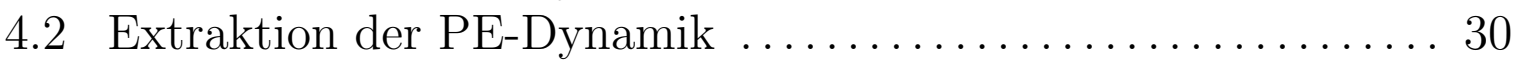

5 Modellbasierte Klassifizierung 33

5.1 Zwei-Massen-Modell ............................... 35

5.1 .1 Ankerkraft ................................ 37

5.1 .2 Vertikale Kopplungskraft $\ldots \ldots \ldots \ldots \ldots \ldots \ldots \ldots \ldots$ 
5.1 .3 Kollisionskraft ............................. 38

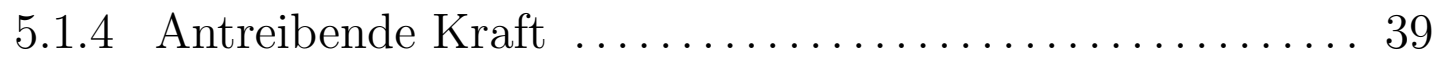

5.2 Simulation von Stimmlippenschwingungen $\ldots \ldots \ldots \ldots \ldots \ldots 40$

5.2.1 Definition verschiedener Modellkonfigurationen ........ 41

5.2.2 Dynamik asymmetrischer Modellkonfigurationen ...... 41

5.3 Zielfunktion .................................. 43

5.4 Automatische Parameteroptimierung ................. 45

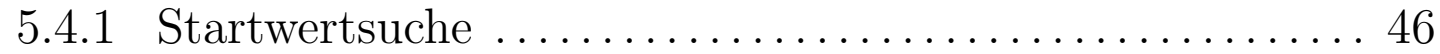

5.4 .2 Optimierungsprozedur $\ldots \ldots \ldots \ldots \ldots \ldots \ldots \ldots \ldots \ldots \ldots$

5.5 Validierung der Parameteroptimierung ................ 50

5.6 Anwendung auf klinische Datensätze .................. 51

5.6 .1 Klinische Daten ............................ 51

5.6 .2 Anpassungsergebnisse ...................... 53

5.6.3 Interpretation der modellbasierten Klassifizierung ..... 57

6 Räumlich-Zeitliche Quantifizierung 63

6.1 Mehr-Massen-Modell .............................. 64

6.1 .1 Ankerkraft ............................... 68

6.1 .2 Vertikale Kopplungskraft $\ldots \ldots \ldots \ldots \ldots \ldots \ldots \ldots 68$

6.1.3 Longitudinale Kopplungskraft ................. 68

6.1 .4 Kollisionskraft ............................ 69

6.1.5 Antreibende Kraft ........................... 70

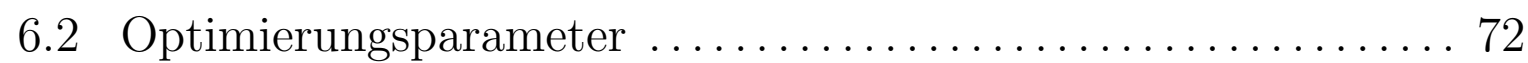

6.3 Zielfunktion ..................................... 72

6.4 Automatische Parameteroptimierung ................. 73

6.4.1 Modellinitialisierung ........................ 74

6.4.2 Optimierungsprozedur ...................... 75

6.5 Validierung mit synthetischen Datensätzen .............. 78

6.5.1 Validierungsergebnisse $\ldots \ldots \ldots \ldots \ldots \ldots \ldots \ldots \ldots \ldots \ldots$

6.6 Anwendung auf klinische Datensätze ................. 81

6.7 Interpretation der klinischen Ergebnisse ............... 89

7 Quantifizierung von Schwingungen des PE-Segments 93

7.1 Mehr-Massen-Modell des PE-Segments ................. 93

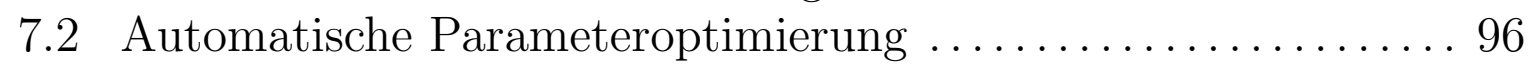

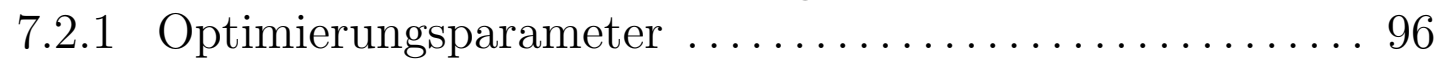

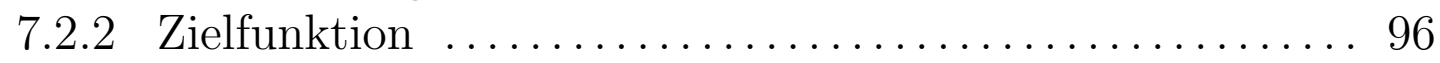


7.2.3 Modellinitialisierung und Optimierung ............ 98

7.2.4 Validierung mit synthetischen Daten ............... 99

7.3 Anwendung auf reelle Schwingungen des PE-Segments ..... 101

8 Zusammenfassung und Ausblick 105

$\begin{array}{ll}\text { A Anpassungsergebnisse des PE-MMM } & 109\end{array}$

$\begin{array}{ll}\text { Abkürzungsverzeichnis } & 113\end{array}$

$\begin{array}{ll}\text { Literaturverzeichnis } & 115\end{array}$

$\begin{array}{ll}\text { Abbildungsverzeichnis } & 129\end{array}$

$\begin{array}{ll}\text { Tabellenverzeichnis } & 131\end{array}$

$\begin{array}{ll}\text { Lebenslauf } & 133\end{array}$ 


\section{Introduction}

Voice is the most important human means of expression. During verbal communication, voice conveys ideas and emotions and represents a very efficient way of interpersonal information exchange [1]. In our modern society its importance is increasing for different areas of life (e.g., work, spare time, consumption). In particular, this development is noticeable for the economic-industrial sector. During the last half of the $20^{\text {th }}$ century, the economic basis of our industrial society has changed significantly. A fundamental change towards a service-oriented economy is observable which results in an increasing emphasis on communication skills - hearing, voice, speech, and language [2,3]. More and more people rely on their ability of verbal communication and thus the treatment of voice disorders comes to the fore. Currently, it is estimated for the US that up to $10 \%$ of the population suffers from voice disorders with an economic impact of approximately $\$ 180$ billion dollars annually, which is equal to $3 \%$ of the Gross National Product [4]. A report of the US Department of Labor from 1997 states that the rate of unemployment amounts nearly $70 \%$ for people with problems in producing intelligible speech [5]. As a consequence, the diagnosis and efficient medical treatment of voice disorders will be an important theme for the $21^{\text {st }}$ century.

The source of the voice signal — the vocal folds - are located within the human larynx. Its functional anatomy and the principles of the voice generating process are summarized in Chapter 2. An overview concerning the classification of voice disorders is given. In addition, an extreme form of voice disorder, the total excision of the larynx due to laryngeal cancer, is presented. Following the loss of the larynx, a substitute voice generating element has to compensate the function of the excised vocal folds. The state-of-the-art rehabilitation technique for this aim, the tracheoesophageal substitute voice is explained. As substitute voice generator, tissue in the upper part of the esophagus (PE segment) is used. 
A common approach in clinical voice assessment is the analysis of the acoustic speech signal,or and thus of the hoarseness, the predominant symptom of voice disorders. However, this method provides only symptomatic information since the etiologies of hoarseness, namely irregular vibrations of the voice generating element, remain unconsidered. A more sophisticated approach are endoscopic high-speed examination techniques, where the vocal folds or the PE segment are observed during voice production. The vibration patterns are observed endoscopically using a digital highspeed camera. The imaging procedures for recording the dynamics of the voice generator in real-time are described in Chapter 3.

Chapter 4 explains the applied image processing algorithms for the segmentation of the opening formed by the vocal fold edges, the so-called glottis, and the contour of the PE segment. Due to the different morphology of vocal folds and the PE segment, their dynamics are described in different ways. Deflection measurements deliver a description of the vocal fold oscillations. The time-dependent distances of specific vocal fold edge points to the glottal axis are extracted as one-dimensional trajectories. For a direct evaluation of these trajectories asymmetry measures as amplitude ratio and phase shift between left and right vocal fold are utilized. Since there exist no symmetry axes for the contour of the PE segment, the dynamics is described by the time-varying opening area. In this way, oscillation amplitude and frequency as well as the ratio between duration of open and closed phase can be evaluated.

The main drawback of the direct evaluated vocal fold trajectories or area function are the unconsidered wave forms of the oscillations as well as the unregarded specific morphology of the voice generator. The present work focuses on the application of a model-based approach for an objective quantification of the segmented high-speed recordings. As principle idea the dynamics of a biomechanical model of the voice generator is fitted to the extracted oscillation patterns by means of an automatic parameter optimization. The resulting parameter values objectively quantify the dynamics of the voice generator.

Chapter 5 addresses the approach of classifying vocal fold oscillations in case of one-sided vocal fold paralyses. As biomechanical vocal fold model the so-called two-mass model, a one-dimensional lumped-element model, is applied $[6,7]$. The automatic parameter optimization is subdivided into a 
knowledge-based initial value search and a genetic search algorithm. The proposed parameter optimization procedure is verified with synthetically generated data sets and applied to vocal fold oscillations of healthy subjects and subjects suffering from unilateral recurrent laryngeal nerve paralysis. The resulting optimization parameters are discussed and a classification scheme is derived. The two-mass model approach is augmented in Chapter 6 to enable an objective quantification that takes also longitudinal vibration modes into account. The multi-mass model, a two-dimensional extension of the two-mass model, combined with a new automatic optimization procedure is introduced. As for the one-dimensional approach, the proposed method is verified with synthetic data sets and applied to clinical data.

The quality of the substitute voice significantly depends on the vibratory characteristics of the PE segment $[8,9]$. For improving the voice rehabilitation the relationship between the PE dynamics and the resulting substitute voice quality is a matter of particular interest. Precondition for a comprehensive analysis of this relationship is an objective quantification of the $\mathrm{PE}$ vibrations. For quantification purpose, in Chapter 7 a method is proposed which is based on the reproduction of the tissue movements with a biomechanical model of the PE segment. This model is derived from the multi-mass model of the vocal folds which is adapted to the morphology of the PE segment. An optimization procedure for an automatic determination of appropriate model parameters is developed to adapt the model dynamics to tissue movements extracted from high-speed videos. The proposed method is applied to clinical data. The resulting model parameters objectively quantify the PE dynamics. 


\section{Einleitung}

Die Stimme ist die wichtigste Ausdrucksform des Menschen und stellt eine sehr effiziente Methode zur Übertragung von Ideen und Gefühlen im Zuge der zwischenmenschlichen Kommunikation dar [1]. Die Bedeutung der verbalen Kommunikation nimmt in verschiedenen Lebensbereichen unserer modernen Gesellschaft (z.B. Beruf, Freizeit, Konsum) stetig zu. Insbesondere ist diese Entwicklung auf dem wirtschaftlichen und industriellen Sektor bemerkbar. In der zweiten Hälfte des 20. Jahrhunderts hat sich die Basis unserer Industriegesellschaft deutlich verändert. Der grundlegende Wandel hin zu einer service-orientierten Wirtschaft ist offensichtlich, was in einer zunehmenden Bedeutung der Kommunikationsfähigkeit Hören, Stimme, Sprechen und Sprache - resultiert [2,3]. Immer mehr Menschen sind auf ihre Fähigkeit zur lautsprachlichen Kommunikation angewiesen, weshalb die Behandlung von Stimmstörungen an Bedeutung gewinnt. Aktuelle Schätzungen gehen davon aus, dass in den USA bis zu $10 \%$ der Bevölkerung unter Stimmstörungen leiden, was einem jährlichen wirtschaftlichen Schaden von annähernd 180 Milliarden Dollar und damit 3\% des Bruttosozialprodukts entspricht [4]. Ein Bericht von 1997 des amerikanischen Arbeitsministeriums gibt an, dass die Arbeitslosenquote für Bevölkerungsgruppen mit Problemen in der Erzeugung verständlicher Sprache nahezu 70\% erreicht [5]. Als Konsequenz wird die Diagnose und effiziente medizinische Behandlung von Stimmstörungen ein wichtiges Thema des 21. Jahrhunderts werden.

Die Quelle des menschlichen Stimmsignals - die Stimmlippen — befinden sich im Kehlkopf. Dessen funktionelle Anatomie und die grundlegenden Mechanismen der Stimmerzeugung werden in Kapitel 2 zusammengefasst. Ebenso wird die Einteilung von Stimmstörungen erläutert. Zusätzlich wird eine extreme Form von Stimmstörungen, die vollständige Entfer- 
nung des Kehlkopfes in Folge von Kehlkopfkrebs, vorgestellt. Aufgrund des Verlusts des Kehlkopfes muss ein Ersatzstimmgenerator die Funktion der entfernten Stimmlippen übernehmen. Hierzu wird der aktuelle Stand der Stimmrehabilitationstechnik, die tracheo-esophageale Ersatzstimme, beschrieben. Als Ersatzstimmgenerator dient hier Gewebe im oberen Bereich der Speiseröhre, das PE-Segment.

Einen weit verbreiteten Ansatz in der klinischen Stimmbewertung stellt die Analyse des akustischen Stimmsignals und damit der Heiserkeit, dem primären Symptom einer Stimmstörung, dar. Diese Methode liefert jedoch nur symptomatische Informationen, da die eigentliche Heiserkeitsursache, die irregulären Stimmlippenschwingungen, unbeobachtet bleibt. Ein weitergehender Ansatz ist die endoskopische Hochgeschwindigkeitsuntersuchungstechnik. Hier werden die Stimmlippen, bzw. das PE-Segment, während der Stimmgebung beobachtet. Die Schwingungsmuster werden mittels einer digitalen Hochgeschwindigkeitskamera, welche an ein starres Endoskop gekoppelt ist, aufgezeichnet. Die Aufnahmeprozedur ist in Kapitel 3 beschrieben.

Kapitel 4 erläutert die Bildverarbeitung, welche zur Segmentierung der von den Stimmlippenkanten definierten Öffnung (Glottis), sowie der Kontur des PE-Segments verwendet wird. Aufgrund der unterschiedlichen Morphologien von Stimmlippen und PE-Segment wird die zugehörige Dynamik unterschiedlich beschrieben. Abstandmessungen liefern eine Beschreibung der Stimmlippenschwingungen. Die zeitabhängigen Abstände bestimmter Punkte der Stimmlippenkanten zur Glottisachse definieren eindimensionale Trajektorien. Für eine direkte Auswertung dieser Trajektorien dienen Asymmetriemaße wie Amplitudenverhältnisse und Phasenverschiebungen zwischen linker und rechter Stimmlippe. Da für die Kontur des PE-Segments aufgrund der im Allgemeinen sehr unregelmäßigen Geometrie keine Symmetrieachsen existieren, wird die Dynamik mittels der zeitveränderlichen Öffnungsfläche beschrieben. Dies erlaubt sowohl die Auswertung von Schwingungsamplitude und -frequenz als auch des Verhältnisses zwischen Öffnungs- und Verschlussdauer.

Als grundsätzlicher Nachteil der direkten Auswertung der Bildverarbeitungsergebnisse bleibt die Form der Schwingungen unberücksichtigt, ebenso die spezifische Morphologie der Stimmlippen bzw. des PE-Segments. Die vorliegende Arbeit behandelt die Verwendung eines modellbasierten 
Ansatzes zur objektiven Quantifizierung der segmentierten Hochgeschwindigkeitsaufnahmen. Die prinzipielle Idee besteht darin, die Dynamik eines biomechanischen Modells des Tongenerators an die extrahierte Dynamik mittels einer automatischen Optimierungsprozedur anzupassen. Die berechneten Parameterwerte quantifizieren die Schwingungen des Tongenerators objektiv.

Kapitel 5 beschäftigt sich mit der Klassifizierung von Stimmlippenschwingungen im Fall einseitiger Stimmlippenlähmungen. Als biomechanisches Stimmlippenmodell wird ein Modell aus konzentrierten Elementen, das sogenannte Zwei-Massen-Modell, verwendet [6,7]. Die automatische Parameteroptimierung ist unterteilt in eine wissensbasierte Startwertsuche und einen genetischen Suchalgorithmus. Die vorgeschlagene Parameteroptimierung wird mittels synthetisch generierter Schwingungsmuster verifiziert und sowohl auf Stimmlippenschwingungen gesunder Personen als auch Patienten mit einseitigen Rekurrensparesen angewendet. Die Optimierungsergebnisse werden diskutiert und zur Ableitung eines Klassifizierungsschemas verwendet. Kapitel 6 erweitert den Ansatz mit dem Zwei-Massen-Modell um eine objektive Quantifizierung von Stimmlippenschwingungen zu ermöglichen, welche longitudinale Schwingungsmoden berücksichtigt. Hierzu wird das Mehr-Massen-Modell, eine zweidimensionale Erweiterung des Zwei-Massen-Modells, in Kombination mit einer neuen automatischen Parameteroptimierung eingeführt. Wie im eindimensionalen Fall wird die Methode mit synthetischen Daten verifiziert und auf klinische Datensätze angewendet.

Die Qualität der tracheo-esophagealen Ersatzstimme ist von den Schwingungseigenschaften des PE-Segments abhängig [8,9]. Um die Stimmrehabilitation zu verbessern ist der Zusammenhang zwischen PE-Dynamik und resultierender Qualität der Ersatzstimme von besonderem Interesse. Voraussetzung einer umfassenden Analyse dieser Beziehung ist eine objektive Quantifizierung der Schwingung des PE-Segments. Um diese Quantifizierung zu ermöglichen wird in Kapitel 7 eine Methode, basierend auf der Reproduktion von Gewebeschwingungen mit einem biomechanischen Modell des PE-Segments, vorgeschlagen. Dieses Modell ist vom Mehr-MassenModell abgeleitet und an die Morphologie des PE-Segments angepasst. Es wird eine Optimierungsprozedur entwickelt, um passende Modellparameter zur Simulation extrahierter Schwingungen des PE-Segments automatisch zu bestimmen. Die vorgeschlagene Methode wird auf klinische Datensätze 
angewendet. Die berechneten Modellparameter liefern eine quantitative Beschreibung der PE-Dynamik. 


\section{Fundamentals}

Limitations of the ability to verbal communication due to hoarseness the primary symptom of voice disorders - is a well-known phenomenon. The voice sounds breathy, strained, or raspy and thus the intelligibility of speech is reduced. Though there are many different pathologies which may result in hoarseness, they all disturb the speech process during the generation of the voice signal [10-14]. Commonly, the terms voice and speech are used almost interchangeably in everyday life. For an effective evaluation and analysis of the etiologies of hoarseness it is important to distinguish between these two terms [15]:

- Voice refers to sound produced by humans and other vertebrates using the lungs and the vocal folds in the larynx. During voice generation, the vocal folds form a narrow constriction, the so-called glottis, for the exhaled airstream between the lower and the upper part of the aerodigestive tract. The streaming air excites vocal fold vibrations and thus the airstream is modulated itself and termed voice signal [16]. All sounds generated between the lungs and the lips are either voiced or unvoiced, depending on whether the vocal folds are set into vibration or not. The term phonation summarizes all physical and physiological processes during voice generation [1]. It is also used to describe the capability of sound production with the larynx: A person is dysphonic if the vocal folds do not vibrate normally and aphonic if no oscillation occurs at all, respectively.

- Speech is the human ability to express thoughts, feelings, and ideas orally one another by forming a voice signal into specific, decodable sounds. Speech constitutes an efficient, robust, and fast method for interpersonal information exchange and represents an essential evolutionary achievement [1]. Precisely coordinated muscle actions in the 
head, neck, chest, and abdomen are necessary for speech production $[17]$.

Precondition for an effective speech communication is a proper voice as carrier for the speech signal. Perturbations during phonation result into irregular vocal fold oscillations and thus into a disturbed carrier signal, i.e. hoarse voice [18]. Commonly, hoarseness which lasts for more than three weeks requires a medical examination [19]. In this case, a reliable voice assessment and documentation is essential to evaluate actual status and therapeutical outcome $[20,21]$. Therefore, an objective quantification of the phonation process is important for medical voice assessment $[10,22]$. The focus of this work is on model-based quantification of pathologic human voice production up to the extreme case of alaryngeal voice as consequence of laryngeal cancer.

In preparation for later chapters, the following section introduces anatomical terminologies and basic concepts concerning phonation.

\subsection{Functional Anatomy of the Larynx}

The larynx is located within the neck and marks the transition between pharynx and esophagus on the one as well as pharynx and trachea on the other hand, see Fig. 2.1. At this location the larynx takes on its phylogenetically oldest roles $[1,15,23]$ : Directing inhaled air from the upper airways into the lungs as well as transferring food through the esophagus into the stomach. Besides these vitally important functions, the human larynx serves as voice generating element. The anatomic structures and their interaction during the phonation process are discussed in the following.

\section{Cartilaginous Framework}

The structure of the larynx is based on a cartilaginous framework $[1,15]$. The outer laryngeal framework is composed by the thyroid and the cricoid cartilages. Both cartilages are connected together with the cricothyroid joint. The arytenoid cartilages are placed on the upper edge of the cricoid cartilage. Between the cricoid and the arytenoid cartilages the vocal folds 


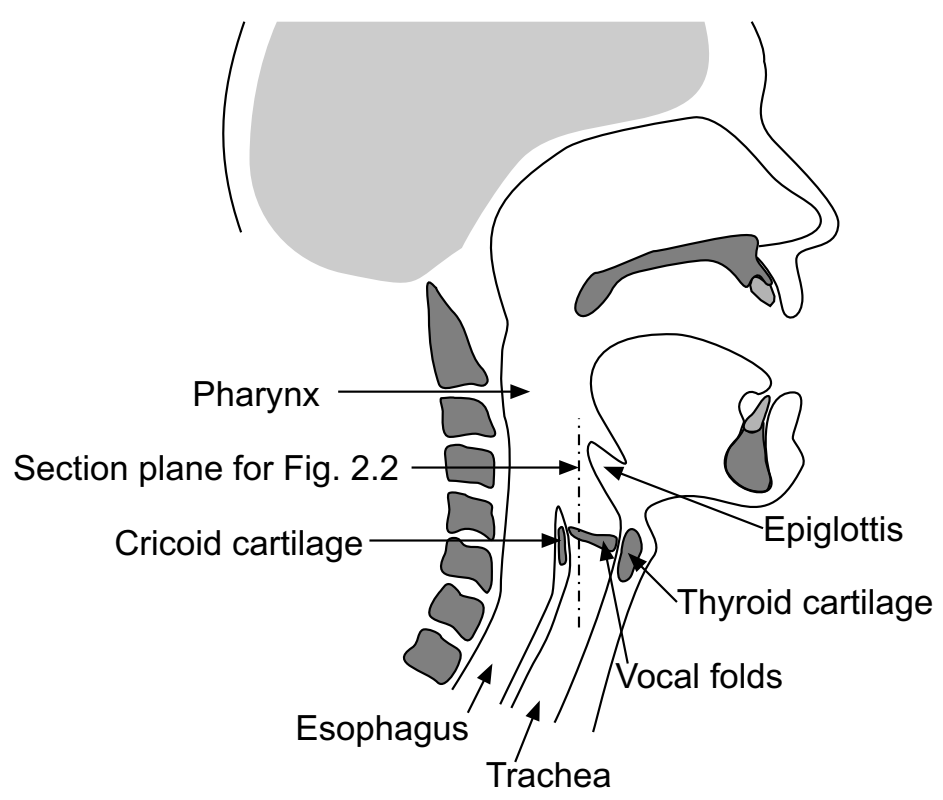

Figure 2.1: Schematic cross section of the head. The larynx is located at the branching of the trachea and the esophagus from the pharynx.

are aligned parallel. By means of tilting the cricothyroid cartilage the vocal folds can be elongated $[14,24]$. Using the arytenoid cartilages the vocal folds move apart or one to another for opening or closing the airways. The entire laryngeal structure is anchored elastically to the extrinsic laryngeal muscles, a system of ligaments and the hyoid bone as shown in Fig. 2.2 $[1,15]$. Due to this construction, the laryngeal mobility amounts several centimeters in the horizontal direction [23].

\section{Intrinsic Muscles}

The different movements during respiration and phonation of the laryngeal framework as well as the positioning and elongation of the vocal folds are realized by the intrinsic muscles of the larynx [24]. Two intrinsic muscles of the larynx control the tension of vocal folds. In this way, the vibration characteristics of the vocal folds concerning amplitude and frequency are influenced $[14,24,25]$ :

- The thyroarytenoid muscle, or simply vocalis, courses from the thyroid cartilage to the arytenoid cartilage and constitutes the bulk of the vocal fold, see Fig. 2.2 and 2.3 [15]. The vocalis controls the 


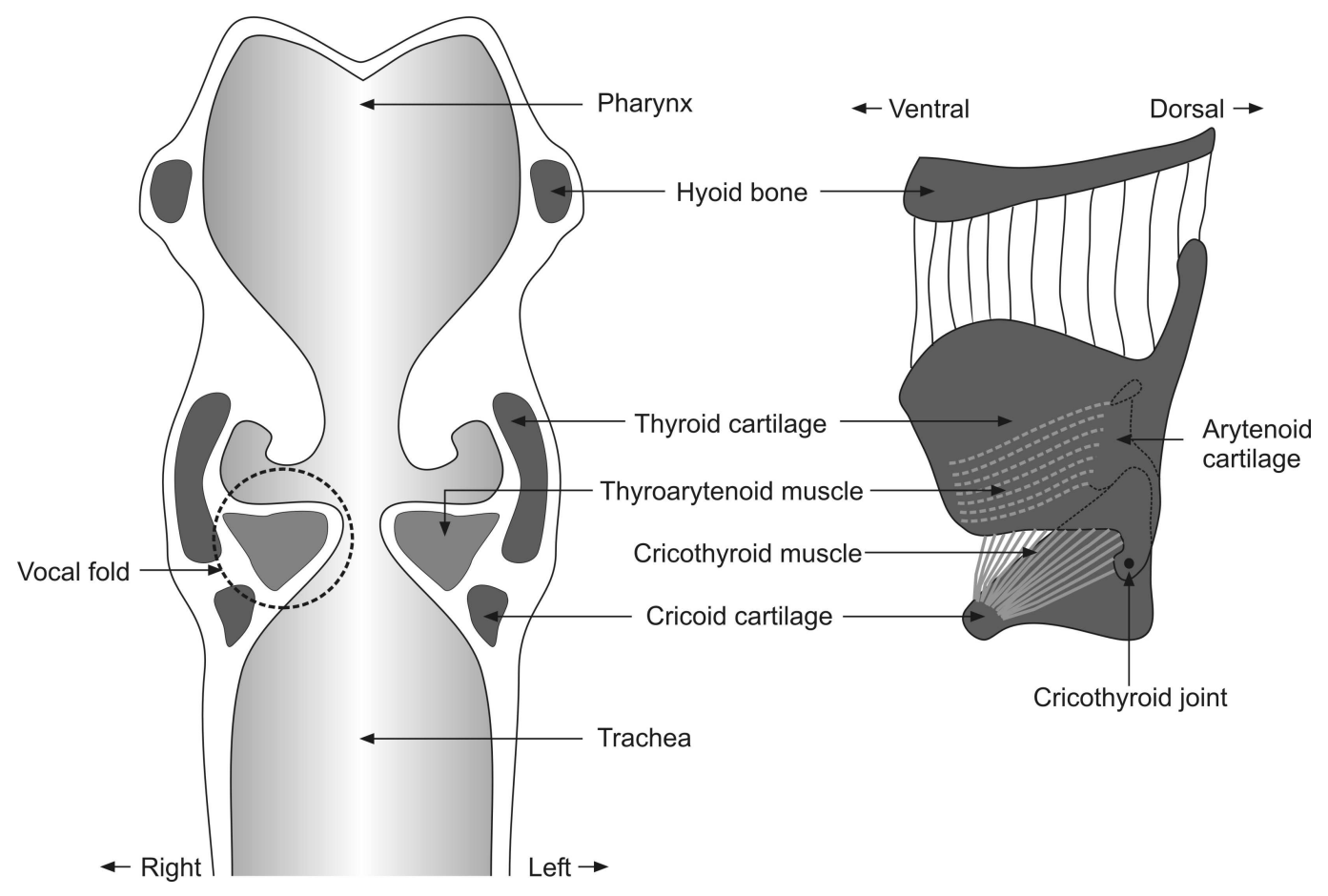

Figure 2.2: Frontal section of the larynx (left) and lateral view from the left side (right).

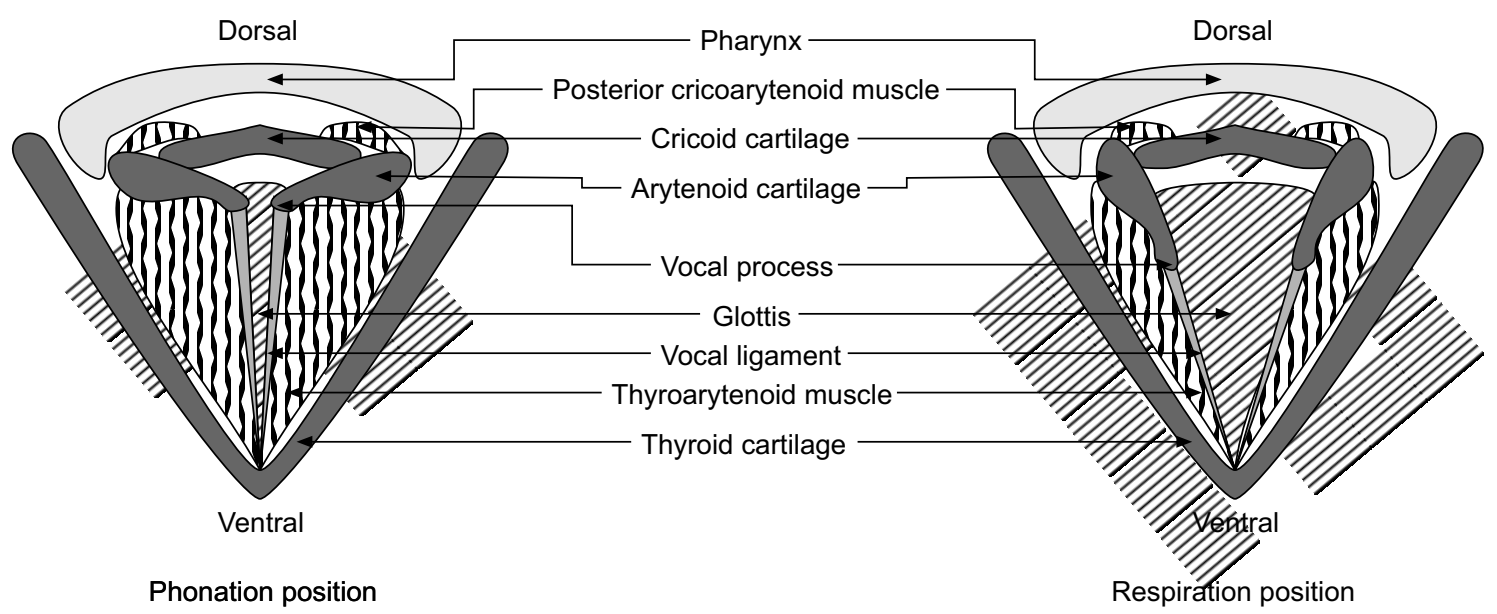

Figure 2.3: Transverse section of the larynx at the level of the vocal folds. 
tension and vernier adjustment of the vocal folds especially during phonation.

- As an antagonist to the vocalis, the cricothyroid muscle elongates and stiffens the vocal folds. It tilts the thyroid cartilage towards the cricoid cartilage around the cricothyroid joint as pivot point, see Fig. 2.2.

Besides a correct elongation of the vocal folds, a proper positioning of the vocal folds is required for an undisturbed phonation arranged by the following laryngeal muscles [14]:

- The posterior cricoarytenoid muscles are positioned between the cricoid and the arytenoid cartilages, see Fig. 2.3. They serve as primary abductors of the vocal folds by rotating and moving the arytenoid cartilages. In this way, the glottis is maximally opened. These muscles are important especially for respiration.

- The lateral cricoarytenoid muscle works as the antagonist to the posterior cricoarytenoid. It functions as an adductor by rotating the arytenoids towards the phonation position.

- The closing of the glottis is supported by the interarytenoid muscle which connects the two arytenoid cartilages. By means of activation of this muscle, both arytenoid cartilages move towards each other.

\section{Vocal Fold Histology}

The voice generating element during phonation are the vocal folds. Due to their histological structure self-sustained oscillations excited by the pulmonary airflow are facilitated. Precondition for the flow-induced vibration is the multi-layered vocal fold structure with different physical characteristics [26,27]. Fig. 2.4 shows a cross sectional schematic view of the vocal folds. The different layers of the soft tissue are partitioned in three groups $[28,29]$ : 


\section{Supraglottal}

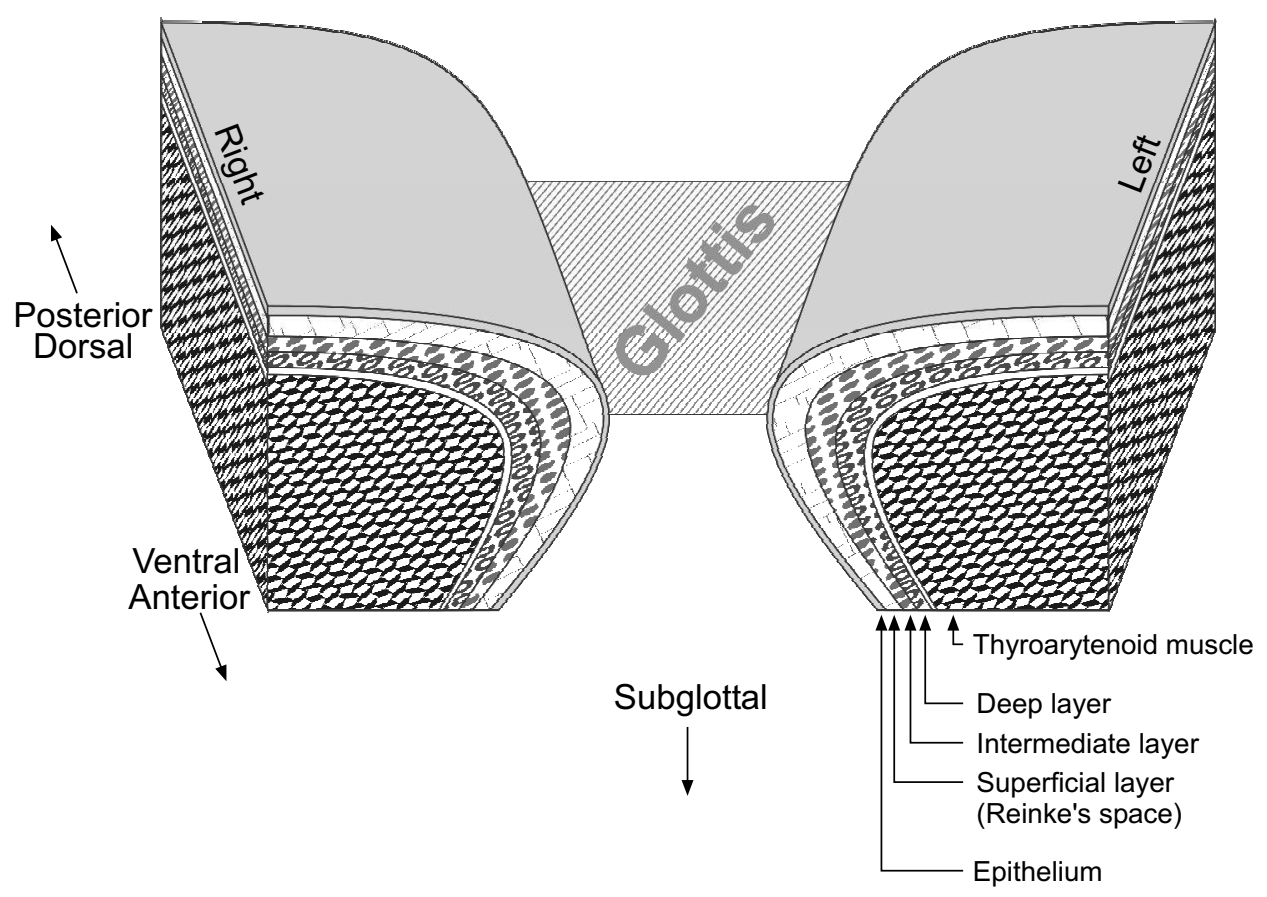

Figure 2.4: Coronal section of the vocal folds showing the layered tissues. 
1. Epithelium. This outermost thin layer $(0.05 \mathrm{~mm}$ to $0.10 \mathrm{~mm})$ is composed of stratified squamous cells [26]. The epithelium encapsulates soft and fluid-like tissue [15]. The physical properties are somewhat like a water-filled balloon.

2. Lamina propria. The lamina propria represents the transition layer between the epithelium and the vocalis muscle. It is subdivided into the superficial, intermediate and deep layer. The superficial layer, also called Reinke's space, has a mean thickness of approximately $0.5 \mathrm{~mm}$ [29]. It consists primarily of loosely organized elastin fibers which provide a rubber band-like elasticity. The intermediate and the deep layer have a thickness of about $1 \mathrm{~mm}$ to $2 \mathrm{~mm}$ [29]. The intermediate layer is composed of elastin fibers mainly orientated in anterior-posterior direction, whereas the deep layer primarily comprises collagen fibers. These anterior-posterior oriented fibers are nearly inextensible like a cotton thread.

3. Muscle. The thyroarytenoid muscle courses laterally to the lamina propria and represents the major portion of the vocal fold with a thickness of approximately 7 to $8 \mathrm{~mm}$ [29]. The muscle is organized in fascicles, i.e. bundles of skeletal muscle fibers surrounded by connective tissue.

These different layers can be classified concerning their function during phonation or physical properties like stiffness, mass, or mobility $[15,30,31]$ :

- 3-layer scheme. The vocal fold is subdivided in mucosa (epithelium, superficial layer), ligament (intermediate layer, deep layer), and muscle [32]. The vocal ligament is regarded as the tension-bearing element in the vocal fold, especially at high pitches. It has traditionally been treated as a vibrating string [33].

- 2-layer scheme. This scheme is often referred to as body-cover model of the vocal folds [31]. Epithelium, superficial layer and intermediate layer constitute a loose skin-like cover. The deep layer and the vocalis muscle form the body of the vocal fold. The stiffness of the body is determined by the muscle tension of the vocalis. 


\subsection{Voice Generating Process}

First experiments concerning the physiological voice function are known from Galen of Pergamon (AD 129-199), a prominent ancient Greek physician. He used vivisectional swine larynges for his studies to gain first insights in the laryngeal anatomy. In 1741, the French physician Antoine Ferrein (1693-1769) published his examination results from experiments with excised human larynges. In his works he stated the idea of string-like vocal fold vibrations excited by the streaming air during phonation. In 1925 the German physician Woldemar Tonndorf published the basic ideas which result into the myoelastic-aerodynamic theory of voice production, suggested by J. W. van den Berg $[34,35]$. In principal this theory is valid up to date and describes the vocal fold oscillation process as follows:

1. The cricoarytenoid muscles and the interarytenoid muscle turn and tilt the arytenoid cartilages. Thus the vocal folds are moved into phonation position. The glottal opening is reduced and the vocal folds form a constriction within the airway.

2. During exhalation, the subglottal pressure and the glottal flow resistance are increased. If a sufficient subglottal pressure is obtained, the vocal folds are forced open and the air passes the glottis.

3. The leaking air subsides the subglottal pressure. The forces caused by muscle fibers and the elastic connective tissue lead to an adduction of the vocal folds. The flow velocity within the glottis increases and thus the dynamic pressure. Following Bernoulli's law, the static pressure acting on the vocal folds is reduced.

4. Again, the vocal folds form a constriction which causes an increased subglottal pressure and the process starts again. Thus, a self-sustained vocal fold oscillation arises.

The vocal fold vibrations separate the continuous pulmonary airstream in single air pulses which represent the sources of sound waves. Following the source-filter theory after Gunar Fant (1960), this pulsing stream represents the primary voice signal which is filtered by the vocal tract [36]. The 
glottal sound passes the cavities of pharynx, mouth, and nose which serve as resonators and thus shape the sound signal acoustically. The shaping depends on the actual vocal tract configuration. The adjustment of a certain configuration is termed articulation. The articulation process defines whether a certain voice signal is emitted for example as an /i/ or an /a/.

\subsection{Voice Disorders}

A normal voice sound is termed euphonic. Disturbances of the complex muscle interaction during phonation or variations of the organic constitution of the vocal folds induce a disphonic voice. The reduced voice quality has a negative influence on the social integration of the concerned person $[37,38]$. Thus, an efficient medical treatment which is able to achieve sustained success is necessary. For the design of systematic examination procedures of voice patients and the development of voice therapies a classification of voice disorders is needed $[1,10,21,39-42]$. For clinical purposes, a classification in organic dysphonia and functional (non-organic) dysphonia has been established $[1,23]$. This scheme is based on the appropriate examination technique: Whereas organic voice disorders are recognizable by visual inspection of the laryngeal structure, the diagnose of a functional dysphonia requires the observation of the vibrating vocal folds during phonation $[23,43,44]$.

\subsubsection{Organic Voice Disorders}

An organic dysphonia is characterized as a voice disorder due to morphological changes of the vocal folds. Additionally, an impaired nerve innervation is regarded as an organic disorder [1]. The causes for the anatomic or physiologic alteration are for e.g., inflammations, edemas, nodules, scars, nerve paralyses, or diseases of the central nervous system (CNS) [45]. Usually, such voice disorders are recognized by anamnestic and endoscopic examinations. A common approach is the so-called laryngoscopy, i.e. the examination with a laryngeal mirror. The forms of appearance of the organic voice disorders are quite different and vary from one-sided or two-sided structural changes of the vocal folds to disorders which affect the entire larynx. 


\subsubsection{Functional Voice Disorders}

A functional dysphonia is the result of erroneously coordinated motions of the phonation apparatus. As a consequence, irregularities of the vocal fold vibrations can be identified during phonation. The voice sounds hoarse and often the vocal capacity is reduced, although structural changes within the larynx are not observable. There are two types of functional disorders. The first type is characterized by immoderate (hyperfunctional) the second by insufficient muscular tensions (hypofunctional) [1]:

- Hyperfunctional dysphonia. This is the most frequently functional voice disorder. The premature use of the voice after laryngitis or a mis-compensation of an organic disorder are possible reasons for the appearance of hyperfunctional dysphonia [19]. Due to the excessive muscular tension the voice sounds hoarse and pressed. As a symptom of fatigue the voice is decreased in intensity and sounds hushed and throatily [23].

- Hypofunctional dysphonia. A chronic overstraining of the voice is one main reason for the hypofunctional voice disorders. In many cases hypofunctional voice disorders are coupled to oncological therapies or organic impairments, e.g., cirrhosis of the liver [46]. Usually the voice sounds breathy and hushed due to an insufficient glottal closure.

\subsection{Total Laryngectomy}

An oncological therapy of laryngeal cancer may result in an extreme form of voice disorder, namely an entire loss of voice. This is the case if the oncological therapy requires a laryngectomy, i.e. the total surgical excision of the larynx. The necessity of this step depends on the stage and position of the laryngeal cancer. In the following, the surgical intervention during a laryngectomy and the consequences are explained. Subsequently, the principles of voice rehabilitation techniques are introduced. 


\subsubsection{Laryngeal Cancer}

For Western Europe the incidence of cancer of the lip, oral cavity, and pharynx amounts 21 per 100,000 male individuals [47]. A comparison of the male-to-female rate of laryngeal cancer between the periods 1959-1973 and 1974-1988 revealed a decrease from 6:1 to 4:1 [48]. An increased tobacco consumption by women since the 1950s is assumed as a main reason for this development [49]. It has been estimated that over $75 \%$ of all head and neck cancers can be attributed to tobacco and alcohol abuse [50]. The majority of larynx cancers are found in the glottic region (56\%) followed by the supraglottic region (41\%), while tumors of the subglottic region are relatively rare (3\%) [51]. Thereby, squamous cell carcinoma within the mucosal tissue accounts for over $90 \%$ of all cancers at these sites. The appropriate treatment depends on the stage of the laryngeal cancer and varies from chemo therapy and radiation therapy up to partial or total laryngectomy. Also a combination of surgical and non-surgical treatments is common practice. In the majority of patients with advanced tumors the surgical treatment consists of a total laryngectomy [49]. In Germany about 2,000 patients are larynectomized each year [52].

The first laryngectomy was described by T. Billroth (1829-1894) in 1873. Two years later the Italian F. Bottini removed the larynx of a patient who survived ten years after operation [53]. Besides a high tumor relapse rate, main problems of the first laryngectomees were aspiration and pneumonia. An improved surgical technique with a permanent separation of trachea and esophagus reduced the surgical mortality significantly [54]. In the last 100 years the operative mortality has fallen from $34 \%$ to $1 \%$, and the 1year-survival rate was increased from $13 \%$ to $77 \%$ [55]. Fig. 2.5 shows the modified laryngeal anatomy after laryngectomy with separated trachea and esophagus. Whereas the esophagus remains connected to the pharynx to maintain swallowing and ingestion, the upper end of the trachea is sutured to an artificial opening at the lower, frontal part of the neck, the so-called tracheostoma. By means of the tracheostoma respiration is enabled, see Fig. 2.5. 


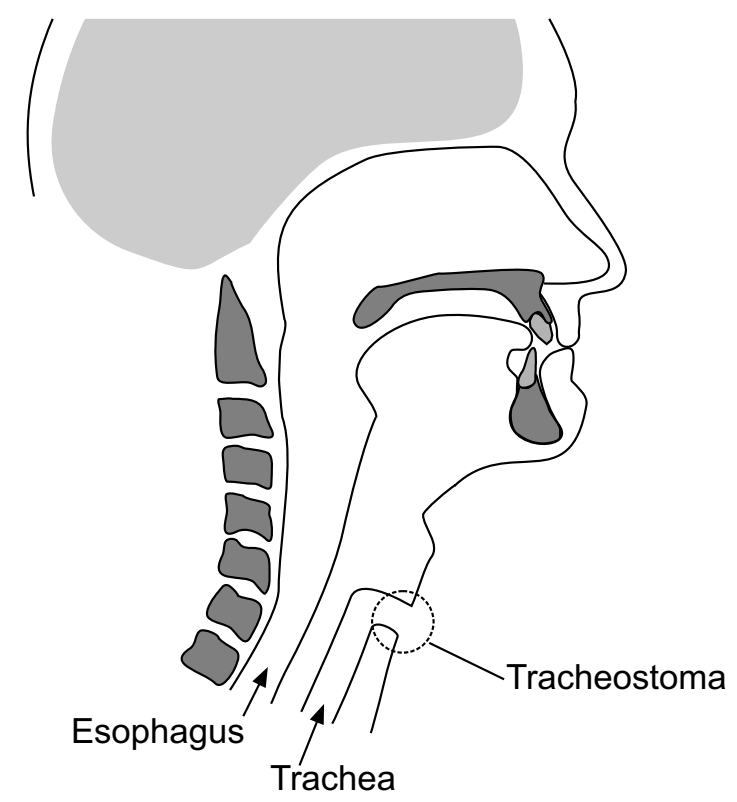

Figure 2.5: Schematic cross section of the head after a laryngectomy. Esophagus and trachea are separated from each other.

\subsubsection{Substitute Voice Generation}

A serious problem of the laryngectomy is the excision of the voice generating vocal folds. In addition, the connection to the pulmonary air volume as energy source for voice production is interrupted. The resulting loss of voice deeply affects the patient's psychosocial well-being [56]. Therefore, the reestablishment of acceptable voice and intelligible speech are critical points after the surgical intervention. Three common approaches for substitute voice generation exist:

- Electrolarynx. A hand-held, battery operated electro-acoustic vibrator (electrolarynx) is positioned on the skin of the neck. The resulting vibrations generates the primary voice signal within the vocal tract. As the vocal tract is usually not concerned from the laryngectomy, articulation is performed as usual. However, the achieved voice quality is poor and the electrolarynx is primarily used as an alternative if the patient failed in adopting other substitute voice techniques $[23,57]$.

- Esophageal voice. The patient swallows a small amount of air and deposes it within the esophagus. For the aim of using this air 
volume in the sense of substitute voice production, the air is forced back to the oral cavity by means of a ructus. The airflow causes esophageal tissue vibrations which generate a substitute voice signal. A main shortcoming of this technique is the small air reservoir of only $80 \mathrm{ml}$, compared to the $3000 \mathrm{ml}$ of the lungs. This results in numerous interruptions of the speech accompanied by a burping way of speaking [58].

- Tracheoesophageal voice. This method, introduced in 1979, requires an additional surgical intervention either instantaneously following the laryngectomy or as an additional surgery [59]. As a result, a tracheoesophageal puncture creates a reconnection between esophagus and trachea, a so-called shunt. Aspiration is prevented by the insertion of a silicon valve into the shunt. A manual closing of the tracheostoma redirects the pulmonary airflow through the shunt valve in the upper part of the esophagus. Thereby, the shunt valve constitutes a low resistance for the streaming air. The soft tissue at the transition between esophagus and pharynx, the so-called pharyngeal-esophageal segment ( $\mathrm{PE}$ segment), is set into vibrations as shown in Fig. 2.6. According to the term glottis the opening of the PE segment passed by the airstream is called pseudoglottis. As in laryngeal voice production, the vocal tract filters the substitute voice signal which is finally emitted as acoustic speech signal. Usually 10 days after surgical insertion of the shunt valve, a logopedic voice therapy is started for initiation of the tracheoesophageal voice. The patient adopts a proper coordination of exhalation and speech production [23]. In general the tracheoesophageal voice production is learned faster by the patient compared to the esophageal voice. In addition, it makes use of the entire pulmonary air reservoir which results in a longer sustained phonation, a higher speech rate and less interruptions compared to the esophageal voice [59].

The insertion of a shunt valve evolved worldwide to the standard for postlaryngectomy voice rehabilitation as it allows nearly any laryngectomee, regardless of physical, sensory, or mental limitations to be rehabilitated with this method. Nevertheless, the voice quality and intelligibility are significantly reduced compared to normal laryngeal voice with a distinct variance between different laryngectomees [60,61]. 


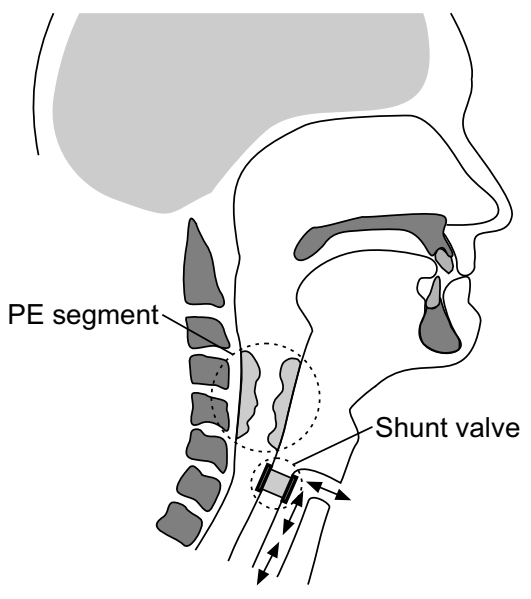

Respiration

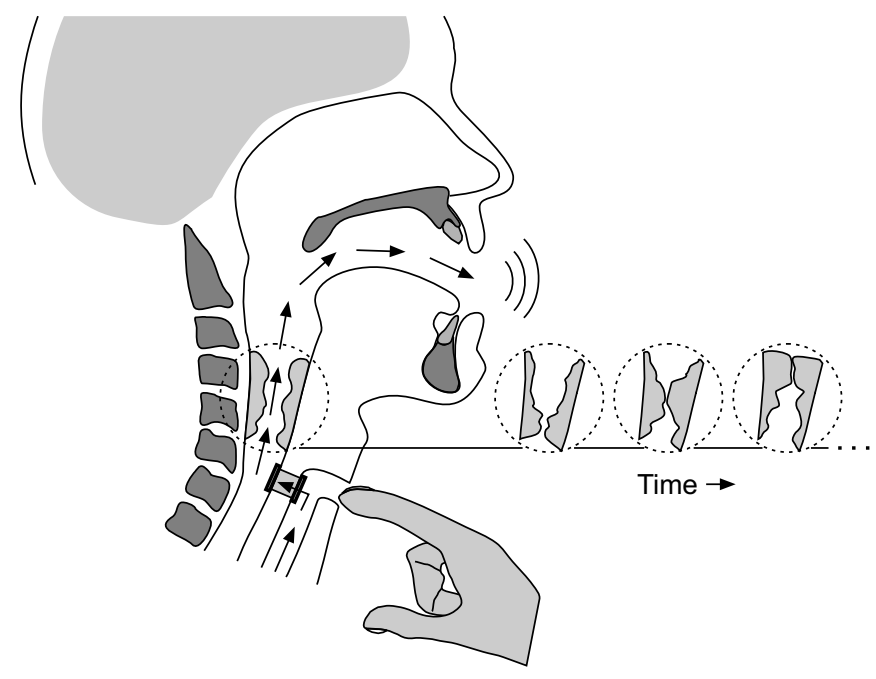

Phonation

Figure 2.6: Respiration and substitute voice production after insertion of a shunt valve. 


\section{High-Speed Recordings}

A widely used approach in medical voice assessment is the analysis of the acoustic speech signal [62-64]. However, speech signals provide only symptomatic information about the laryngeal dysfunction. Predications about the voice disorder itself are thus ambiguous [12]. In addition, discrepancies between laryngoscopic and auditory findings are not unusual. Some patients obviously suffer from hoarseness while the laryngeal morphology reveals no obvious pathologic alteration (e.g., due to a functional voice disorder) and vice versa [65]. Whether variations of the larynx or functional impairments result in voice perturbations depends on their effect on the vocal fold vibrations $[18,66]$. Therefore, supporting clinical diagnosis and classification of voice pathologies by means of imaging the phonation process is an important issue in medical voice assessment [11,67-69]. Established imaging techniques are stroboscopy (high spatial but low temporal resolution [70]) and the kymography (sufficient temporal but low spatial resolution [44]). Digital high-speed cameras comprising a rigid endoscope provide both, sufficient spatial and temporal resolution for observing the oscillation patterns of the vocal folds during phonation $[43,71,72]$.

In 1940, the first high-speed recordings on celluloid were made by D. Farnsworth at the Bell Laboratories [73]. In 1954, Luchsinger and K. Pfister produced the first clinical high-speed recordings [74], still using analog techniques. With the introduction of digital high-speed imaging techniques, the first automatic quantitative evaluation of the recordings was developed by J. Booth in 1979 [75]. Significant enhancement of the image quality was achieved by cameras equipped with CCD sensors. These new systems were applied to several clinical studies $[43,68,76,77]$. The camera technology was further improved up to the actual system used for this work [66,78-80]. The employed high-speed camera HS ENDOCAM (Richard Wolf Corp., Knittlingen, Germany) has a frame rate of 4, $000 \mathrm{fps}$ and a spatial resolution of $256 \times 256$ pixels. The color depth amounts 8 bit 
which results in 256 gray levels. For illumination, a $250 \mathrm{~W}$ Xenon light source is deployed. In addition, a calibrated condenser microphone (B\&K 4129, Brüel \& Kjær Corp., Nærum, Denmark) with a sampling rate of $44.1 \mathrm{kHz}$ and a discretization of 8 bit is mounted on the camera body for simultaneous recordings of the acoustic signal [81].

\subsection{High-Speed Imaging of the Vocal Folds}

Commonly, high-speed recordings are performed during stationary sustained phonation in accordance to stroboscopic examination techniques $[77,78]$. The vocal fold vibrations are observed from a top-view position with a rigid $90^{\circ}$-zoom endoscope which is coupled to the high-speed camera $[11,82]$. Fig. 3.1 shows the recording situation (a) and two single images

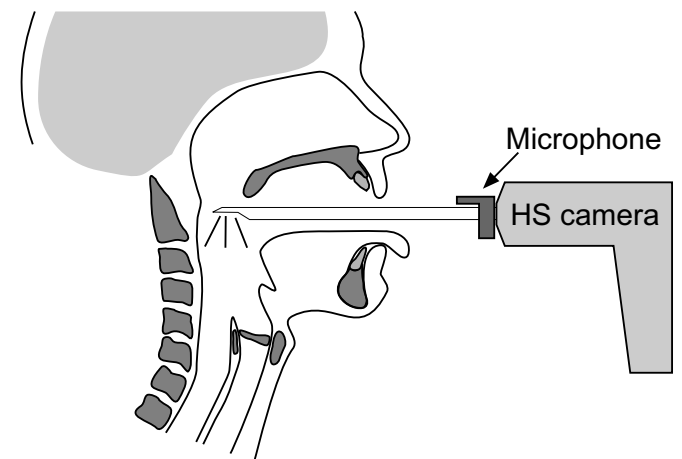

(a)

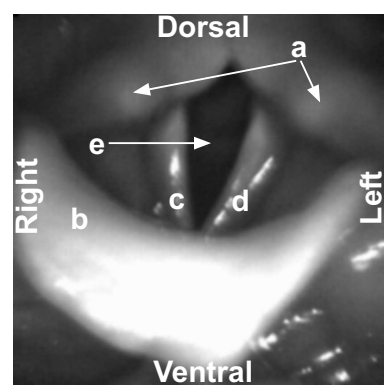

Abduction

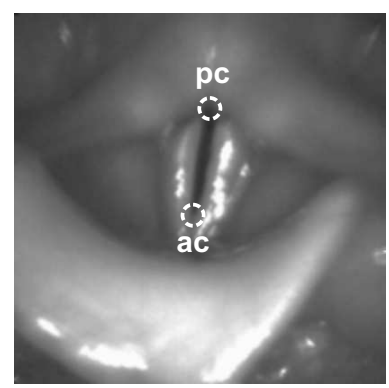

Adduction (b)

Figure 3.1: Recording Situation. (a) A rigid $90^{\circ}$-zoom endoscope connected to a digital high-speed video camera is placed into the oropharynx. (b) Two high-speed images of the vocal folds at different positions, i.e. during respiration (left) and phonation (right) ( $a$ - arytenoid cartilages, $b$ epiglottis, $c$ and $d$-right and left vocal fold, $e$-glottis). Dorsal and ventral endings of the maximal opened glottis (during phonation) are termed posterior ( $p c$ ) and anterior commissure (ac).

from a high-speed recording (b). The situations during respiration and phonation are depicted. The different positioning of the arytenoid cartilages and the vocal folds is visible. During phonation the dorsal and ventral endings of the maximally opened glottis are defined as posterior (pc) and 
anterior commissure (ac) (see second high-speed image). In Fig. 3.2 a highspeed sequence of vocal fold vibrations of a healthy voice subject (male, age $23)$ is presented. The fundamental frequency $f_{0}$ amounts $143 \mathrm{~Hz}$. From

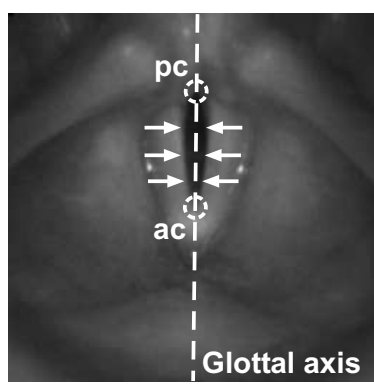

$t=0 \mathrm{~ms}$

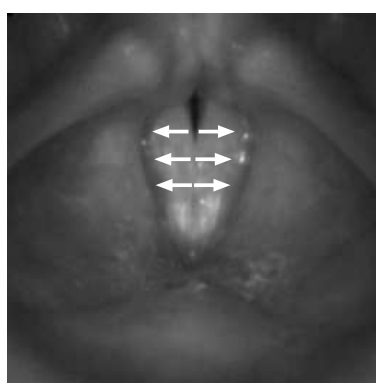

$t=4 \mathrm{~ms}$

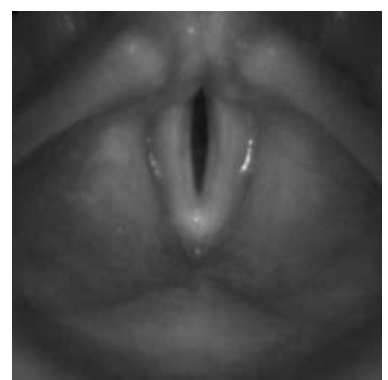

$t=1 \mathrm{~ms}$

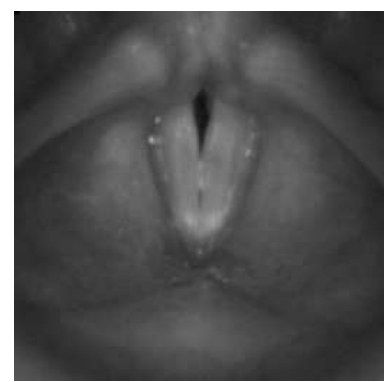

$t=5 \mathrm{~ms}$

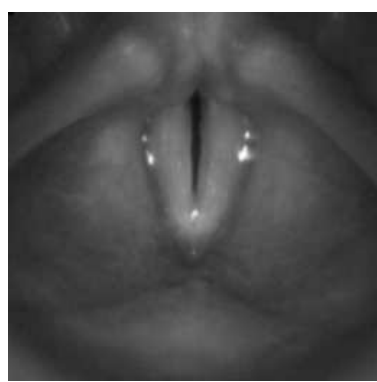

$t=2 \mathrm{~ms}$

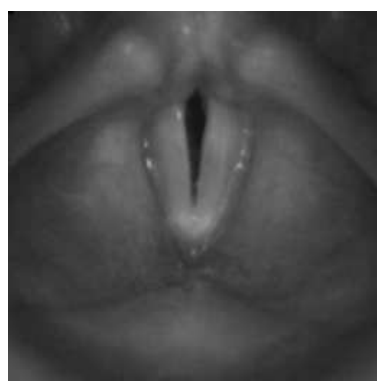

$t=6 \mathrm{~ms}$

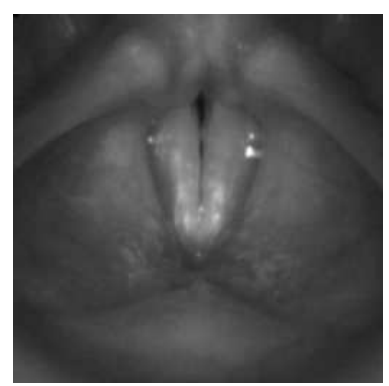

$t=3 \mathrm{~ms}$

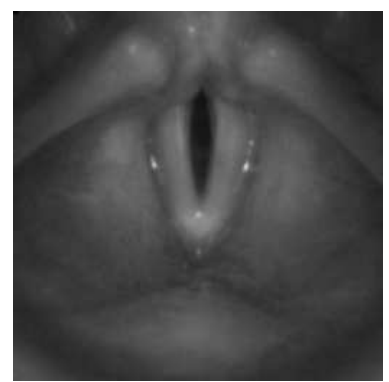

$t=7 \mathrm{~ms}$

Figure 3.2: High-speed sequence of a healthy voice subject (male, 23) with $f_{0}=143 \mathrm{~Hz}$. One oscillation cycle with a duration of $7 \mathrm{~ms}$ is shown. The white arrows mark the main directions of motion of the vocal fold edges. The glottal axis is defined by the anterior and posterior commissure.

the recorded oscillation cycle every fourth image is depicted. Left and right vocal fold oscillate in phase with same amplitudes. The glottal axis can be regarded as symmetry axis for the movements of opposing points of the vocal fold edges.

The HS ENDOCAM system delivers no metrical information and thus vocal fold length, oscillation amplitudes, etc. are measured in pixel. However, for facilitating a quantitative comparison between different recordings, a metrical scaling can be approximated from anatomical knowledge. For female subjects, a mean glottal length (i.e. the distance from the anterior to the posterior commissure) of $\bar{l}_{g}=0.7 \mathrm{~cm}$ is assumed (male subjects: $1.4 \mathrm{~cm}$ ). Within the short intervals of the evaluated high-speed sequences (less than $100 \mathrm{~ms}$ ), changes of the length $l_{g}$ of the glottal axis can be neglected due to the stationary phonation paradigm. Thus, by means of $l_{g}$ 
measured in pixel, a scaling factor $\gamma=\bar{l}_{g} / l_{g} \quad[\mathrm{~cm} /$ pixel $]$ is derived and used for a metrical scaling of the high-speed recordings.

\subsection{High-Speed Imaging of the PE Segment}

The high-speed imaging technique is also applicable to the observation of the vibrating $\mathrm{PE}$ segment during substitute voice production $[8,83,84]$. Fig. 3.3 shows the recording situation in case of laryngectomy (a) and two single images from a high-speed recording (b). During the recording

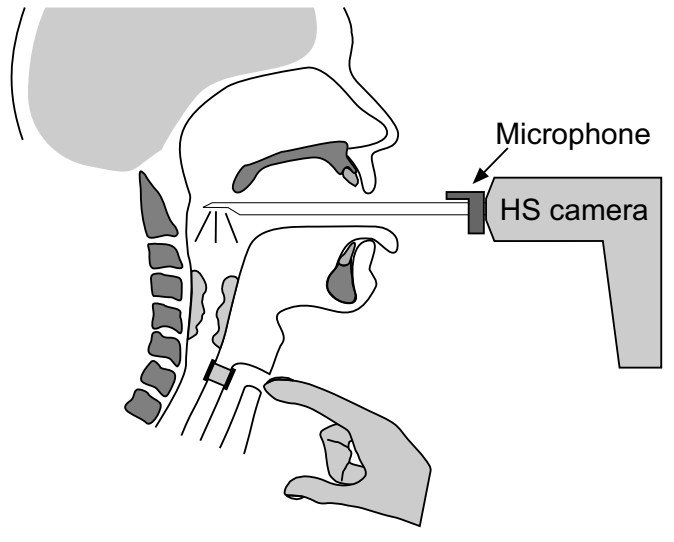

(a)

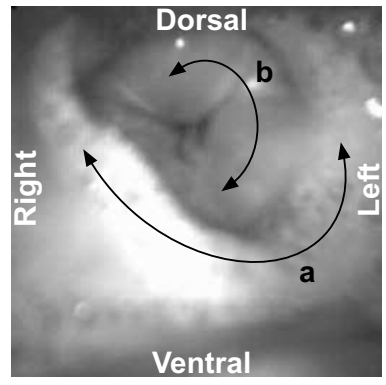

$t=0 \mathrm{~ms}$

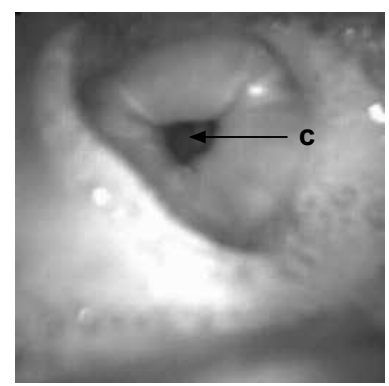

$t=4.5 \mathrm{~ms}$

(b)

Figure 3.3: Recording Situation in case of laryngectomy. (a) High-speed recording during substitute voice production. (b) Two high-speed images of the PE segment at different states ( $a$ - esophageal wall, $b$ - mucosal tissue, $c$-pseudoglottis). The images show the PE segment with closed (left) and opened (right) pseudoglottis.

procedure, the tracheostoma is manually closed by the patient for substitute voice production. A high-speed sequence of the vibrating PE segment from a male laryngectomee aged $67\left(f_{0}=125 \mathrm{~Hz}\right)$ is given in Fig. 3.4. Alternately, every fifth and fourth image is shown, respectively. As the vocal folds, the PE segment reveals a quasi-periodic opening and closing behavior. However, the morphology and oscillation pattern of the PE segment is less regular compared to the vocal folds. Whereas the vocal fold vibration pattern includes the glottal axis as symmetry axis, the PE segment vibration reveals no symmetry. 


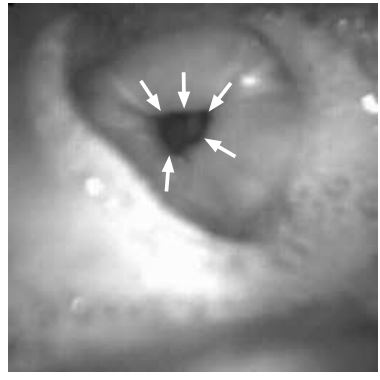

$t=0 \mathrm{~ms}$

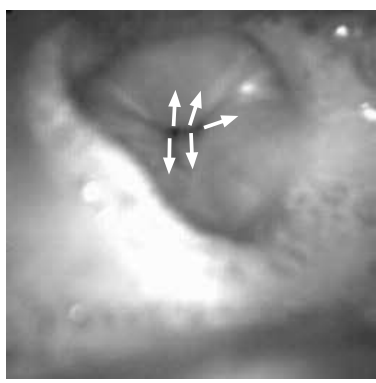

$t=4.5 \mathrm{~ms}$

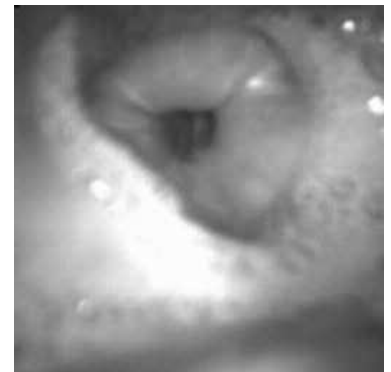

$t=1.25 \mathrm{~ms}$

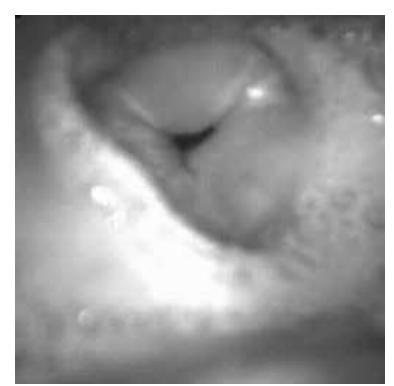

$t=5.75 \mathrm{~ms}$

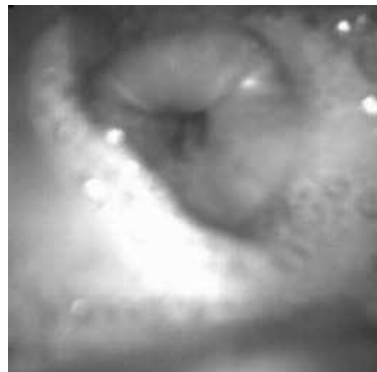

$t=2.25 \mathrm{~ms}$

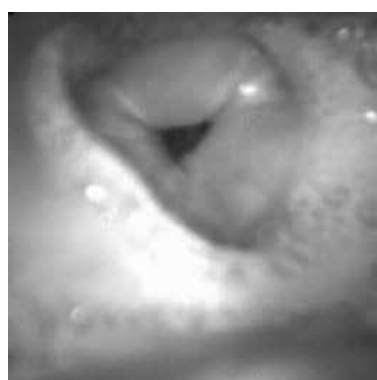

$t=6.75 \mathrm{~ms}$

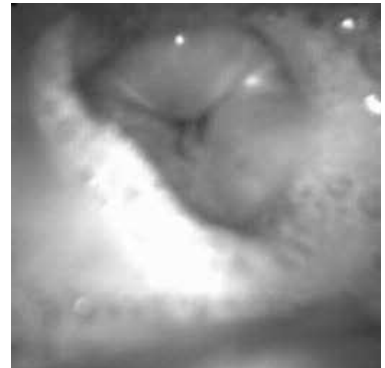

$t=3.5 \mathrm{~ms}$

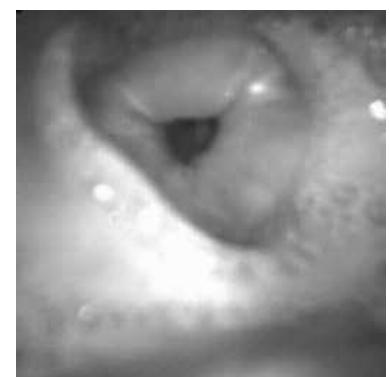

$t=8.0 \mathrm{~ms}$

Figure 3.4: High-speed sequence of the vibrating PE segment of a male laryngectomee (age 67) during substitute voice production $\left(f_{0}=125 \mathrm{~Hz}\right)$. The white arrows mark the main directions of motion of the PE segment. 


\section{Image Processing}

Digital high-speed recordings provide a permanent image record of the vibrating vocal folds or PE segment. Using these experimental data to support the clinical diagnosis of voice disorders, therapy selection or analysis of the phonation process requires an objective measurement and quantification of the recorded oscillation patterns $[8,70,85]$. In the following, the techniques for segmenting the contours of the glottis and the pseudoglottis as well as the description of the corresponding dynamics are described.

\subsection{Extraction of the Vocal Fold Dynamics}

By applying appropriate image processing techniques, the vocal fold edges are segmented in each single frame of the high-speed recordings $[80,82,86-$ 88]. In this work, the high-speed sequences are processed with a threshold segmentation technique [80]. The following example is used to illustrate the results of the applied image processing technique. Fig. 4.1 (first row) depicts an oscillation cycle in case of healthy voice (male subject, age 22). The segmentation result is shown as a white line in each image. Here, the cycle starts with a maximum opening. The glottal closing occurs with a phase shift starting from the ventral part of the vocal folds (second image). The minimum glottal area is achieved after $3 \mathrm{~ms}$ with a minor glottal closure insufficiency at the dorsal end. After $6 \mathrm{~ms}$ the maximum opening is reached again. The lower two rows show the construction of a compact illustration of the vocal fold dynamics. The first image of the second row represents the segmented contour of the first frame. The subsequent segmentation results are also drawn in the same figure (second image). In the third image (doubled border) the contours of the whole closing phase are depicted. For the opening phase, a second image is produced in the same way (third row). The resulting figure for the closing phase is shown in the third image of the second row. 


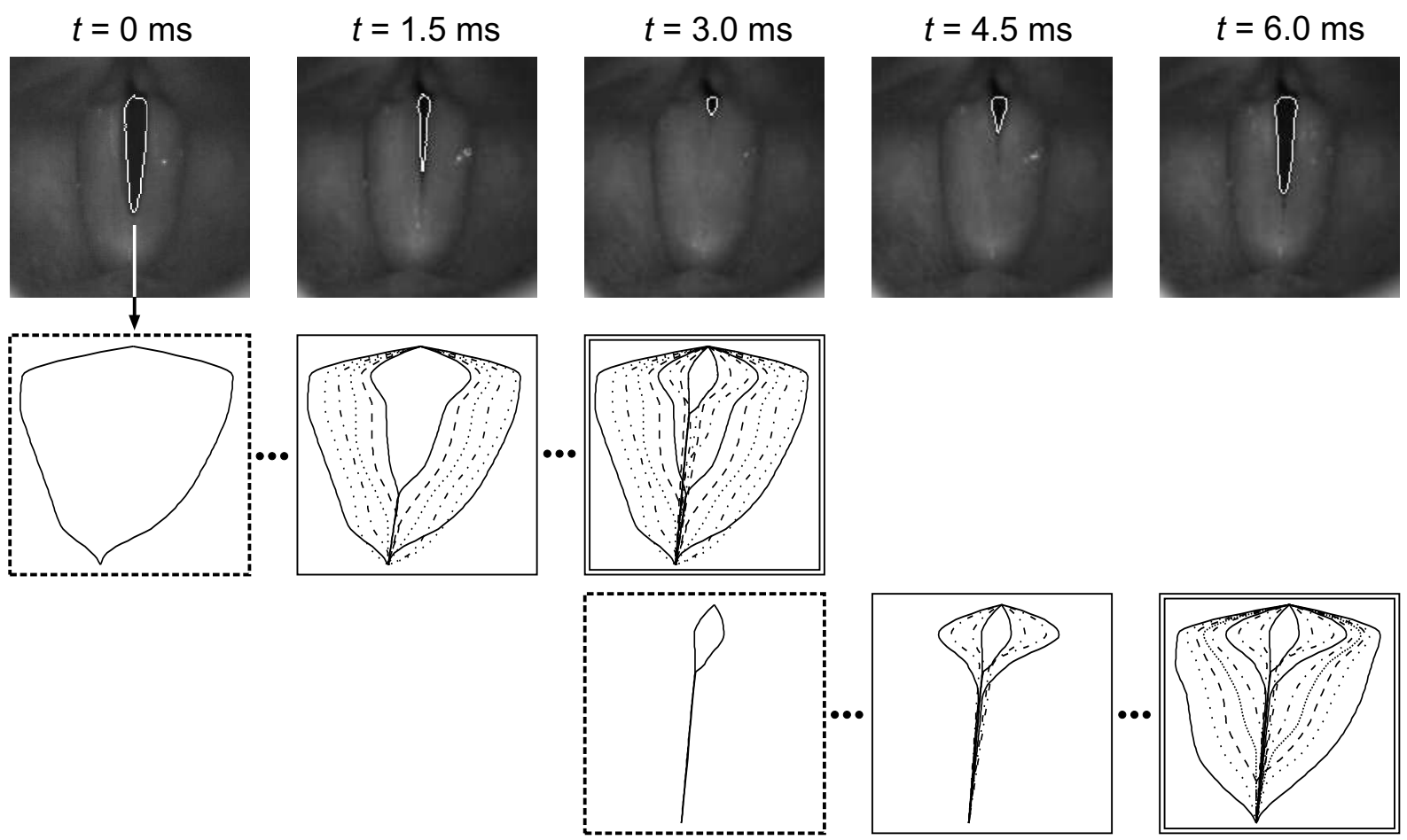

Figure 4.1: Image sequence from a digital high-speed recording. An oscillation cycle for healthy vocal fold vibrations $\left(f_{0}^{\text {exp }}=138 \mathrm{~Hz}\right.$ ) of a male subject aged 22 is shown (first row). An alternative illustration of the vocal fold dynamics is depicted in the second (closing phase) and the third (opening phase) row. 


\subsubsection{Single-Line Trajectories}

Derived from the videokymography, a common approach in clinical routine is a one-dimensional description of the vocal fold dynamics $[44,89]$. In this way, left-right asymmetries of the vocal fold vibrations are sufficiently captured [66]. The movements of the vocal fold edges along a line $k$ are described as a function of time at one specific position, see Fig. 4.2. Commonly, the medial position of the vocal folds is used in this approach, since this typically corresponds to the point of maximum oscillation amplitude [90]. The line $k$ is perpendicular to the glottis axis with intersection point

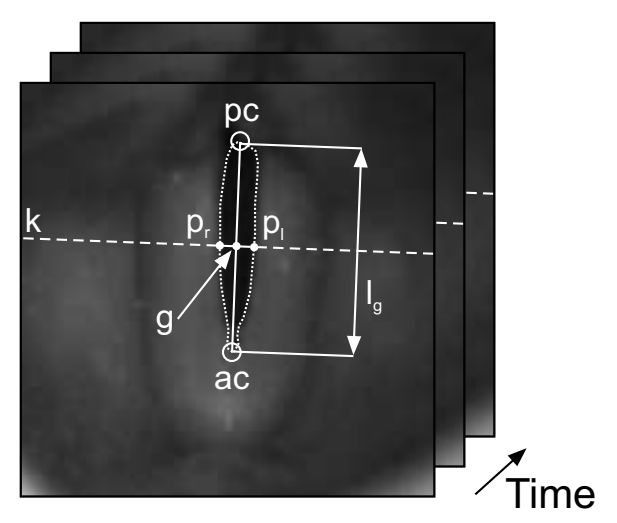

Figure 4.2: Single-line extraction. The dotted white line marks the segmented vocal fold edges. The vocal fold dynamics is described by the time-varying distance of $p_{r}$ and $p_{l}$ to $g$ on the glottal axis (defined by the anterior and posterior commissure). The points $p_{r}$ and $p_{l}$ move along the dashed line $k$, which is perpendicular to the glottal axis.

$g$ at half way from ac to pc. The position of line $k$ is fixed for all $N$ frames of the evaluated high-speed sequence. The time-varying deflections of the opposing vocal fold edge points from the glottal axis are defined as experimental trajectories $c_{r}^{e x p}$ and $c_{l}^{e x p}$ for the right and the left vocal fold:

$$
\begin{aligned}
& c_{r}^{\exp }[n]:=(-1)^{\kappa_{r}} \cdot\left\|\mathbf{p}_{r}-\mathbf{g}\right\|_{2}, \\
& c_{l}^{\exp }[n]:=(-1)^{\kappa_{l}-1} \cdot\left\|\mathbf{p}_{l}-\mathbf{g}\right\|_{2},
\end{aligned}
$$

and

$$
\kappa_{r, l}=\left\{\begin{array}{lc}
1, & \mathbf{p}_{r, l} \text { crosses glottal axis } \\
2, & \text { otherwise }
\end{array} .\right.
$$

Thereby, $c_{r, l}^{\exp }[n]=c_{r, l}^{e x p}(t=n \cdot \Delta T)$ with $n=0, \ldots, N-1$ and the interval of two successive high-speed images $\Delta T=0.25 \mathrm{~ms}$. 
In the upper chart of Fig. 4.3 the experimental curves (fundamental frequency $f_{0}^{\text {exp }}=255 \mathrm{~Hz}$ ) of a healthy voice subject (female, aged 19) are presented. The upper curve represents the movement of the right vocal

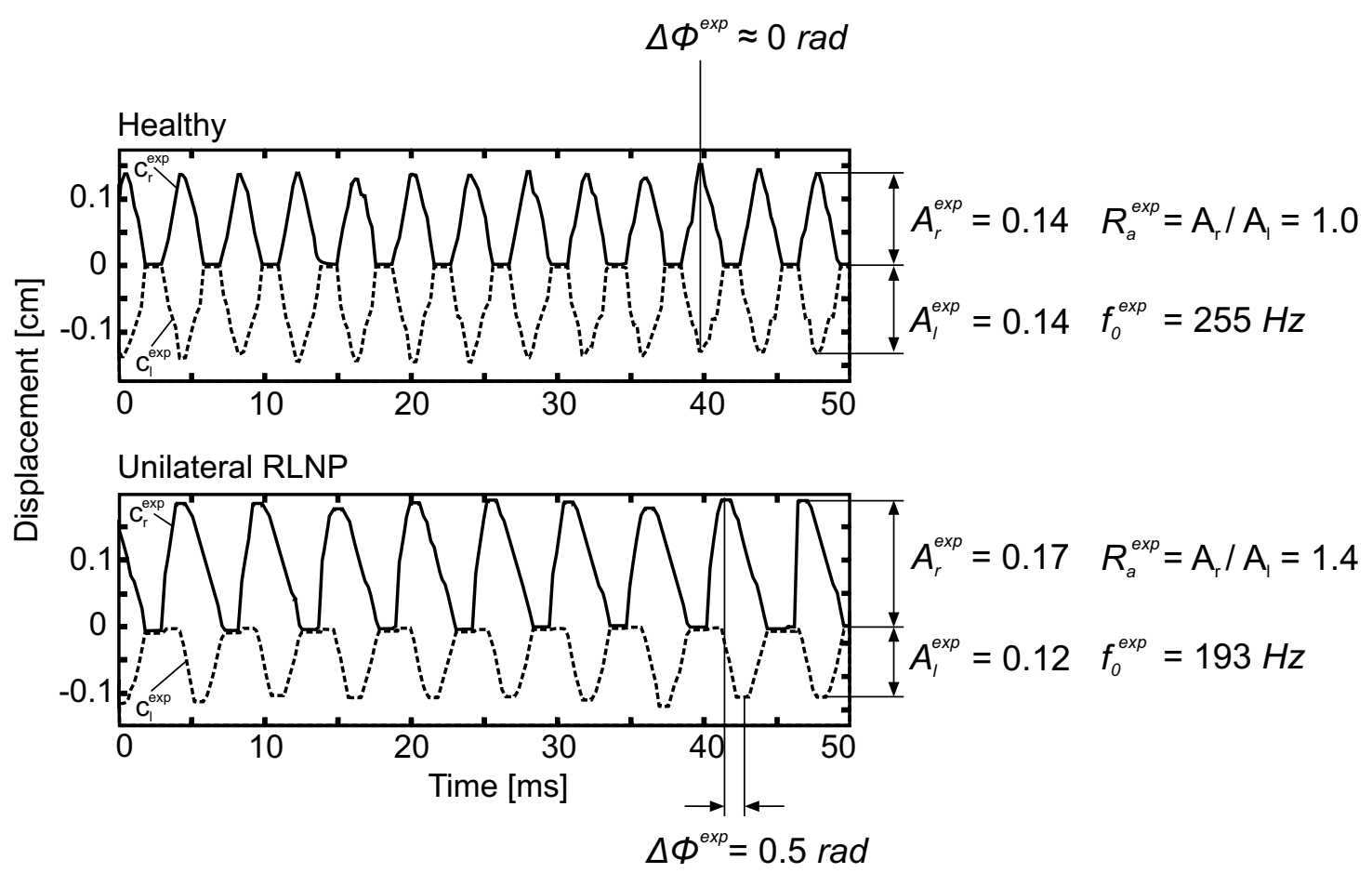

Figure 4.3: Experimental curves for a healthy female subject (upper) and a female patient suffering from unilateral RLNP (lower). In each chart the upper solid (lower dashed) curve represents the right (left) vocal fold oscillation $c_{r}^{\text {exp }}\left(c_{l}^{e x p}\right)$.

fold and the lower curve of the left fold, respectively. Both curves exhibit high symmetry concerning frequency, amplitude (ratio $R_{a}^{\exp }$ between left $\left(A_{l}^{e x p}\right)$ and right $\left(A_{r}^{e x p}\right)$ amplitude is equal to one), and phase (phase shift $\left.\Delta \phi^{e x p} \approx 0 \mathrm{rad}\right)$. The lower chart in Fig. 4.3 shows the experimental curves $\left(f_{0}^{\text {exp }}=193 \mathrm{~Hz}\right)$ corresponding to a subject (female, aged 49) suffering from unilateral recurrent laryngeal nerve paralysis (RLNP). The upper curve represents the movement of the healthy left vocal fold, the lower curve shows the oscillation of the paralyzed right one. In contrast to experimental curves of the healthy voice subject, the RLNP curves exhibit asymmetries in amplitude and phase. 


\subsubsection{Multi-Line Trajectories}

Following local impairments of the vocal fold physiology, e.g. due to organic voice disorders, significant differences of the vibration characteristics along a single vocal fold are possible. Besides left-right also longitudinal asymmetries are observable in this case $[71,72]$. For incorporating both forms of asymmetry within the quantification, a spatio-temporal capturing of the vocal fold dynamics is necessary. For this aim, the principle of the single-line extraction is extended to a multi-line approach. Within

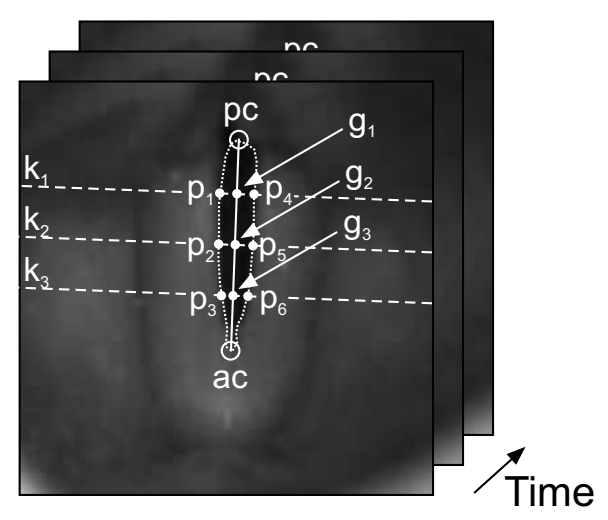

Figure 4.4: Multi-line extraction. The dotted white line marks the segmented vocal fold edges. The multi-line trajectories are defined as the deflections of the vocal fold edges from the glottal axis along the lines $k_{i}$.

Fig. 4.4 the segmented vocal fold edges are depicted as a dotted white line. The time-varying opening area of the glottis, the so-called area function, is denoted with $a^{\exp }[n]$. In the sense of multi-line extraction, the points $\mathbf{g}_{j}$, with $j=1, \ldots, 3$, are positioned at $25 \%, 50 \%$, and $75 \%$ of the glottal axis length, starting from the posterior commissure. The contour points $\mathbf{p}_{j}$ (right vocal fold) and $\mathbf{p}_{j+3}$ (left vocal fold), located on the lines $k_{j}$, are determined as shown in Fig. 4.4. The lines $k_{j}$ are perpendicular to the glottal axis. For each contour point the time-varying distance to the point $\mathbf{g}_{j}$ is extracted from the high-speed sequence. For the $n^{\text {th }}$ frame, the distance of the right vocal fold to $\mathbf{g}_{j}$ is $c_{j}^{e x p}[n]$ and $c_{j+3}^{e x p}[n]$ for the left vocal fold respectively:

$$
\begin{aligned}
c_{j}^{\exp }[n] & :=(-1)^{\kappa_{j}} \cdot\left\|\mathbf{p}_{j}-\mathbf{g}_{j}\right\|_{2}, \\
c_{j+3}^{\exp }[n] & :=(-1)^{\kappa_{j+3}-1} \cdot\left\|\mathbf{p}_{j+3}-\mathbf{g}_{j}\right\|_{2},
\end{aligned}
$$


and

$$
\kappa_{i}=\left\{\begin{array}{lc}
1, & \mathbf{p}_{i} \text { crosses glottal axis } \\
2, & \text { otherwise }
\end{array},\right.
$$

with $i=1, \ldots, 6$. Following, the vocal fold deflections are described by the one-dimensional trajectories $c_{i}^{e x p}[n]$ together with the glottal area function $a^{\exp }[n]$, with $i=1, \ldots, 6$ and $n=0, \ldots, N-1$.

Fig. 4.5 depicts the resulting trajectories for the healthy voice subject shown in Fig. 3.2. The left picture shows the opening phase (duration
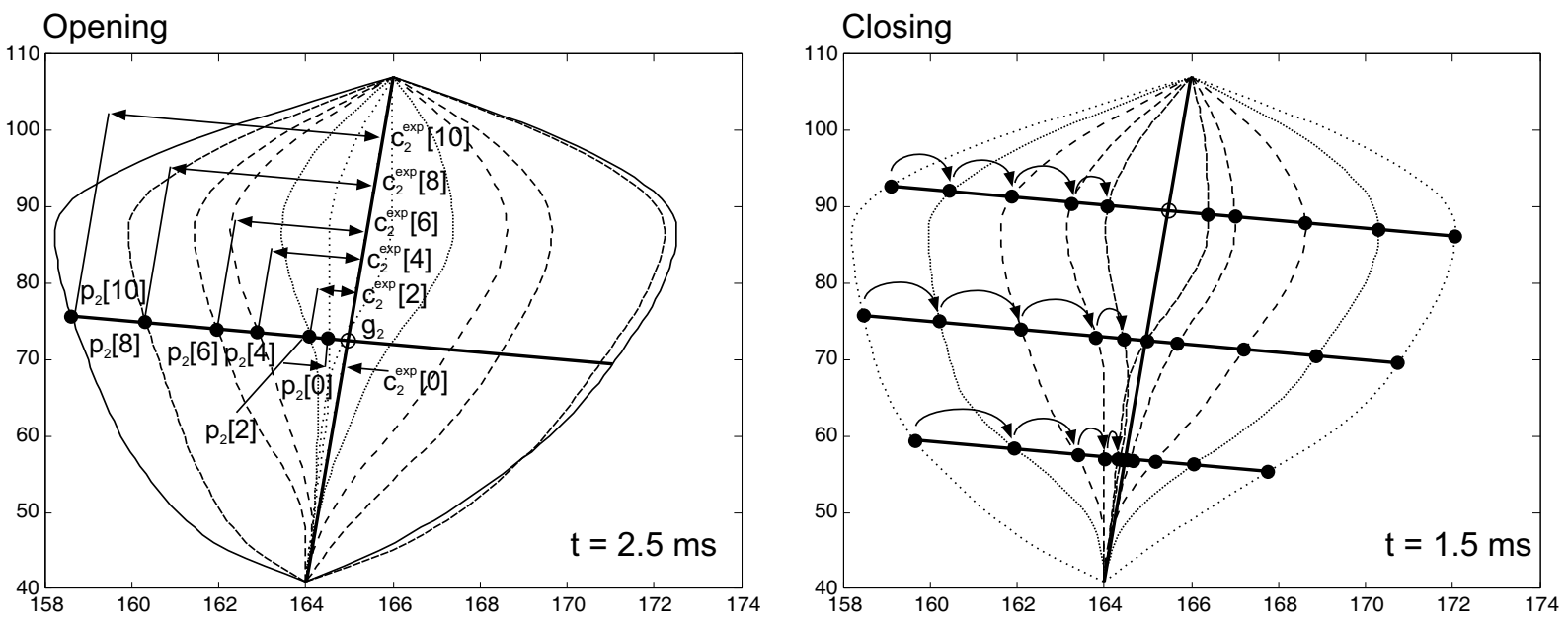

Figure 4.5: Left: Opening phase of the vocal fold vibrations shown in Fig. 4.1. The trajectory of the right vocal fold at medial position is marked with dots. Right: The corresponding closing phase. The trajectories of both vocal folds at dorsal, medial, and ventral position are depicted.

$2.5 \mathrm{~ms})$ and the right the closing phase $(1.5 \mathrm{~ms})$. For the opening phase every second point of $c_{2}^{e x p}[n]$, i.e. the trajectory at medial position of the right vocal fold, is marked with a black-filled circle. During the closing phase each second point in all six trajectories are depicted.

\subsection{Extraction of the PE Dynamics}

For the segmentation of the pseudoglottis, a knowledge-based image processing algorithm based on active contour models is applied [85,91]. The 
algorithm is subdivided into two steps: First, the region relevant for the substitute voice production - the so-called region of interest (ROI) - is determined by fusion of the optical (HS camera) and acoustical (microphone) sensor data. The ROI describes the mean location and shape of the PE segment [85]. Second, by means of the ROI and an adapted active contour model the PE segment vibrations are segmented within the highspeed recording. Fig. 4.6 shows the segmentation result of a high-speed sequence.

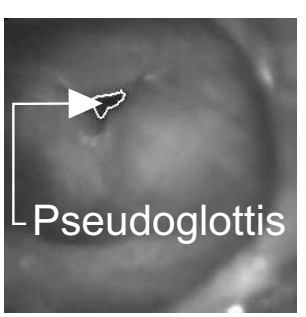

$t=0 \mathrm{~ms}$

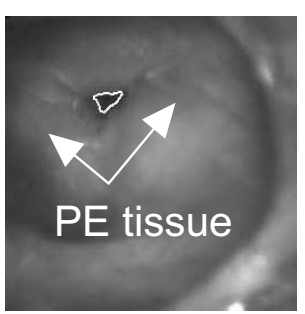

$t=1.5 \mathrm{~ms}$

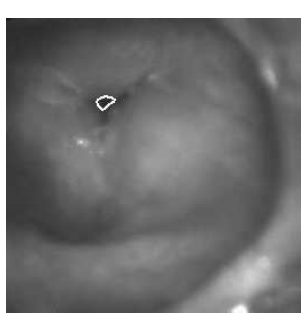

$t=3.0 \mathrm{~ms}$

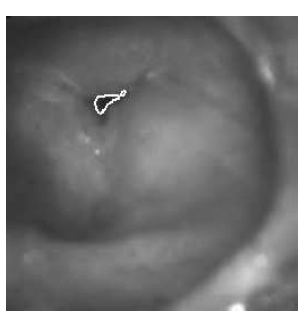

$t=4.5 \mathrm{~ms}$

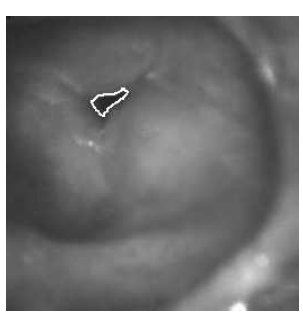

$t=6.0 \mathrm{~ms}$

Figure 4.6: One oscillation cycle extracted from a high-speed recording. The white lines mark the segmented contours of the pseudoglottis.

As the vibration pattern of the PE segment has an irregular shape, there is no symmetry axis or point of symmetry for extracting trajectories for different points of the segmented contours. For the aim of quantification the area function $a^{e x p}$, i.e. the time-varying opening area of the pseudoglottis and the parameterized time-variant contours $\mathbf{c}^{\exp }[z, n](z \in[0,1], n=$ $0, \ldots, N-1)$ are used [92]. Fig. 4.7 shows the area function extracted from the segmented high-speed sequence and the corresponding segmented contours. The fundamental frequency $f_{0}^{e x p}$ amounts to $153 \mathrm{~Hz}$. 


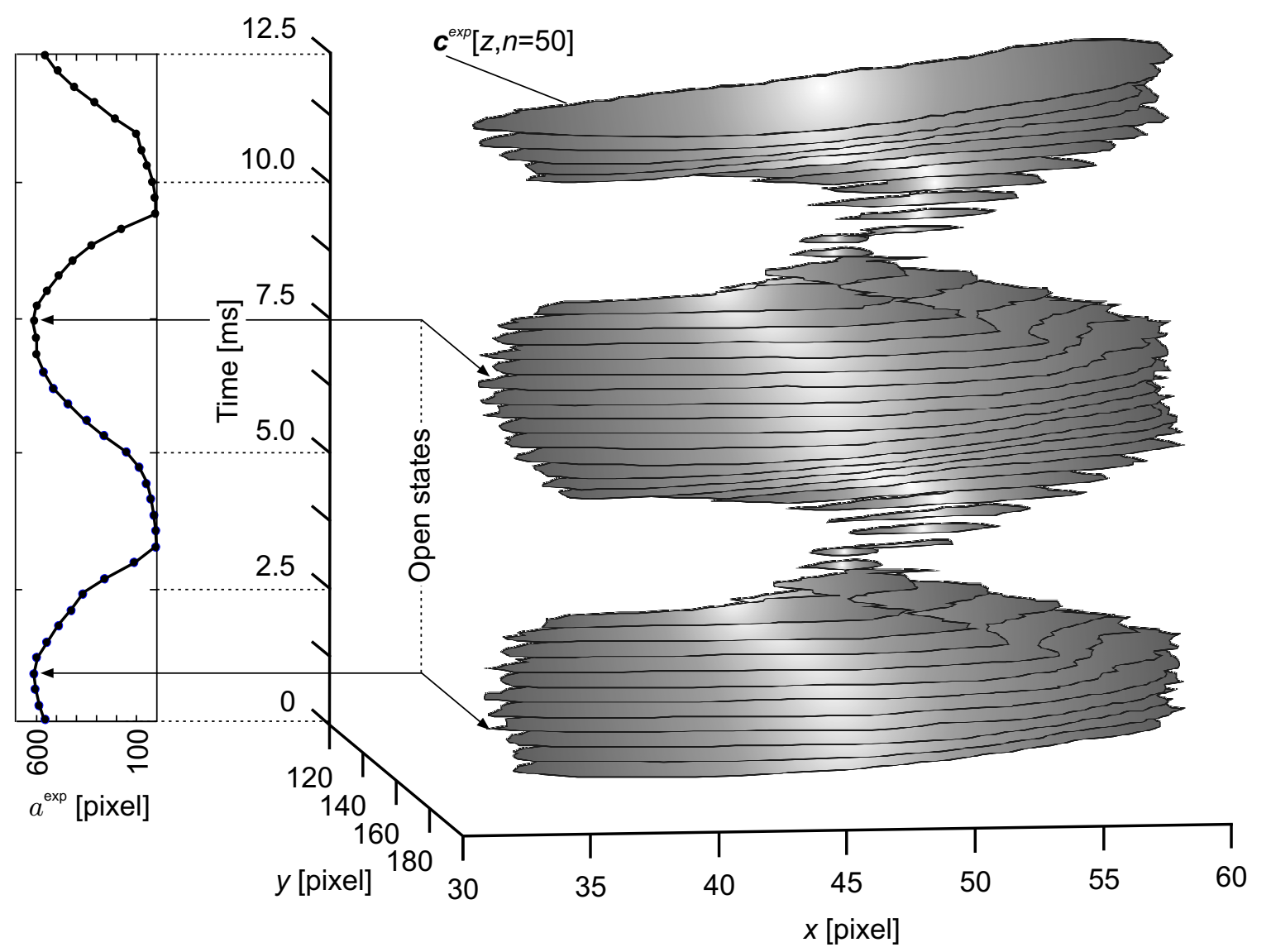

Figure 4.7: Area function $a^{e x p}$ and PE segment contours $\mathbf{c}^{\text {exp }}$ of a high-speed sequence $\left(f_{0}^{e x p}=153 \mathrm{~Hz}\right)$. 


\section{Model-Based Classification of Unilateral Vocal Fold Paralysis}

Parts of this chapter are revised and extended versions of Raphael Schwarz, Ulrich Hoppe, Maria Schuster, Tobias Wurzbacher, Ulrich Eysholdt and Jörg Lohscheller, "Classification of unilateral vocal fold paralysis by endoscopic digital high-speed recordings and inversion of a biomechanical model", IEEE Transactions on Biomedical Engineering, Vol. 53(6), pp. 1099-1108, 2006.

In principle, the clinical evaluation of vocal fold vibrations follows a basic protocol proposed by the European Laryngeal Society (ELS) [22]. It is the aim to facilitate uniformity concerning the methodology for the assessment of pathologic voices. This allows relevant comparisons of voice treatment results, e.g. for different phonosurgical techniques, new or improved instruments or investigative procedures. The ELS protocol is primarily based on subjective criteria for assessing the vocal fold vibrations, voice perception and efficiency as well as self-evaluation by the patient. The analysis of digital high-speed recordings offer the potential to supplement this protocol with objective measures $[11,12,77,93]$. A common approach is the evaluation of the phase shift and amplitude ratio between left and right vocal fold derived from the single-line trajectories [12,66, 89]. In Fig. 5.1 the single-line trajectories of two subjects A (female, age 60) and B (male, age 52) suffering from left-sided RLNP are shown. As a typical vibration pattern, the oscillation amplitudes of the paralyzed vocal fold are reduced compared to the healthy side and a phase shift occurs. Here, the pathologic vocal fold lags behind the healthy one for both subjects (defined as positive phase shift), but also negative phase shifts are possible in unilateral RLNP $[18,94]$. The measured asymmetries concerning amplitude ratio $R_{a}^{e x p}$ and phase shift $\Delta \phi^{e x p}$ are almost identical for subject $\mathrm{A}$ and $\mathrm{B}$. However, if the shapes of the trajectories are taken into consideration dif- 


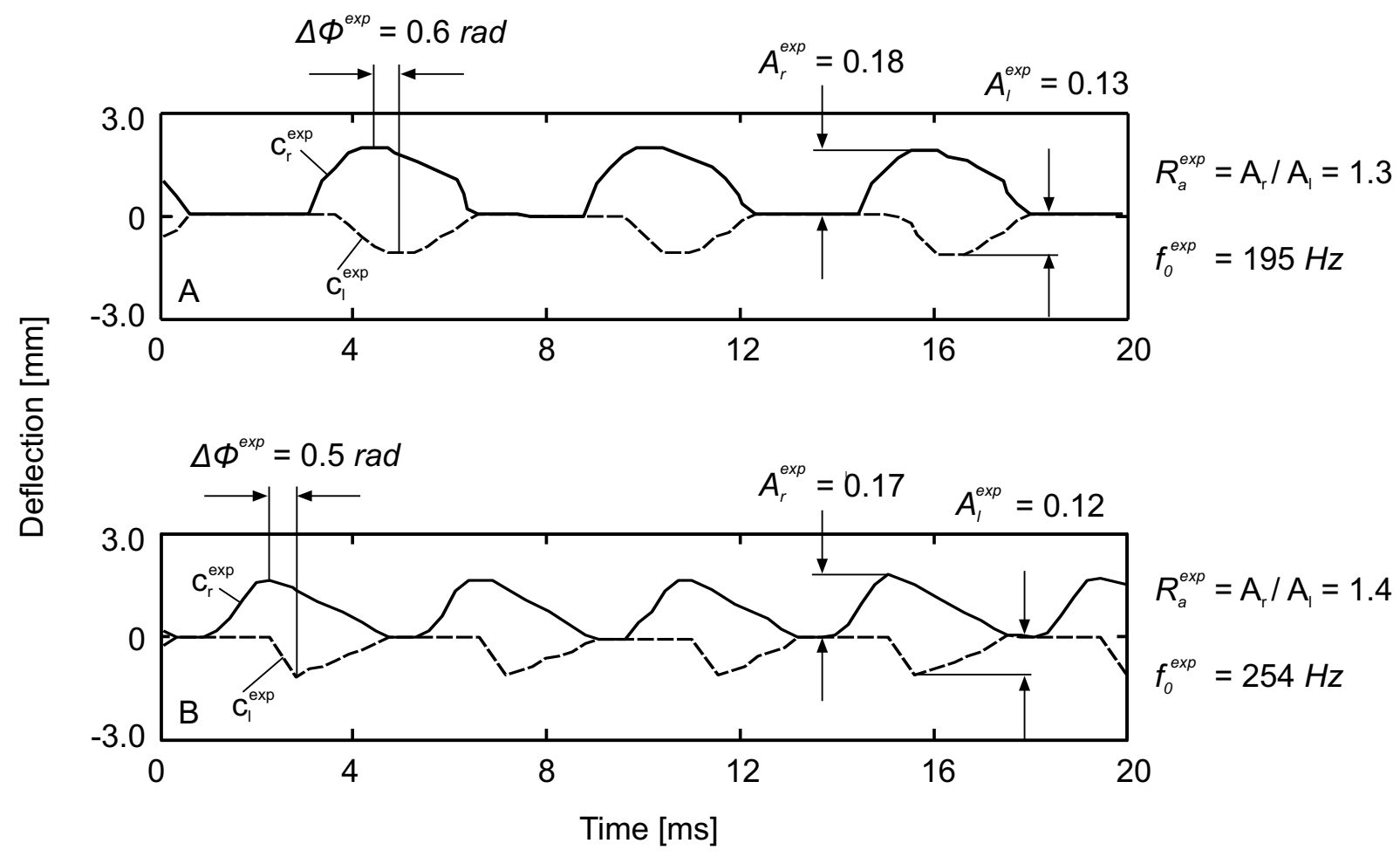

Figure 5.1: Trajectories of two subjects $A$ and $B$ suffering from unilateral vocal fold paralysis ( $A$ - female, age 60, B-male, age 52). The solid line represents the right vocal fold, the dashed line the left one. Measurements as phase shift $\Delta \phi^{\exp }$ or amplitude ratio $R_{a}^{\text {exp }}$ are similar for both subjects. The trajectories of subject $A$ are approximately sinusoidal, whereas for subject $B$ they are more sawtooth-shaped.

ferences are conspicuous. For subject A the trajectories are approximately sinusoidal (during open half-period), whereas for subject B they have a more sawtooth-like shape. Thus, for distinguishing between subjects as $\mathrm{A}$ and $\mathrm{B}$, an objective measure has to assess the shape of the trajectories. An alternative for evaluating the deflection measurements is a model-based approach $[66,95]$. The vocal fold dynamics are reproduced with a lumpedelement model, the so-called two-mass model (2MM) [6]. By means of automatic parameter optimization, the model oscillations are fitted to the bilateral motion curves. The optimized model parameters enable an objective quantification of the vocal fold dynamics. The model-based method is advantageous, as besides temporal oscillation properties like frequency, 
amplitude, and phase, also the specific waveforms of the oscillations are incorporated for the quantification. Additionally, the resulting model configurations facilitate further research into normal and pathologic human voice production by means of model simulations [25].

In this chapter a model-based approach for the assessment of single-line trajectories as shown in Fig. 5.1, i.e. in case of unilateral RLNP, is introduced. Unilateral RLNP results from impairments of the recurrent nerve which splits from the vagus nerve and courses downward along the neck into the thorax where it returns to innervate the posterior intrinsic laryngeal muscles. This complex course exposes the recurrent nerve to many risks, especially during surgical interventions [96,97]. For e.g., the postoperative incidence reaches $8 \%$ after thyroid gland surgery and almost $100 \%$ following the excision of an esophageal carcinoma [98-100]. In the following, the biomechanical model of the vocal folds and the parameter optimization are explained. Finally, a classification scheme is derived by the model-based evaluation of 15 healthy voice subjects and 15 subjects suffering from unilateral RLNP.

\subsection{Two-Mass Model}

The most widely used biomechanical model of the vocal folds, the twomass model (2MM), was presented by Ishizaka \& Flanagan in 1972 for synthetic voice production and simplified by Steinecke \& Herzel [6,7], see Fig. 5.2. Each vocal fold is represented by two coupled oscillators [28]. The oscillators comprise one mass $m_{s, i}$, an anchor spring with stiffness $k_{s, i}^{a}$ and damping $r_{s, i}^{a}$ as well as a vertical coupling spring $k_{i}^{v}$. The indices $s, i$ represent the lower $(s=1)$ and upper $(s=2)$ position, as well as the left $(i=l)$ and right $(i=r)$ side. For the sake of clarity, the damping coefficients $r_{s, i}^{a}$ are not depicted within Fig. 5.2. The masses are coupled to a rigid wall, representing the laryngeal cartilaginous framework. For the masses only a lateral displacement is allowed. According to $\bar{l}_{g}$ (see Sec. 4.1.1), the length $l_{m}$ of the masses is set to $0.7 \mathrm{~cm}$ for female subjects and $1.4 \mathrm{~cm}$ for male subjects. The opening area $a_{s}$ is formed by the opposing masses $m_{s, l}$ and $m_{s, r}$, see Fig. 5.2. As base configuration all model parameters are set to the standard values as described in $[6,90]$. A brief summary of the standard parameter values is given in Tab. 5.1. The subglottal pressure 


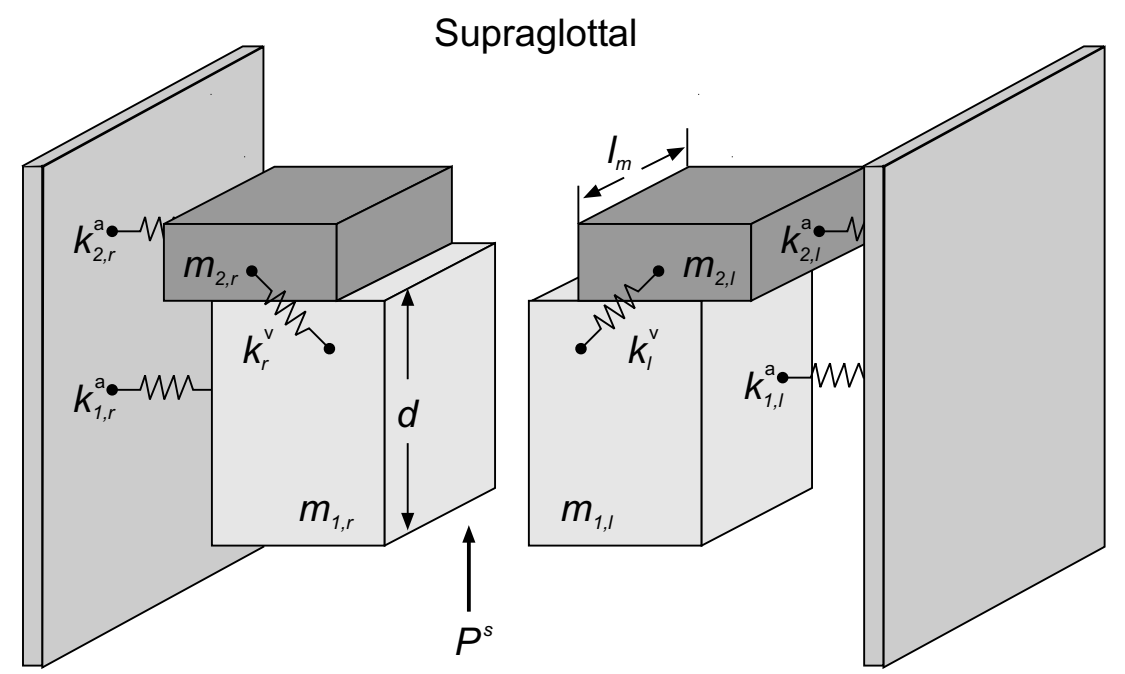

Subglottal

(a)

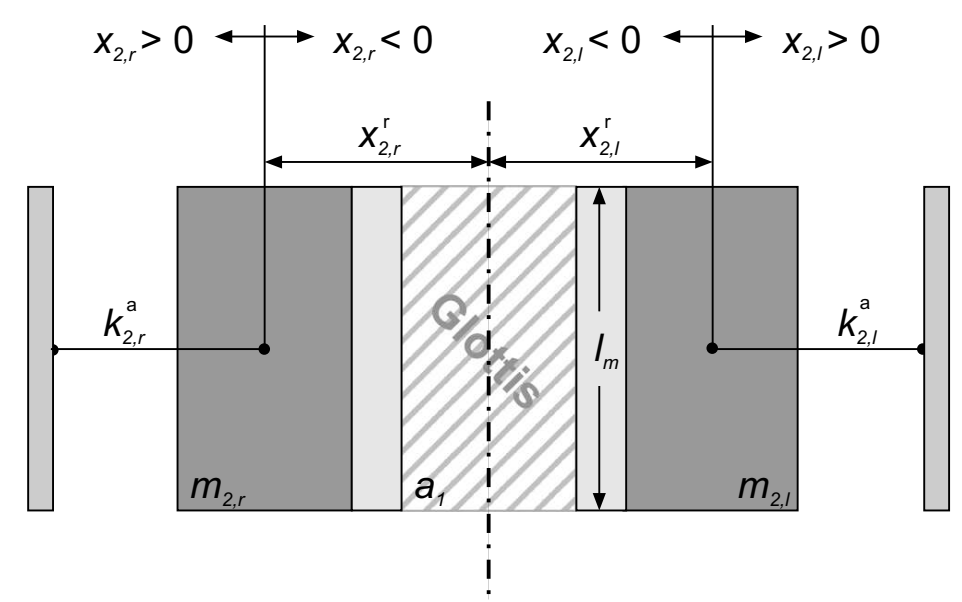

Glottal axis

(b)

Figure 5.2: (a) Schematic representation of the two-mass model of the vocal folds. The masses $m_{s, i}$ are elastically connected to a rigid wall (springs: $\left.k_{1, l}^{a}, k_{2, l}^{a}, k_{1, r}^{a}, k_{2, r}^{a}\right)$ representing the laryngeal cartilaginous framework and to each other (springs: $k_{l}^{v}, k_{r}^{v}$ ). For the masses only a lateral displacement is allowed. (b) 2MM from topview position. The glottis is defined by the minimum opening, i.e. $a_{1}$ in this case. 
Table 5.1: Standard parameters in the symmetric 2MM for the simulation of normal phonation as proposed in [6].

\begin{tabular}{c|c|c|c|c|c}
\hline \hline$m_{1, i}[g]$ & $m_{2, i}[g]$ & $k_{1, i}^{a}[\mathrm{~N} / \mathrm{m}]$ & $k_{2, i}^{a}[\mathrm{~N} / \mathrm{m}]$ & $k_{1, i}^{c}$ & $k_{2, i}^{c}$ \\
\hline 0.125 & 0.025 & 80 & 8 & $3 \cdot k_{1, i}^{a}$ & $3 \cdot k_{2, i}^{a}$ \\
\hline \hline$r_{1, i}^{a}[\mathrm{Ns} / \mathrm{m}]$ & $r_{2, i}^{a}[\mathrm{Ns} / \mathrm{m}]$ & $k_{i}^{v}[\mathrm{~N} / \mathrm{m}]$ & $d[\mathrm{~cm}]$ & $P^{s}\left[\mathrm{~cm} \mathrm{H} \mathrm{H}_{2} \mathrm{O}\right]$ & $l_{m}[\mathrm{~cm}]$ \\
\hline 0.02 & 0.02 & 25 & 0.25 & 8 & $0.7 / 1.4$ \\
\hline
\end{tabular}

$P^{s}$ causes an aerodynamic force which is the driving force to enable vocal fold oscillations [7]. The equation of motion for the mass element $m_{s, i}$ is defined as

$$
0=m_{s, i} \ddot{x}_{s, i}+F_{s, i}^{a}+F_{s, i}^{v}+F_{s, i}^{c}+F_{s, i}^{d},
$$

with the following forces:

$$
\begin{aligned}
& F_{s, i}^{a}-\text { force due to the anchor spring, } \\
& F_{s, i}^{v}-\text { vertical coupling force, } \\
& F_{s, i}^{c}-\text { force due to collision with the opposing mass, } \\
& F_{s, i}^{d}-\text { driving force generated by glottal flow. }
\end{aligned}
$$

Within the cartesian coordinate system the position with regard to the rest position $x_{s, i}^{r}$ of each mass $m_{s, i}$ is denoted $x_{s, i}$ (see Fig. 5.2) with first and second derivative with respect to time $\dot{x}_{s, i}$ and $\ddot{x}_{s, i}$. Nonlinearities of the elastic forces and interactions with the vocal tract are neglected [7]. Hence, the only nonlinearities result from the driving force $F_{s, i}^{d}$ which is assumed to act only on the lower masses, and from the collision forces $F_{s, i}^{c}[7]$.

\subsubsection{Anchor Force}

The anchor forces are defined as

$$
F_{s, i}^{a}:=k_{s, i}^{a} x_{s, i}+r_{s, i}^{a} \dot{x}_{s, i} .
$$

The stiffness $k_{s, i}$ causes a restoring force dependent from the deviation $x_{s, i}$ according to the equilibrium position $x_{s, i}^{r}$. The second term models the 
viscous loss of the vibrating vocal folds [101,102]. The damping coefficients $r_{s, i}^{a}$ are assumed piece-wise linear. The loss increases step-wise on closure of the glottis, i.e. during collision, to represent the stickiness of the soft and moist contacting. The viscous resistances $r_{s, i}^{a}$ are expressed in terms of damping ratio $\zeta_{s}$ as

$$
r_{s, i}^{a}=2 \zeta_{s} \sqrt{m_{s, i} k_{s, i}} .
$$

Following experiments with excised human vocal folds, the loss is taken as $\zeta_{1}=0.1$ and $\zeta_{2}=0.6$ at open-glottis condition [6,102]. During collision of opposing masses $\zeta_{1}=1.1$ and $\zeta_{2}=1.6$ are used.

\subsubsection{Vertical Coupling Force}

For the vertical coupling between the upper and lower masses, damping losses are neglected [95]. The coupling Force $F_{i}^{v}$ is calculated after

$$
F_{s, i}^{v}:=k_{i}^{v}\left(x_{s, i}-x_{s^{*}, i}\right) \text {, }
$$

with

$$
s^{*}=\left\{\begin{array}{ll}
1, & s=2 \\
2, & s=1
\end{array} .\right.
$$

Due to this coupling, the vertical phase differences during vocal fold oscillation are reproduced $[27,103]$. This vertical phase differences are necessary for the self-sustained oscillation of the simplified $2 \mathrm{MM}$ as a) the inertia of the air is not considered within the driving force and b) no vocal tract loading is considered $[7,104,105]$.

\subsubsection{Collision Force}

During closure of the glottis, i.e. the masses $m_{s, l}$ collide with their counterparts $m_{s, r}$, the $2 \mathrm{MM}$ should rebuild the conditions of colliding vocal folds. A contact force at collision will cause some elastic deformations in the structure of the vocal folds. The restoring force due to this deformation is represented by an additional spring to the anchor spring [6]. The resulting collision forces $F_{s, i}^{c}$ can be written as

$$
F_{s, i}^{c}:=-\Theta\left(-a_{s}\right) k_{s, i}^{c} \frac{a_{s}}{2 l_{m}}
$$


with the Heaviside function $\Theta[106]$

$$
\Theta(x)= \begin{cases}1, & x>0 \\ 0, & x \leq 0\end{cases}
$$

and the glottal area

$$
a_{s}:=l_{m} \sum_{i=r, l}\left(x_{s, i}^{r}+x_{s, i}\right) .
$$

For the case of permeation of opposing masses, the glottal area $a_{s}$ becomes negative. The collision is modeled fully elastic, i.e. no friction losses or plastic deformations are incorporated [107].

\subsubsection{Driving Force}

$F_{s, i}^{d}$ is the driving force for the 2MM oscillations. The velocities of the vocal folds are small (typical $0.1-1 \mathrm{~m} / \mathrm{s}$ ) compared to the flow velocity of the air in the glottis (typical $10-30 \mathrm{~m} / \mathrm{s}$ ) $[6,108,109]$. Therefore, the glottal flow is assumed to be quasi-steady and the aerodynamic forces are described by the Bernoulli law based on the following assumptions:

- Subglottal and supraglottal pressure, namely $P^{s}$ and $P^{\text {supra }}$, are constant with $P^{\text {supra }}=0$ [7]. For $P^{s}>0$ an airflow evolves through the glottis due to the pressure difference.

- The flow detaches at the minimum glottal diameter. From the subglottal region to the minimum glottal diameter a Bernoulli-type flow exists. From the minimum glottal diameter to the glottal exit the pressure is considered to be equal to $P^{\text {supra }}$ (jet flow) [110].

- Pressure drops due to viscous losses within the glottis are neglected [111].

- Interactions of the glottal flow with the subglottal and supraglottal vocal tract are neglected [25].

Following these assumptions the driving force is calculated as

$$
F_{s, i}^{d}:=\left\{\begin{array}{cc}
P_{1} l_{m} d, & s=1 \\
0, & s=2
\end{array} .\right.
$$


The static pressure $P_{1}$ within the lower plane is defined as

$$
P_{1}:=P^{s}\left(1-\Theta\left(a_{m i n}\right)\left(\frac{a_{m i n}}{a_{1}}\right)^{2}\right) \Theta\left(a_{1}\right)
$$

with

$$
a_{\text {min }}:=\left\{\begin{array}{lc}
a_{1}=l_{m}\left(\left(x_{1, r}^{r}+x_{1, r}\right)+\left(x_{1, l}^{r}+x_{1, l}\right)\right), & a_{1} \leq a_{2} \\
a_{2}=l_{m}\left(\left(x_{2, r}^{r}+x_{2, r}\right)+\left(x_{2, l}^{r}+x_{2, l}\right)\right), & \text { else }
\end{array},\right.
$$

in accordance to [7].

The differential equation (5.1) is solved with a fourth-order Runge-Kutta method using an increment of $\Delta T=0.25 \mathrm{~ms}[95,112]$. As for the experimental curves, the model dynamics is described by the minimum opening formed by the vibrating masses. In the following these $2 \mathrm{MM}$ oscillations are called theoretical curves $c_{r}$ and $c_{l}$ with

$$
\begin{aligned}
& c_{r}[n]:=\left(x_{s^{*}, r}^{r}+x_{s^{*}, r}[n]\right), \\
& c_{l}[n]:=-\left(x_{s^{*}, l}^{r}+x_{s^{*}, l}[n]\right),
\end{aligned}
$$

with

$$
s^{*}=\left\{\begin{array}{ll}
1, & a_{\min }[n]=a_{1}[n] \\
2, & a_{\min }[n]=a_{2}[n]
\end{array} .\right.
$$

\subsection{Simulation of Vocal Fold Vibrations}

Using the standard configuration after Tab. 5.1, symmetric vibration patterns are produced with the 2MM. Different amplitudes and frequencies for the oscillations are obtained by modified masses and spring constants. In addition, for simulating pathologic vibration patterns (e.g., lower chart in Fig. 4.3 or Fig. 5.1) asymmetric model configurations are required. To do so, parameters are introduced for changing the standard configuration of the $2 \mathrm{MM}$ for reproducing healthy and pathologic vocal fold oscillations in shape, amplitude, frequency, and phase. First, the parameters for modifying the model configuration are defined. Second, the effect of the parameters on the model dynamics is discussed. 


\subsubsection{Defining Non-Standard Model Configurations}

The actual lower mass $\hat{m}_{s, i}$ and the corresponding spring constant $\hat{k}_{s, i}^{a}$ are derived from the standard values $m_{s, i}$ and $k_{s, i}^{a}$ by scaling with $Q_{i}$ after

$$
\begin{aligned}
\hat{m}_{s, i} & =m_{s, i} / Q_{i}, \\
\hat{k}_{s, i}^{a} & =k_{s, i}^{a} \cdot Q_{i},
\end{aligned}
$$

to modify the vocal fold tension. The reciprocal scaling of $m_{s, i}$ and $k_{s, i}^{a}$ models a decreased vibrating portion of the vocal fold mass when the vocal fold tension is increased and vice versa [6].

The actual subglottal pressure $\hat{P}^{s}$ is derived from the standard value $P^{s}$ after

$$
\hat{P}^{s}=P^{s} \cdot Q_{p} .
$$

Using the parameter $Q_{p}$ the amount of energy provided for the voice generating process is varied following Eq. (5.9) and (5.10).

To impose asymmetry between the vocal folds, two unilateral acting parameters are introduced and the actual spring constants $\hat{k}_{1, \beta}^{a}$ and $\hat{k}_{\beta}^{v}$ are calculated as follows:

$$
\begin{aligned}
\hat{k}_{1, \beta}^{a} & =\left(k_{1, \beta}^{a} \cdot Q_{i}\right) \cdot Q_{k 1}, \\
\hat{k}_{\beta}^{v} & =k_{\beta}^{v} \cdot Q_{k c} .
\end{aligned}
$$

The index $\beta$ denotes the pathologic side, i.e. $\beta=l(\beta=r)$ e.g. in case of a left-sided (right-sided) paralysis. Again $k_{1, \beta}^{a}$ and $k_{\beta}^{c}$ denote the standard parameters, see Tab. 5.1.

\subsubsection{Dynamics of Asymmetric Model Configurations}

The defined parameters $Q_{i}, Q_{p}, Q_{k 1}$, and $Q_{k c}$ show a functional interrelation with the oscillation characteristics of the 2MM. The analysis of this interrelation gives information about the usage of these parameters for simulating specific vibration patterns and is discussed in the following.

Fig. 5.3 shows a surface plot of the phase shift $\Delta \phi$ between the oscillations of the lower masses as a function of $Q_{k 1}$ and $Q_{k c}\left(Q_{p}\right.$ and $Q_{i}$ are set to 1$)$, 


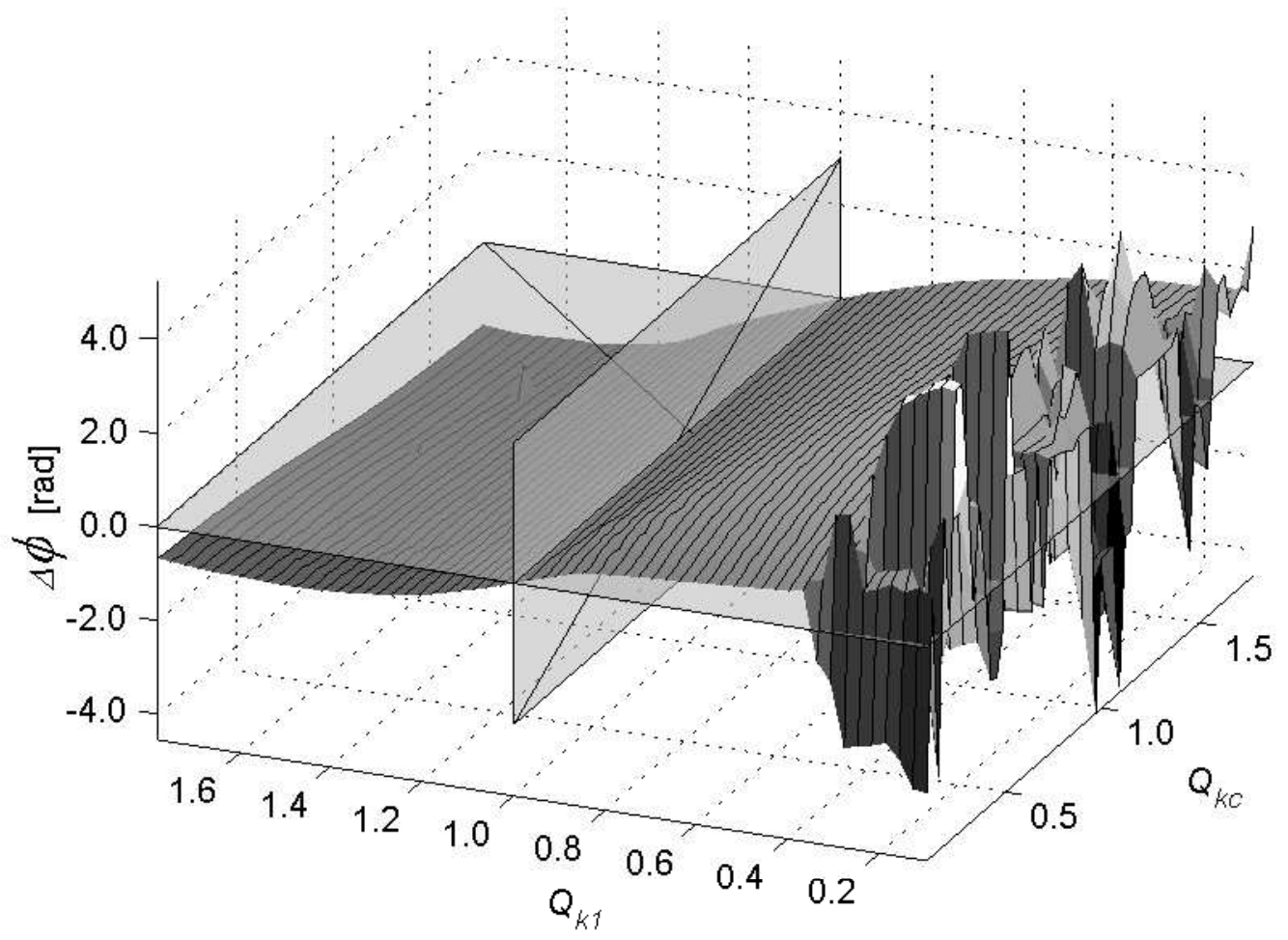

Figure 5.3: Phase difference $\Delta \phi$ as a function of $Q_{k 1}$ and $Q_{k c}\left(Q_{p}\right.$ and $Q_{i}$ are set to 1). The planes $\Delta \phi=0$ and $Q_{k 1}=1$ are depicted. For $Q_{k 1}<1$ the phase shift $\Delta \phi$ is positive. For $Q_{k 1}>1$ a negative phase shift $\Delta \phi$ occurs. Small values of $Q_{k 1}$ result into chaotic behavior of the $2 M M$.

i.e. $\Delta \phi=\Delta \phi\left(Q_{k 1}, Q_{k c}\right)$. For values of $Q_{k 1}$ less than 0.5 , the $2 \mathrm{MM}$ shows chaotic behavior, as presented in Fig. 5.3. A chaotic model behavior is not useful for the optimization approach. To avoid obtaining model configurations with a chaotic vibration characteristics, $Q_{k 1}>0.5$ is assumed. $\Delta \phi$ almost remains constant for a fixed value $Q_{k 1}$, i.e. $Q_{k c}$ has a negligible influence. Thus, the phase shift is assumed to be a function of $Q_{k 1}$, i.e. $\Delta \phi=\Delta \phi\left(Q_{k 1}\right)$. Furthermore, Fig. 5.3 reveals that the phase shift $\Delta \phi$ is positive for $Q_{k 1}<1$ and negative for $Q_{k 1}>1$.

Variations of the subglottal pressure $P_{s}$ and its effect on the 2MM are examined in several publications $[7,104,105,113]$. The most conspicuous property of $P_{s}$ is to adjust the oscillation amplitudes. As the subglottal pressure is linearly scaled with $Q_{p}$ (see Equ. (5.17)) the oscillation amplitudes $A_{r, l}$ are approximated as a function of $Q_{p}$ for given masses and 
tensions, i.e. $A_{r, l}=A_{r, l}\left(Q_{p}\right)$.

According to [95], the fundamental frequencies of the 2MM oscillations are approximated by the simple mass-spring oscillator equation

$$
\begin{aligned}
f_{0, i} & =\frac{1}{2 \pi} \sqrt{\frac{\hat{k}_{1, i}^{a}}{\hat{m}_{1, i}}}, \\
f_{0, i} & =\frac{1}{2 \pi} \sqrt{\frac{k_{1, i}^{a} Q_{i}}{\frac{m_{1, i}}{Q_{i}}}} \Leftrightarrow \quad Q_{i}=2 \pi f_{0, i} \sqrt{\frac{m_{1, i}}{k_{1, i}^{a}}} .
\end{aligned}
$$

In Eq. (5.21) $k_{1, i}^{a}$ and $m_{1, i}$ denote the standard parameters. After (5.21) a linear dependency between the optimization parameter $Q_{i}$ and the frequency $f_{0, i}$ of the theoretical curve is assumed.

Fig. 5.4 exemplarily shows the theoretical curves which are produced with the parameter sets $\left(Q_{r, l}, Q_{p}, Q_{k 1}, Q_{k c}\right)=(1.94,1.38,1.02,1.08)$ for the upper chart and $\left(Q_{r, l}, Q_{p}, Q_{k 1}, Q_{k c}\right)=(1.49,4.00,0.57,1.01)$ for the lower chart. The theoretical curves of the first parameter set reproduce the experimental curves of the healthy voice subject depicted in Fig. 4.3 (upper chart). The model oscillations of the second parameter set show similar characteristics concerning phase shift and amplitude ratio as paralytic voice subjects, see Fig. 4.3 (lower chart). Thus, the 2MM comprising the introduced parameters $Q_{i}, Q_{p}, Q_{k 1}$, and $Q_{k c}$ is capable to reproduce healthy and paralytic vibration patterns.

\subsection{Objective Function}

The principal idea of model-based quantification is the reproduction of experimental curves with the $2 \mathrm{MM}$. In the previous section we have seen, that a desired vibration pattern is producible using appropriate values for the parameters $Q_{i}, Q_{p}, Q_{k 1}$, and $Q_{k c}$. In the following, a so-called objective function $\eta$ is introduced for quantifying the deviation of theoretical curves obtained for a specific model configuration from observed experimental curves, i.e. the consistency between the model dynamics and the vocal fold oscillations is measured.

The objective function $\eta$ is defined as the total energy of the difference signal between the theoretical and the experimental curves. The value $\eta_{j}$ 


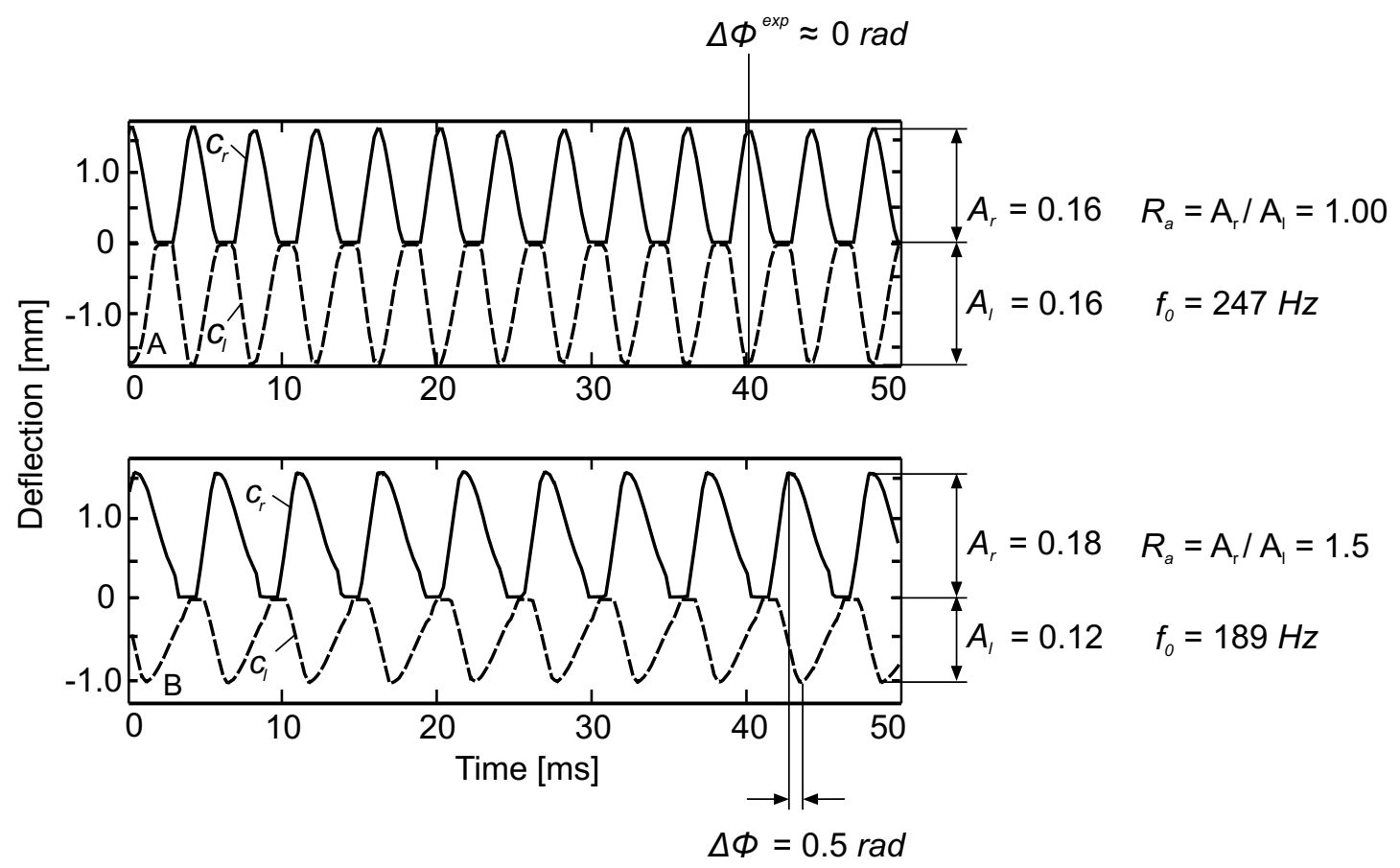

Figure 5.4: Theoretical curves representing symmetric (upper) and irregular (lower) vocal fold oscillations. The predefined optimization parameters $\left(Q_{r, l}, Q_{p}, Q_{k 1}, Q_{k c}\right)$ are $(1.94,1.38,1.02,1.08)$ for the upper chart and $(1.49,4.00,0.57,1.01)$ for the lower chart.

of a specific parameter set $\left(Q_{i}, Q_{p}, Q_{k 1}, Q_{k c}\right)_{j}$ is calculated after

$$
\eta_{j}:=\left(\left\|c_{r}^{e x p}-c_{r}^{j}\right\|_{2}^{2}+\left\|c_{l}^{e x p}-c_{l}^{j}\right\|_{2}^{2}\right)=\left(\left\|e_{r}^{j}\right\|_{2}^{2}+\left\|e_{l}^{j}\right\|_{2}^{2}\right),
$$

where $c_{r}^{j}\left(c_{l}^{j}\right)$ defines the right (left) theoretical curve corresponding to the parameter set $j$. The $j^{\text {th }}$ right (left) error signal is denoted by $e_{r}^{j}\left(e_{l}^{j}\right)$ with the $n^{\text {th }}$ sample $e_{r}^{j}[n]\left(e_{l}^{j}[n]\right)$ and $n=0, \ldots, N-1$. An increased value for $\eta$ means an increased deviation of the theoretical curves from the considered experimental ones, whereas for a small deviation the resulting $\eta$ is close to zero.

Fig. 5.5 shows $\eta$ in a section of the $\left(Q_{k 1}, Q_{k c}\right)$-hyperplane for $Q_{p}=4.00$ and $Q_{r, l}=1.49$ comparing the theoretical curves with the experimental curves of the paralytic voice subject from Fig. 4.3 (lower chart). The objective function has different local minima and thus a non-convex interrelation with $Q_{k 1}$ and $Q_{k c}$. The position of the parameter set resulting in the 


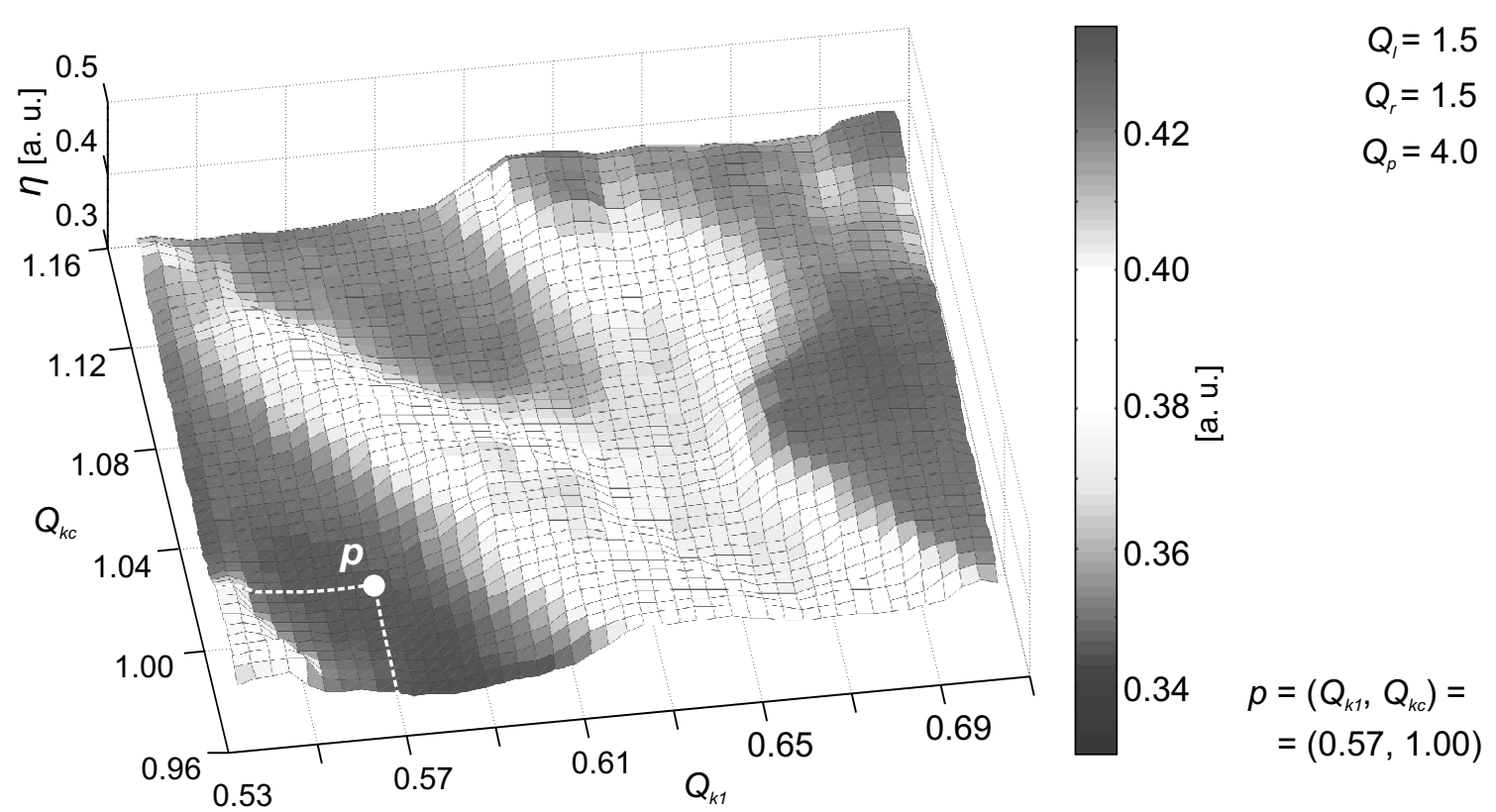

Figure 5.5: The non-convex objective function $\eta$ in the $\left(Q_{k 1}, Q_{k c}\right)$ hyperplane for $Q_{l}=Q_{r}=1.5$ and $Q_{p}=4.0$. The point $p$ marks the local minimum $\left(Q_{k 1}, Q_{k c}\right)=(0.57,1.00)$. The parameter set corresponding to $p$ delivers the theoretical trajectories shown in the lower chart of Fig. 5.4.

theoretical curves depicted in Fig. 5.4 (lower chart) is located at a local minimum of $\eta$.

\subsection{Automatic Parameter Optimization}

For the best fitting of the model dynamics, the parameter set $\left(Q_{i}, Q_{p}, Q_{k 1}\right.$, $\left.Q_{k c}\right)$ reproducing a specific experimental curve with the smallest deviation, i.e. $\min (\eta)$, has to be identified. Assuming following restrictions

1. $Q_{i} \in[0.5,2.0]$ with step size $\Delta Q_{i}=0.05$, i.e. $f_{0} \in[60 \mathrm{~Hz}, 250 \mathrm{~Hz}]$ with a frequency resolution $\Delta f=1.25 \mathrm{~Hz}$ for covering male and female subjects $[95,110]$,

2. $Q_{p} \in[0.1,8.0]$ with step size $\Delta Q_{p}=0.1$, i.e. the subglottal pressure varies between $0.8 \mathrm{~cm} \mathrm{H}_{2} \mathrm{O}$ and $64 \mathrm{~cm} \mathrm{H}_{2} \mathrm{O}$ with a step size of $0.8 \mathrm{~cm} \mathrm{H}_{2} \mathrm{O}[113,114]$, 
3. $Q_{k 1}$ and $Q_{k c}$ with restrictions as for $Q_{i}$ are sufficient for reproducing vocal fold paralyses $[115,116]$, and

4. $Q_{l}=Q_{r}=Q$ is used, i.e. left and right model side oscillate with same fundamental frequency,

there are approximately $3.6 \cdot 10^{6}$ possible parameter combinations. If the calculation of $\eta$ takes $1 s$ for each parameter set, then about 40 days would be necessary to determine the best solution. There exists no analytical solution for calculating $\min (\eta)$ and the determination of $\eta$ for the entire parameter space is not possible within feasible time. Therefore, an automatic optimization procedure is introduced, which determines a parameter set $\left(Q_{i}^{*}, Q_{p}^{*}, Q_{k 1}^{*}, Q_{k c}^{*}\right)$ resulting in theoretical curves with minimum deviations from the experimental curves without evaluating the whole parameter space. In the following the parameters $\left(Q_{i}, Q_{p}, Q_{k 1}, Q_{k c}\right)$ are termed optimization parameters. The proposed parameter optimization procedure is subdivided into two steps: Step 1 is an initial value search based on the analysis from section 5.2.2. In this step initial values $\left(Q_{i}^{i}, Q_{p}^{i}, Q_{k 1}^{i}, Q_{k c}^{i}\right)$ are calculated for limiting the search space. Step 2 is defined as an optimization procedure using a genetic search algorithm for determining the set $\left(Q_{i}^{*}, Q_{p}^{*}, Q_{k 1}^{*}, Q_{k c}^{*}\right)$.

\subsubsection{Initial Value Search}

Values for the optimization parameters are calculated which are capable to reproduce characteristic properties of the experimental curves (fundamental frequency, amplitudes, phase shifts). These values are defined as initial values. For limiting the search space, intervals around the initial values determine the search space for the subsequent search algorithm.

By means of the investigated functional interrelations between optimization parameters and the $2 \mathrm{MM}$ the initial value search algorithm is defined. The flow diagram of this algorithm is depicted in Fig. 5.6.

Step 1 starts the search procedure with a symmetric parameter configuration $Q_{k 1}^{i}=1$ and $Q_{k c}^{i}=1$. The fundamental frequencies of the model oscillations are adjusted to the experimental vocal fold vibrations. Here, the initial value $Q_{i}^{i}$ is calculated after the mass-spring oscillator equation (5.21), where $f_{0, i}$ is set to $f_{0, i}^{e x p}$. 


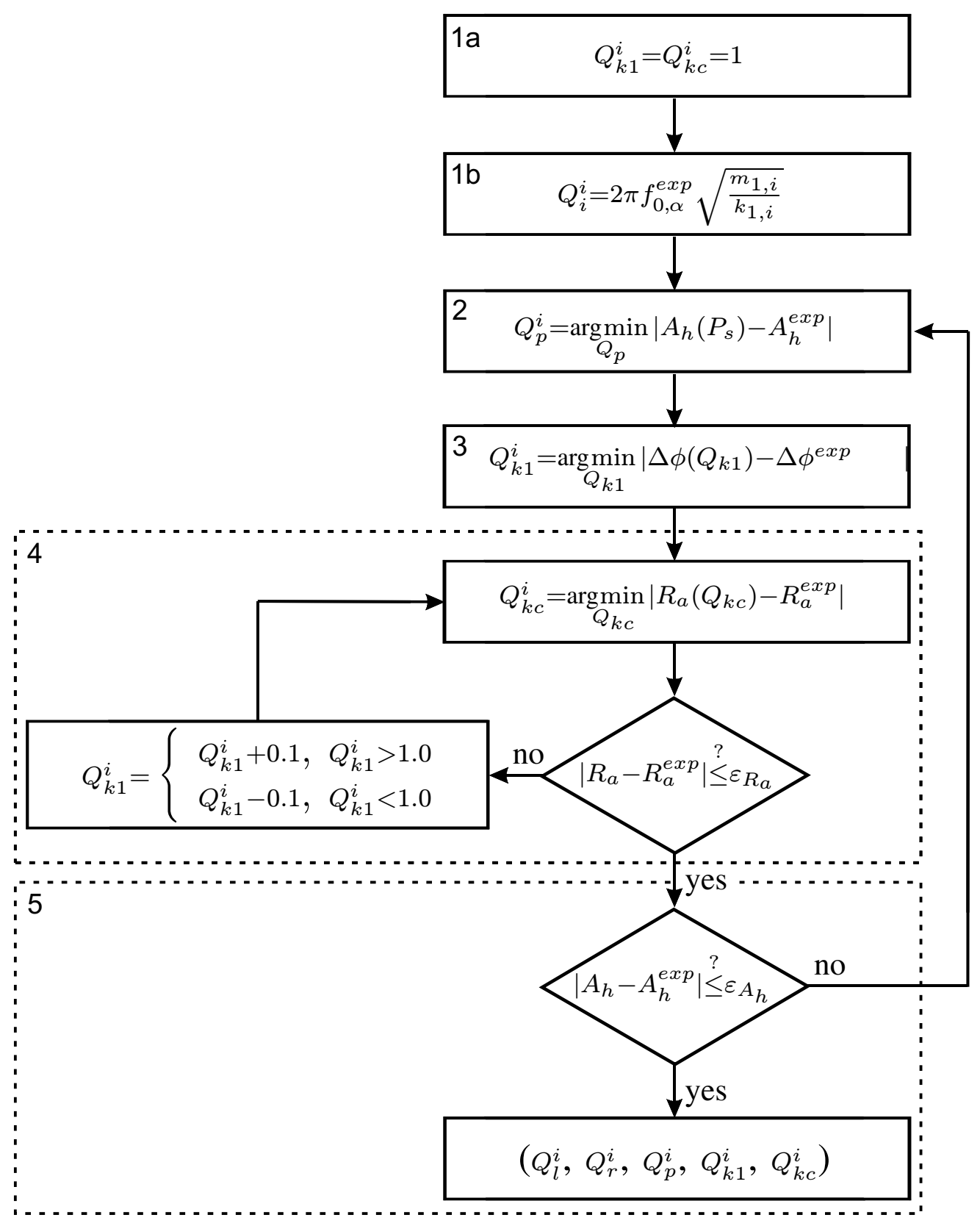

Figure 5.6: Flow chart of the initial value search procedure. 
Step 2 determines the required value of $Q_{p}$ for reproducing the experimental oscillation amplitude of the healthy side $A_{h}^{\text {exp }}$. The difference $\left|A_{h}\left(Q_{p}\right)-A_{h}^{e x p}\right|$ is minimized by increasing $Q_{p}$ in steps of 0.01 starting from 0 . The value $Q_{p}$, which delivers the minimum, is assumed to be the preliminary initial value $Q_{p}^{i}$.

Step 3 calculates $Q_{k 1}$ to reach the phase shift $\Delta \phi^{\exp }$ between left and right vocal fold oscillation. Starting from $Q_{k 1}=1, Q_{k 1}$ is decreased in steps of 0.01 if the phase shift is positive. For $\Delta \phi<0, Q_{k 1}$ is increased in steps of 0.01. If the minimum of $\left|\Delta \phi\left(Q_{k 1}\right)-\Delta \phi^{\exp }\right|$ is achieved, $Q_{k 1}$ is assumed to be the preliminary initial value $Q_{k 1}^{i}$.

Step 4 searches a value for $Q_{k c}$ within the interval $[0.5,1]$ for $Q_{k 1} \geq 1$ $\left([1,2]\right.$ and for $Q_{k 1} \leq 1$, respectively) with an accuracy of 0.01 to match the amplitude ratio $R_{a}^{e x p}$ with the theoretical amplitude ratio $R_{a}$. If the minimum of $\left|R_{a}-R_{a}^{e x p}\right|$ is obtained, the instantaneous $Q_{k c}$ is used as the preliminary initial value $Q_{k c}^{i}$ and the algorithm continuous with step 5. Otherwise, the instantaneous value of $Q_{k 1}^{i}$ is increased or decreased by 0.1 , depending on whether the phase shift of the experimental curves is negative or positive and step 4 is iterated until a preliminary value $Q_{k c}^{i}$ is identified, i.e. the difference between $R_{a}$ and $R_{a}^{e x p}$ is below a threshold value $\varepsilon_{R_{a}}$. The value of $\varepsilon_{R_{a}}$ depends on the required accuracy of the initial values. For this study, $\varepsilon_{R_{a}}$ was set to $0.05 \cdot R_{a}^{e x p}$.

Step 5 verifies whether $\left|A_{h}\left(P_{s}^{i}\right)-A_{h}^{e x p}\right|$ falls below a threshold value $\varepsilon_{A_{h}}$. If this is the case, the initial values $\left(Q_{p}^{i}, Q_{i}^{i}, Q_{k 1}^{i}, Q_{k c}^{i}\right)$ are identified and the algorithm stops. Otherwise, the preliminary initial value $Q_{p}^{i}$ has to be updated and the algorithm is iterated starting from step 2. The value of $\varepsilon_{A_{h}}$ depends on the required accuracy of the initial values. Here, $\varepsilon_{A_{h}}=0.01 \cdot A_{h}^{\exp }$ is chosen.

The initial values are used to define the search space within the parameter domain in the following way [115-117]: $Q_{k 1} \in\left\{(1 \pm 0.33) \cdot Q_{k 1}^{i}\right\}, Q_{k c} \in$ $[0.50,1.00]$ for $Q_{k 1} \geq 1.00$ or $Q_{k c} \in[1.00,2.00]$ for $Q_{k 1} \leq 1.00, Q_{i} \in$ $\left\{(1 \pm 0.25) \cdot Q_{i}^{i}\right\}$, and $Q_{p} \in\left\{(1 \pm 0.50) \cdot Q_{p}^{i}\right\}$. 


\subsubsection{Optimization Procedure}

As shown in Sec. 5.3, the objective function $\eta$ is a non-convex function within the search space spanned by the introduced optimization parameters. Stochastic sampling methods as genetic algorithms (GA) are an appropriate technique solving optimization problems with such objective functions $[118,119]$. A general description of genetic algorithms can be found in [118]. Here, a real-valued GA is used for the optimization procedure. In principle it works as follows [119]:

1. Optimization parameters - the interface between GA and the variable model parameters - are combined in a group and referred to as individual. A set of $M$ individuals forms the actual population. Here, the initial population consists of $M=10$ randomly chosen parameter sets $\left(Q_{p}, Q_{i}, Q_{k 1}, Q_{k c}\right)$.

2. Using the parameters of an individual, the variable model parameters are calculated from the standard values and a simulation is carried out with the modified 2MM. This step is performed for each member of the population.

3. The match between the resulting model dynamics and the vocal fold vibrations is quantified with the objective function. A fitness value $-\eta$ is assigned to each parameter set. In this way, an increased fitness is associated with an increased consistency between theoretical and experimental curves.

4. Using the parameter values of the individuals and their corresponding fitness, the GA determines the new population. The parameter set with the best fitness is always selected for the next generation (elite selection strategy). This procedure is iterated from step 2 until a termination condition (here: a fixed number of iterations) is fulfilled.

The parameter set $\left(Q_{p}^{*}, Q_{i}^{*}, Q_{k 1}^{*}, Q_{k c}^{*}\right)$ of the last generation with the maximum fitness $-\eta$ is the final result of the optimization procedure. 


\subsection{Validation of the Parameter Optimization Using the Synthetic Data Set}

Before the automatic parameter optimization is applied to clinical data its stability and reliability needs to be verified. For this aim, the procedure is applied to synthetic data sets. These data sets are generated by model simulations with predefined parameter configurations. 430 parameter sets $\left(Q_{p}^{p}, Q_{i}^{p}, Q_{k 1}^{p}, Q_{k c}^{p}\right)$ are randomly selected from the parameter space for generating synthetic experimental curves. Finally, these curves are evaluated with the optimization procedure.

The maximum number of generations for the genetic algorithm was set sufficiently high to 300 . Fig. 5.7 shows the grand average (i.e. across all synthetic data sets) for the fitness (solid line) over the number of generations. The convergence behavior of the synthetic cases resulting in the best and the worst fitting result (dashed lines) are also depicted.

The progression of the fitness traces show a strong convergence of the fitness behavior depending on the number of generations. By applying 300 generations a mean fitness of $-0.11 \pm 0.08$ (solid line) and a correlation of $98 \%$ is achieved. The mean norm of all final error signals 0.11 is only $2 \%$ of the mean norm of the synthetical curves $\left\|c_{r}^{s}\right\|_{2}+\left\|c_{l}^{s}\right\|_{2}$, which demonstrates the quality of the parameter optimization.

After 250 generations the mean fitness deviates just $1 \%$ from the fitness after 300 generations. Further generations after the $250^{\text {th }}$ will barely augment the performance of the optimization procedure. In the following, the maximum number of generations is set to 250 which guarantees a reasonable quality of the results and limits the computational costs of the optimization.

The performance of the algorithm is described by the correlation between the predefined synthetic parameters and the optimized parameters. The four charts in Fig. 5.8 depict the computed optimized parameters over the predefined parameters. In each chart, the two solid lines define the regions containing $85 \%$ of the calculated optimization parameters. The maximum relative errors (differences between claculated values $\left(Q_{x x}^{*}\right)$ and predefined $\left(Q_{x x}^{p}\right)$ value, normalized to $\left.\left(Q_{x x}^{p}\right)\right)$ within these regions are $8.8 \%, 1.3 \%$, $6.3 \%$, and $19 \%$ for the parameters $\left(Q_{p}^{*}, Q_{i}^{*}, Q_{k 1}^{*}, Q_{k c}^{*}\right)$. The correlations 


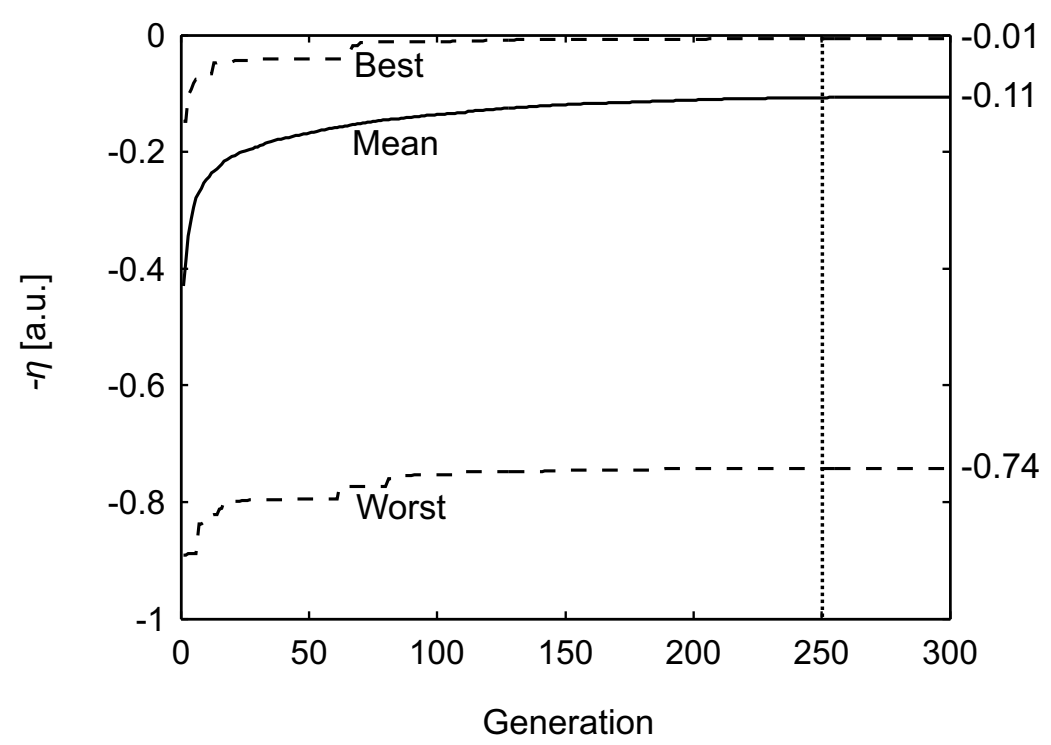

Figure 5.7: Grand average of the convergence behavior of the fitness $-\eta$ (across all 430 predefined parameter sets) over the generations calculated during the optimization procedure using a genetic algorithm (solid line). The courses resulting in the best and worst synthetic adaptation are also depicted (dashed lines).

between the predefined and optimized parameters are $97 \%, 99 \%, 98 \%$, and $91 \%$ in the same order. These results demonstrate the robustness and reliability of the optimization procedure. In the following, the algorithm is applied to clinical data comprising healthy and pathologic voice subjects.

\subsection{Application to Clinical Data}

The high-speed recordings for 15 healthy voice subjects (15 female, age 19 \pm 2 years) and for 12 subjects suffering from left-sided RLNP ( 7 female, 5 male, age $42 \pm 13$ years) are utilized to obtain the experimental curves.

\subsubsection{Clinical Data}

For all subjects, high-speed recordings are performed and the experimental curves are extracted as described in Sec. 4.1.1. All considered high-speed 


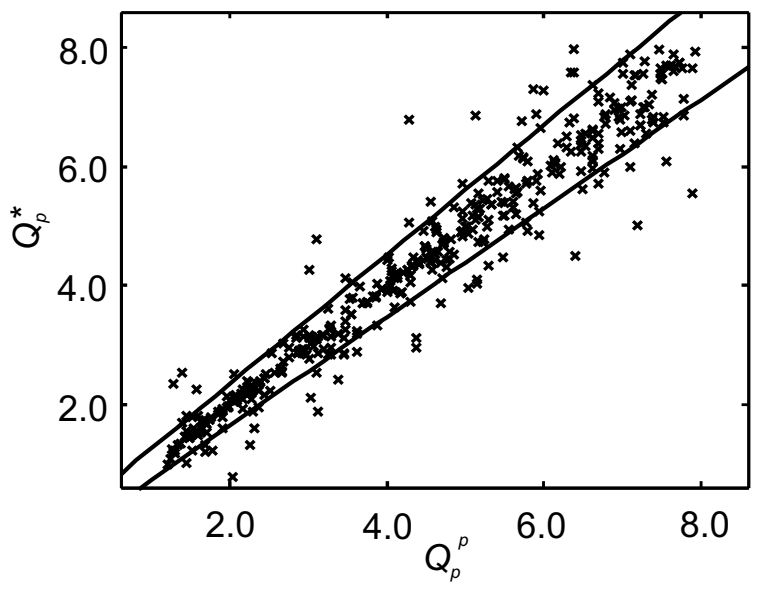

(a)

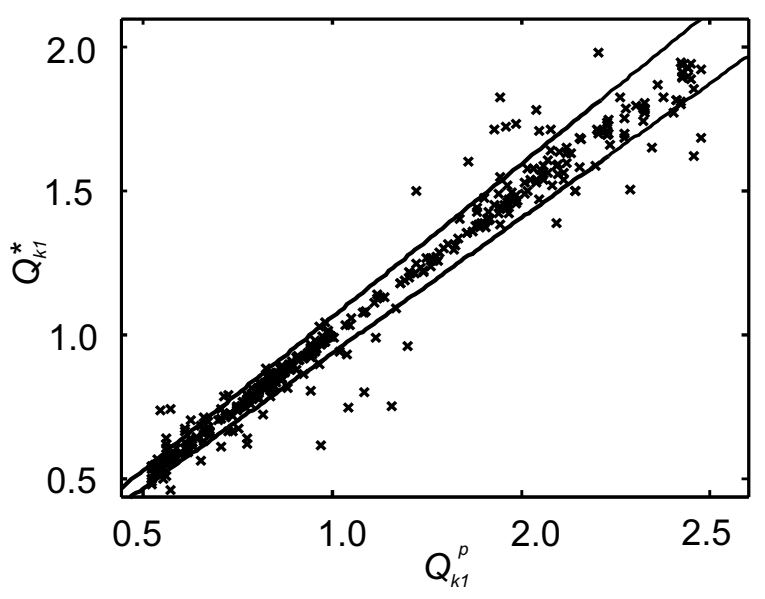

(c)

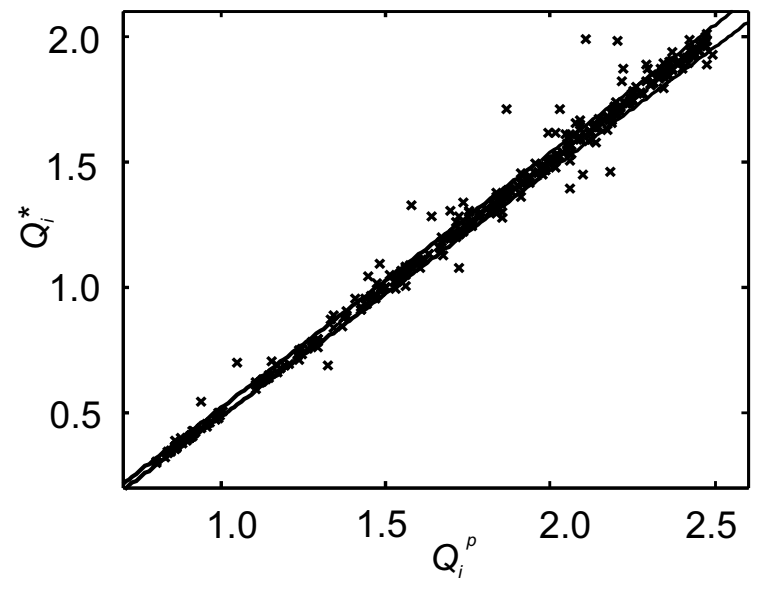

(b)

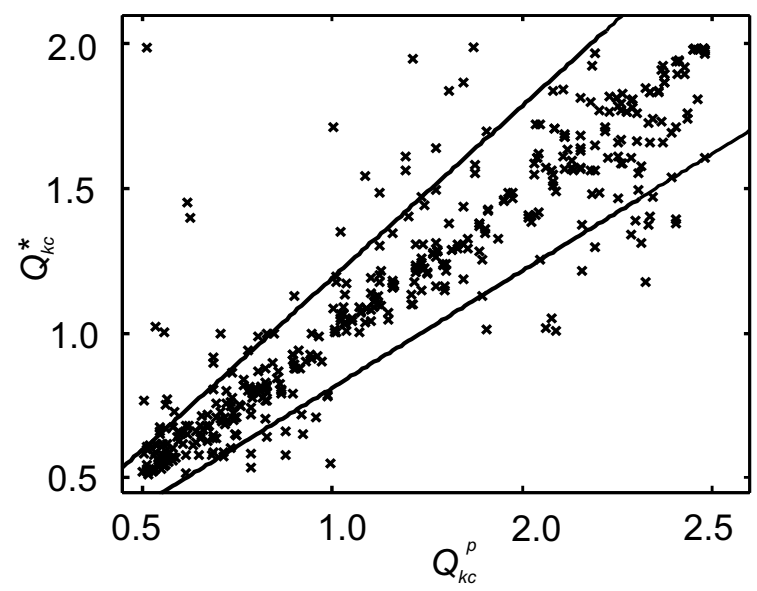

(d)

Figure 5.8: (a)-(d) show the achieved optimization parameters $\left(Q_{p}^{*}, Q_{i}^{*}, Q_{k 1}^{*}, Q_{k c}^{*}\right)$ over the predefined values $\left(Q_{p}^{p}, Q_{i}^{p}, Q_{k 1}^{p}, Q_{k c}^{p}\right)$. The solid lines border the region which contains $85 \%$ of the determined optimization parameters. 
recordings have the same length $N=1000$ which corresponds to $250 \mathrm{~ms}$. For the healthy voice subjects the vocal fold oscillations are nearly symmetric and irregularities in amplitude ratio and phase shift are small, see Tab. 5.2. The fundamental frequencies vary between $189 \mathrm{~Hz}$ and $541 \mathrm{~Hz}$. Positive and negative phase shifts $\Delta \phi^{e x p}$ between right and left vocal fold oscillation occur. The positive phase shift is (mean \pm standard deviation (sd), across all subjects) $0.18 \pm 0.16$ in radian measure. The negative phase shift is $-0.13 \pm 0.12$. The amplitude ratio $R_{a}^{\exp }$ between the healthy and the paralyzed side amounts to $0.96 \pm 0.08$ and thus is close to 1.

Tab. 5.3 summarizes the properties of the extracted experimental curves in case of unilateral RLNP. For three subjects two high-speed recordings were performed. Therefore, the subject Si corresponding to high-speed recording $\mathrm{P} j$ is stated in Tab. 5.3. The fundamental frequencies $f_{0}^{\text {exp }}$ vary between $108 \mathrm{~Hz}$ and $413 \mathrm{~Hz}$. As in healthy subjects, positive and negative phase shifts $\Delta \phi^{e x p}$ occur. The positive phase shift is $0.69 \pm 0.50$ and the negative phase shift is $-0.94 \pm 0.93$. The amplitude ratio $R_{a}^{e x p}$ between the healthy and the paralyzed side amounts to $1.38 \pm 0.37$. Following this, the asymmetry measures are significantly increased compared to the healthy subjects.

\subsubsection{Adaptation Results}

The automatic parameter optimization is applied to experimental curves of the healthy and paralytic voice subjects. For all cases, the experimental curves show a symmetry concerning the fundamental frequencies of the left and right vocal fold oscillations. Thus, in the following the search space for the parameter optimization is limited by setting $Q^{*}=Q_{l}^{*}=Q_{r}^{*}$.

Tab. 5.4 summarizes the results of the optimization procedure applied to the healthy voice group for $\left(Q^{*}, Q_{p}^{*}, Q_{k 1}^{*}, Q_{k c}^{*}\right)$. The mean deviations of $Q_{k 1}^{*}$ and $Q_{k c}^{*}$ from 1 represent model asymmetries and amounts to 0.05 and 0.04. The resulting optimization parameters introducing asymmetry within the model have a value close to 1 . That represents the symmetry of the vocal fold oscillations in healthy voice subjects (see also Tab. 5.2). Across the 15 subjects the mean correlation between the theoretical and the experimental curves is $90 \% \pm 8 \%$. 
Table 5.2: Fundamental frequencies $f_{0}^{e x p}$, phase shifts $\Delta \phi^{e x p}$, and amplitude ratios $R_{a}^{e x p}$ derived from the experimental curves of the healthy voice subjects. H1 - H15 indicate the number of the high-speed recordings.

\begin{tabular}{c|c|c|c}
\hline$\#$ & $f_{0}^{\text {exp }}[\mathrm{Hz}]$ & $\Delta \phi^{\text {exp }}[\mathrm{rad}]$ & $R_{a}^{\text {exp }}$ \\
\hline \hline H1 & 247 & 0.30 & 0.98 \\
\hline H2 & 541 & 0.42 & 0.95 \\
\hline H3 & 334 & 0.01 & 0.84 \\
\hline H4 & 207 & -0.21 & 1.05 \\
\hline H5 & 325 & -0.42 & 0.81 \\
\hline H6 & 354 & 0.25 & 1.01 \\
\hline H7 & 300 & -0.13 & 0.87 \\
\hline H8 & 314 & -0.09 & 1.02 \\
\hline H9 & 297 & -0.06 & 0.98 \\
\hline H10 & 271 & -0.02 & 0.95 \\
\hline H11 & 238 & -0.01 & 1.00 \\
\hline H12 & 189 & 0.08 & 0.88 \\
\hline H13 & 244 & -0.05 & 0.93 \\
\hline H14 & 237 & 0.02 & 1.00 \\
\hline H15 & 230 & -0.2 & 1.09 \\
\hline
\end{tabular}


Table 5.3: Fundamental frequencies $f_{0}^{e x p}$, phase shifts $\Delta \phi^{e x p}$, and amplitude ratios $R_{a}^{\exp }$ derived from the experimental curves of the paralytic voice subjects S1 to S12. P1 - P15 indicate the number of the high-speed recordings.

\begin{tabular}{c|c|c|c|c}
\hline$\#$ & Subject & $f_{0}^{\exp }[\mathrm{Hz}]$ & $\Delta \phi^{\exp }[\mathrm{rad}]$ & $R_{a}^{\text {exp }}$ \\
\hline \hline P1 & S1 & 294 & 0.94 & 1.35 \\
\hline P2 & S2 & 195 & 0.63 & 1.27 \\
\hline P3 & S3 & 277 & -0.19 & 1.02 \\
\hline P4 & S4 & 294 & -1.57 & 1.19 \\
\hline P5 & S4 & 189 & 1.32 & 1.75 \\
\hline P6 & S2 & 191 & 0.19 & 1.02 \\
\hline P7 & S5 & 413 & 0.13 & 1.10 \\
\hline P8 & S6 & 247 & 0.00 & 2.19 \\
\hline P9 & S7 & 209 & -0.06 & 1.02 \\
\hline P10 & S8 & 236 & 1.19 & 1.61 \\
\hline P11 & S9 & 301 & 1.45 & 2.15 \\
\hline P12 & S10 & 280 & -2.01 & 1.17 \\
\hline P13 & S11 & 108 & 1.00 & 1.17 \\
\hline P14 & S12 & 254 & 0.47 & 1.36 \\
\hline P15 & S12 & 281 & 0.38 & 1.27 \\
\hline
\end{tabular}


Table 5.4: Resulting optimization parameters of the parameter optimization, derived from 15 healthy voice subjects. $C_{l}$ and $C_{r}$ denote the obtained correlation between the experimental curves and the theoretical curves.

\begin{tabular}{c|c|c|c|c|c|c}
\hline$\#$ & $Q_{p}^{*}$ & $Q^{*}$ & $Q_{k 1}^{*}$ & $Q_{k c}^{*}$ & $C_{l}$ & $C_{r}$ \\
\hline H1 & 1.38 & 1.94 & 1.02 & 1.13 & 0.94 & 0.97 \\
\hline H2 & 1.75 & 4.25 & 0.92 & 1.00 & 0.77 & 0.73 \\
\hline H3 & 0.63 & 2.63 & 1.06 & 0.93 & 0.87 & 0.86 \\
\hline H4 & 5.88 & 1.63 & 1.02 & 0.95 & 0.97 & 0.97 \\
\hline H5 & 1.38 & 2.56 & 1.15 & 1.00 & 0.92 & 0.94 \\
\hline H6 & 2.25 & 2.78 & 0.96 & 1.11 & 0.90 & 0.90 \\
\hline H7 & 1.63 & 2.36 & 1.04 & 0.99 & 0.94 & 0.94 \\
\hline H8 & 2.13 & 2.47 & 1.07 & 1.00 & 0.75 & 0.74 \\
\hline H9 & 2.00 & 2.34 & 1.02 & 1.00 & 0.93 & 0.97 \\
\hline H10 & 2.63 & 2.13 & 1.04 & 1.00 & 0.96 & 0.95 \\
\hline H11 & 2.88 & 1.87 & 0.98 & 1.00 & 0.97 & 0.96 \\
\hline H12 & 3.63 & 1.49 & 1.08 & 0.97 & 0.85 & 0.84 \\
\hline H13 & 2.63 & 1.92 & 0.99 & 1.00 & 0.90 & 0.90 \\
\hline H14 & 3.13 & 1.86 & 0.97 & 1.00 & 0.97 & 0.96 \\
\hline H15 & 2.63 & 1.81 & 0.97 & 0.99 & 0.94 & 0.95 \\
\hline
\end{tabular}


Tab. 5.5 shows the results for $\left(Q^{*}, Q_{p}^{*}, Q_{k 1}^{*}, Q_{k c}^{*}\right)$ of the optimization procedure achieved from the nine female and six male paralytic voice subjects. The mean deviations of $Q_{k 1}^{*}$ and $Q_{k c}^{*}$ from 1 amounts to 0.24 and 0.22 , respectively. These values are more than five times higher compared to the values of the healthy subjects. This is in accordance to the increased asymmetry within the paralytic vocal fold oscillation patterns, see Tab. 5.3.

For classification purpose, only the unilaterally acting parameters $Q_{k 1}^{*}$ and $Q_{k c}^{*}$ are applied, since the parameters $Q_{p}^{*}$ and $Q^{*}$ do not provide information about model asymmetries. Fig. 5.9 summarizes the results of the optimization procedure for both the healthy and paralytic voice subjects within the $\left(Q_{k c}^{*}, Q_{k 1}^{*}\right)$-plane. The results of the normal voice subjects are marked with crosses, while the circles label the values for the paralytic voice subjects. The numbers $P 1-P 15$ near the circles indicate the corresponding high-speed recordings, see Tab. 5.5. Due to the symmetry of vocal fold oscillation for normal voice, $Q_{k 1}^{*} \approx 1$ and $Q_{k c}^{*} \approx 1$ is obtained for the 15 healthy voice subjects, i.e. the results are located near the point of symmetry $(1,1)$ within the $\left(Q_{k 1}^{*}, Q_{k c}^{*}\right)$ plane. The mean distance to $(1,1)$ is 0.06 . The dashed circle in Fig. 5.9 specifies the region where the deviations for the parameter combinations $\left(Q_{k 1}^{*}, Q_{k c}^{*}\right)$ from $(1,1)$ are less than 0.2 . Within this region the parameters of all healthy voice subjects are located. In contrast all but two parameter combinations of the pathologic subjects are distributed outside the circle. Their mean distance to the point $(1,1)$ amounts to 0.42 , which is seven times higher than the mean distance for the healthy voice subjects.

\subsubsection{Interpretation of the Model-Based Classification}

For classifying healthy and paralytic voice the resulting coordinates of the optimized parameters in the plane $\left(Q_{k 1}^{*}, Q_{k c}^{*}\right)$ can be used. In contrast to healthy voice subjects, the resulting parameter values for the paralytic voice subjects are scattered outside the "normal" circle. Hence, a healthy voice can be classified by a parameter location within this circle and the radius can be regarded as the bandwidth for healthy voice within the parameter space.

The degree of the voice disorder due to unilateral recurrent laryngeal nerve paralysis influences the position of the optimization parameters within the 
Table 5.5: Resulting optimization parameters of the optimization procedure, derived from 15 subjects suffering from $R L N P . C_{l}$ and $C_{r}$ denote the obtained correlation between the experimental curves and the theoretical curves.

\begin{tabular}{c|c|c|c|c|c|c}
\hline$\#$ & $Q_{p}^{*}$ & $Q^{*}$ & $Q_{k 1}^{*}$ & $Q_{k c}^{*}$ & $C_{l}$ & $C_{r}$ \\
\hline \hline P1 & 3.38 & 2.32 & 0.77 & 1.11 & 0.92 & 0.92 \\
\hline P2 & 2.38 & 1.54 & 0.79 & 1.00 & 0.94 & 0.97 \\
\hline P3 & 1.13 & 2.19 & 0.96 & 1.00 & 0.91 & 0.92 \\
\hline P4 & 1.88 & 2.32 & 1.56 & 0.91 & 0.96 & 0.97 \\
\hline P5 & 4.00 & 1.49 & 0.57 & 1.01 & 0.95 & 0.98 \\
\hline P6 & 8.13 & 1.51 & 0.97 & 1.36 & 0.95 & 0.96 \\
\hline P7 & 5.38 & 3.26 & 0.97 & 1.99 & 0.97 & 0.93 \\
\hline P8 & 2.25 & 1.95 & 1.10 & 1.31 & 0.92 & 0.96 \\
\hline P9 & 3.38 & 1.65 & 0.97 & 0.89 & 0.93 & 0.98 \\
\hline P10 & 2.50 & 1.86 & 0.60 & 1.06 & 0.96 & 0.97 \\
\hline P11 & 5.63 & 2.38 & 0.55 & 1.12 & 0.83 & 0.89 \\
\hline P12 & 2.25 & 2.21 & 1.57 & 0.98 & 0.97 & 0.97 \\
\hline P13 & 2.88 & 0.85 & 0.80 & 1.00 & 0.97 & 0.98 \\
\hline P14 & 3.75 & 2.01 & 0.73 & 1.17 & 0.91 & 0.96 \\
\hline P15 & 3.00 & 2.22 & 1.01 & 1.99 & 0.97 & 0.99 \\
\hline
\end{tabular}




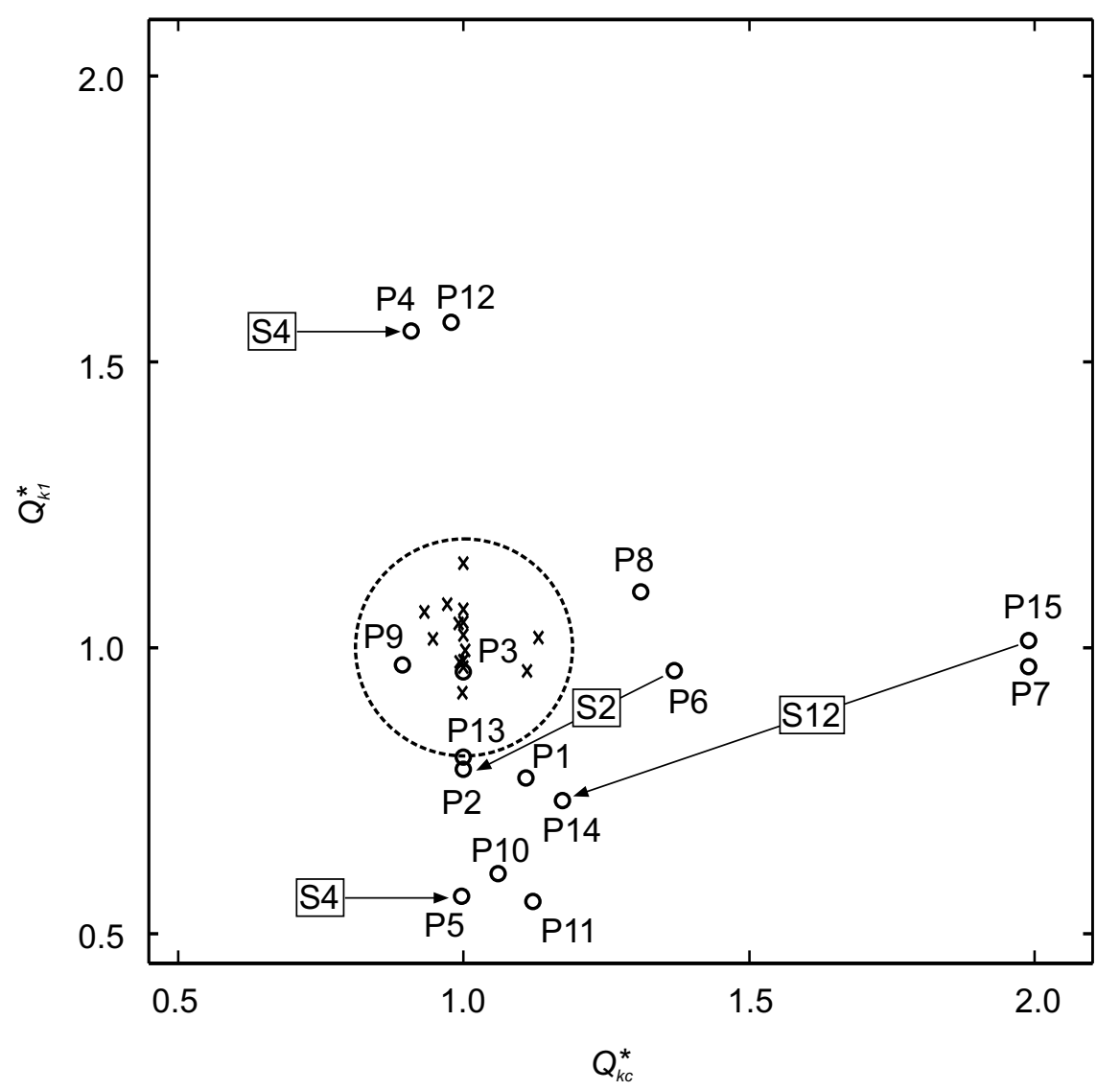

Figure 5.9: Results for the optimization parameters $Q_{k c}^{*}$ over $Q_{k 1}^{*}$ for the healthy (crosses) and pathologic (circles) subjects (P1-P15). The dashed circle encloses the point $(1,1)$ with a radius of 0.2 . The parameters for the healthy subjects are located within the circular area, while most of the parameters of the pathologic subjects are distributed outside. 
parameter plane $\left(Q_{k 1}^{*}, Q_{k c}^{*}\right)$. This can be assumed from the resulting optimization parameters of three paralytic voice subjects S2, S4, and S12. For each of these subjects, two high-speed recordings are evaluated and the optimization results are set in relation to objective measures of voice quality, namely Jitter (J), Shimmer (S), Harmonic-to-Noise Ratio (HNR), and Normalized Noise Energy (NNE) [62].

Subject S2 suffers from a severe paralytic dysphonia. Prior to voice therapy the recording $\mathrm{P} 6$ was performed. At this time the voice perturbation measures showed a very low voice quality with $\mathrm{J}=0.4 \%, \mathrm{~S}=3.66 \%$, HNR $=16.31 \mathrm{~dB}$, and $\mathrm{NNE}=-7.49 \mathrm{~dB}$. After voice therapy, the second recording P2 was performed. As a result of the therapy the patient had learned to compensate for the paralysis. Its voice quality had clearly improved to the following measures $\mathrm{J}=0.23 \%, \mathrm{~S}=1.75 \%, \mathrm{HNR}=23.11 \%$, and $\mathrm{NNE}$ $=-8.24 \%$. The enhanced voice quality is also visible within the parameter space $\left(Q_{k 1}^{*}, Q_{k c}^{*}\right)$ : The parameter combination corresponding to the high-speed recording P2 is situated much closer to the "normal" circle.

Similar results are found in subject S12. The improvement of the voice due to voice therapy leads to improved position of the optimization parameters in the $\left(Q_{k 1}^{*}, Q_{k c}^{*}\right)$ plane. At the beginning of the therapy (P15) the perturbation measures were: $\mathrm{J}=0.82 \%, \mathrm{~S}=2.41 \%, \mathrm{HNR}=16.64$ $\mathrm{dB}$, and $\mathrm{NNE}=-0.95 \mathrm{~dB}$. After therapy (P14) an improved vocal quality could be diagnosed by $\mathrm{J}=0.36 \%, \mathrm{~S}=2.41 \%, \mathrm{HNR}=20.38 \mathrm{~dB}$, and $\mathrm{NNE}$ $=-0.95 \mathrm{~dB}$. As in subject $\mathrm{S} 2$, the position of the optimization parameters $\left(Q_{k 1}^{*}, Q_{k c}^{*}\right)$ clearly shifts towards the "normal" circle.

Within Fig. 5.10 the four upper charts show the experimental curves and the resulting theoretical curves of the subjects S2 and S12 before and after voice therapy. By visual inspection of the curves the progress of voice rehabilitation for the subjects S2 and S12 can not be derived. However, within the $\left(Q_{k 1}^{*}, Q_{k c}^{*}\right)$ classification scheme the outcome of voice therapy is clearly identifiable.

From subject S4 two high-speed recordings P4 and P5 were made immediately one after the other. While the Euclidean distance of the parameter combinations $\left(Q_{k 1}^{*}, Q_{k c}^{*}\right)$ to the point $(1,1)$ are almost constant, their positions within the parameter space clearly deviate from each other. These differences within the $\left(Q_{k 1}^{*}, Q_{k c}^{*}\right)$ plane are a result of the irregular vibration behavior of the paralytic voice. Subject $\mathrm{S} 4$ is not capable to generate 

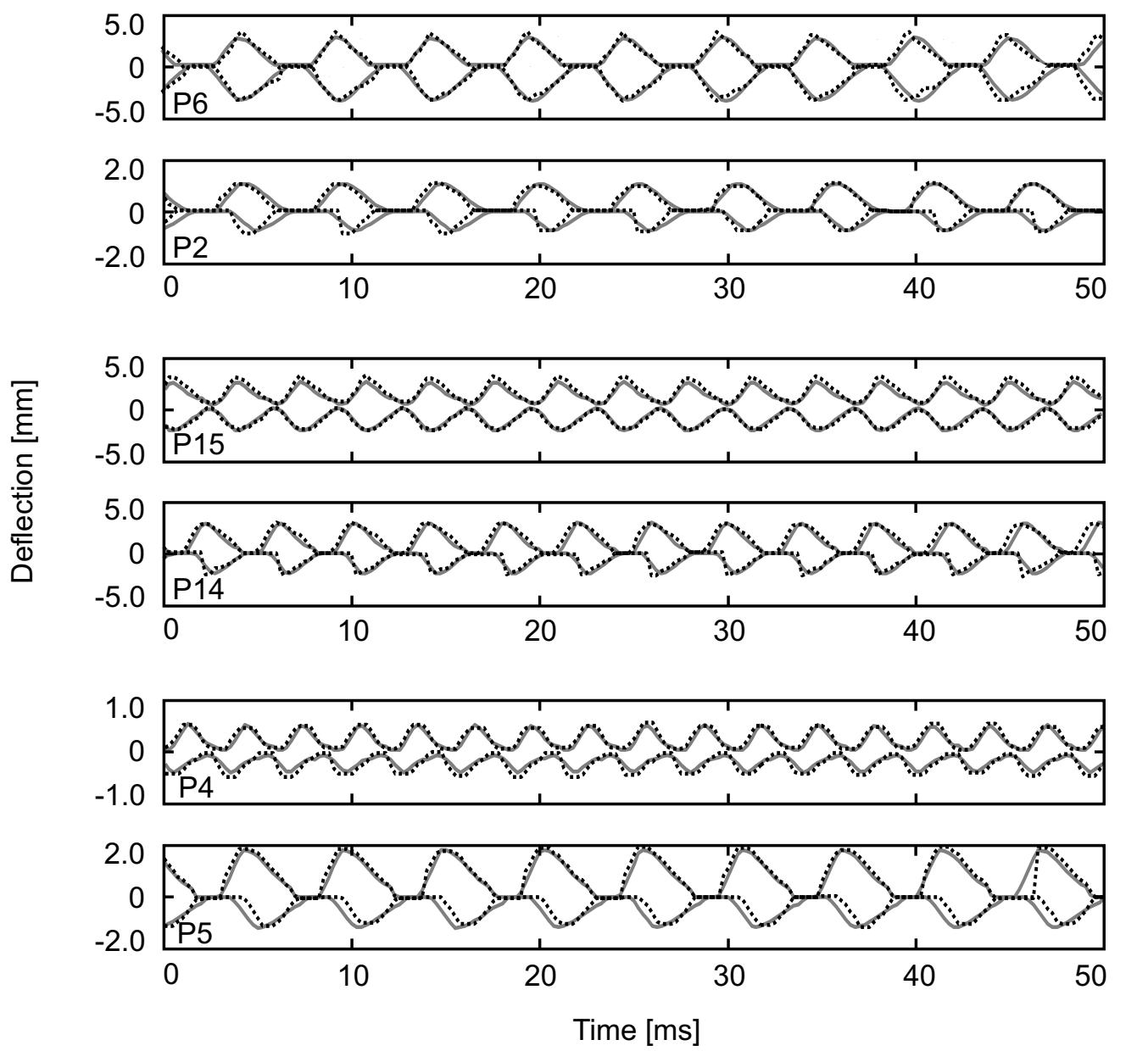

Figure 5.10: Results of the subjects S2 (P6, P2), S12 (P15, P14), and $S_{4}$ (P5, P4). Experimental curves (dotted lines) and theoretical curves (solid lines) are presented. The lower curves in the charts corresponds to the paralyzed side and the upper ones to the healthy side. 
a reproducible oscillation pattern in consequence of the RLNP.

The different phonation conditions of subjects $\mathrm{S} 4$ result in experimental curves P5 and P4 which show different characteristics in amplitude and fundamental frequency but a similar degree of left-to-right asymmetry. The two lower charts of Fig. 5.10 show that except for the different algebraic sign both curves possess a phase shift of more than 1.32. The amplitude ratio deviates from symmetric value 1 for P5 (1.75) and P4 (1.19). The different shapes of the experimental curves results in different locations within the $\left(Q_{k 1}^{*}, Q_{k c}^{*}\right)$ plane with almost the same distance to the symmetry point $(1,1)$ due to the unilateral RLNP.

In this study it was possible to classify unilateral recurrent laryngeal nerve paralysis by exclusively analyzing endoscopic digital high-speed recordings using the proposed parameter optimization. The reliability of the classification by the optimization procedure is sufficient. In $85 \%$ of the cases the relative error within the results for the optimization parameters averaged over all parameters is less than 5\%. Besides the identification of a recurrent laryngeal nerve paralysis the degree of the voice disorder can be classified as well. In further studies the potential in specifying different kinds and degrees of voice disorders will be investigated. 


\section{Spatio-Temporal Quantification of Vocal Fold Vibrations}

In Sec. 4.1 .2 a spatio-temporal description of vocal fold oscillations, the so-called multi-line trajectories, were introduced. Fig. 6.1 shows the multiline trajectories of two high-speed recordings $\mathrm{A}$ and $\mathrm{B}$. The vocal fold

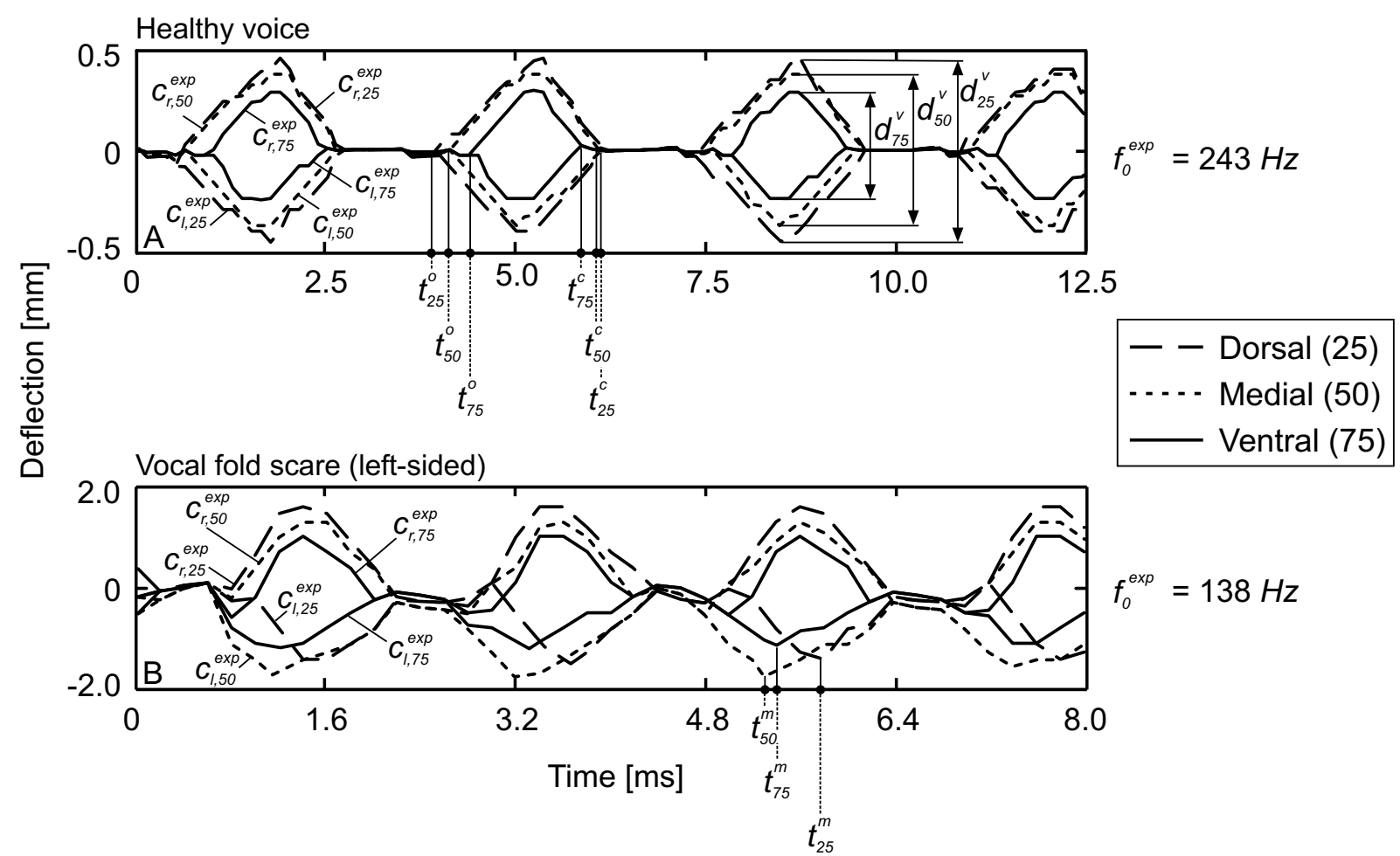

Figure 6.1: Different vocal fold vibration characteristics in longitudinal direction.

oscillations are extracted at dorsal, medial, and ventral position (in the following denoted by the indices 25,50 , and 75 ). The upper chart shows the trajectories of recording A corresponding to the vibration pattern of a male healthy voice subject, aged 22 . The lower chart depicts the trajectories 
extracted from recording B derived from a female subject (age 49) with a scar on the left vocal fold after surgical excision of a Reinke's edema. The following characteristic properties of the oscillations vary with the different longitudinal vocal fold positions:

- For subject A, the opening (index o) and closing (index c) phase starts at different points in time $\left(t_{25}^{o}<t_{50}^{o}<t_{75}^{o}\right.$ and $t_{75}^{c}<t_{50}^{c}<t_{25}^{c}$, see upper chart).

- The maximum distance within an oscillation cycle of opposing vocal fold edges decreases from dorsal to ventral position, i.e. $d_{25}^{v}>d_{50}^{v}>$ $d_{75}^{v}$ (see upper chart).

- The scarred left vocal fold of subject B reveals a longitudinal phase shift (lower chart). The maximum deflection is obtained first for the dorsal position (e.g. at time $t_{50}^{m}$ ), subsequently at medial position $\left(t_{75}^{m}\right)$ and finally at ventral position $\left(t_{25}^{m}\right)$.

Thus, the multi-line trajectories deliver additional spatial information of the vocal fold vibrations which remains undetected using single-line trajectories and the one-dimensional 2MM. In this chapter, the model-based quantification is extended to a two-dimensional approach. Besides the temporal course of the lateral deflection of the vocal fold edge points, also their spatial positions in anterior-posterior direction are incorporated within the quantitative description of vocal fold vibrations.

\subsection{Multi-Mass Model}

For the modeling of the vocal fold dynamics a multi-mass model (MMM), similar to the model proposed in [120] (hereafter called the WO91 model), is used. The WO91 model - developed for studying asymmetric vocal fold vibrations - is similar to the 2MM, but in addition it divides each vocal fold longitudinally in the anterior-posterior direction. Thus, each vocal fold is modeled by three longitudinal coupled mass-spring oscillators. Compared to the WO91 model following extensions are introduced for the MMM: 
1. Besides different values of the anchor spring constances along each model side, also variations of the longitudinal coupling stiffnesses are considered.

2. The mass elements are allowed to move within the whole $x y$-plane in longitudinal and lateral directions. This means a fully two-dimensional extension of the WO91 model.

3. The flow is calculated for the entire opening formed by the mass positions in each horizontal plane. Within the WO91 model, the glottal air flow is constricted to the sum of the parallel flows through each opposing pair of mass-spring oscillators.

Fig. 6.2 shows a perspective view of the MMM. The indices $s=1$ and $s=2$ denote the lower and the upper horizontal plane. In accordance with common clinical convention, the vocal folds are subdivided into the dorsal, medial, and ventral third for the assessment of the organic constitution and the vibration characteristics [121-124]. Consequently, a model configuration with $2 \times 3$ coupled mass-spring oscillators representing the vocal folds is chosen. The $M=6$ coupled mass-spring oscillators numbered with $i=1, \ldots, 6$ are the vibrating elements. In accordance to the view from the high-speed recordings, the elements on the left $(i=1, \ldots, 3)$ model the dynamics of the right vocal fold, the elements on the right $(i=4, \ldots, 6)$ model the left vocal fold vibrations. Towards the posterior commissure, the vibrating elements are coupled to two fix positions. These fixed positions correspond to the stiffened non-vibrating transition between the vocal cord and the arytenoid cartilage, the so-called vocal process [125]. At the ventral ending of the glottis the two model sides join together at a single fixed position (anterior commissure). The vector $\mathbf{x}_{s, i}=\left(x_{s, i}, y_{s, i}\right)^{T}$, where $(\cdot)^{T}$ denotes the transposed vector, defines the position of the mass element $m_{s, i}$, with velocity $\dot{\mathbf{x}}_{s, i}$ and acceleration $\ddot{\mathbf{x}}_{s, i}$. Together with the fix positions, the mass positions $\mathbf{x}_{s, i}[n]$ define the model opening $a_{s}[n]$ for each horizontal plane for the $n^{\text {th }}$ time step. As for the vocal folds, onedimensional trajectories $c_{i}[n]$ with $i=1, \ldots, 6$ and $n=0, \ldots, N-1$ are defined. Using

$$
\mathbf{x}_{i}[n]:=\left\{\begin{array}{lc}
\mathbf{x}_{1, i}[n], & a_{1}[n]<a_{2}[n] \\
\mathbf{x}_{2, i}[n], & \text { otherwise }
\end{array},\right.
$$




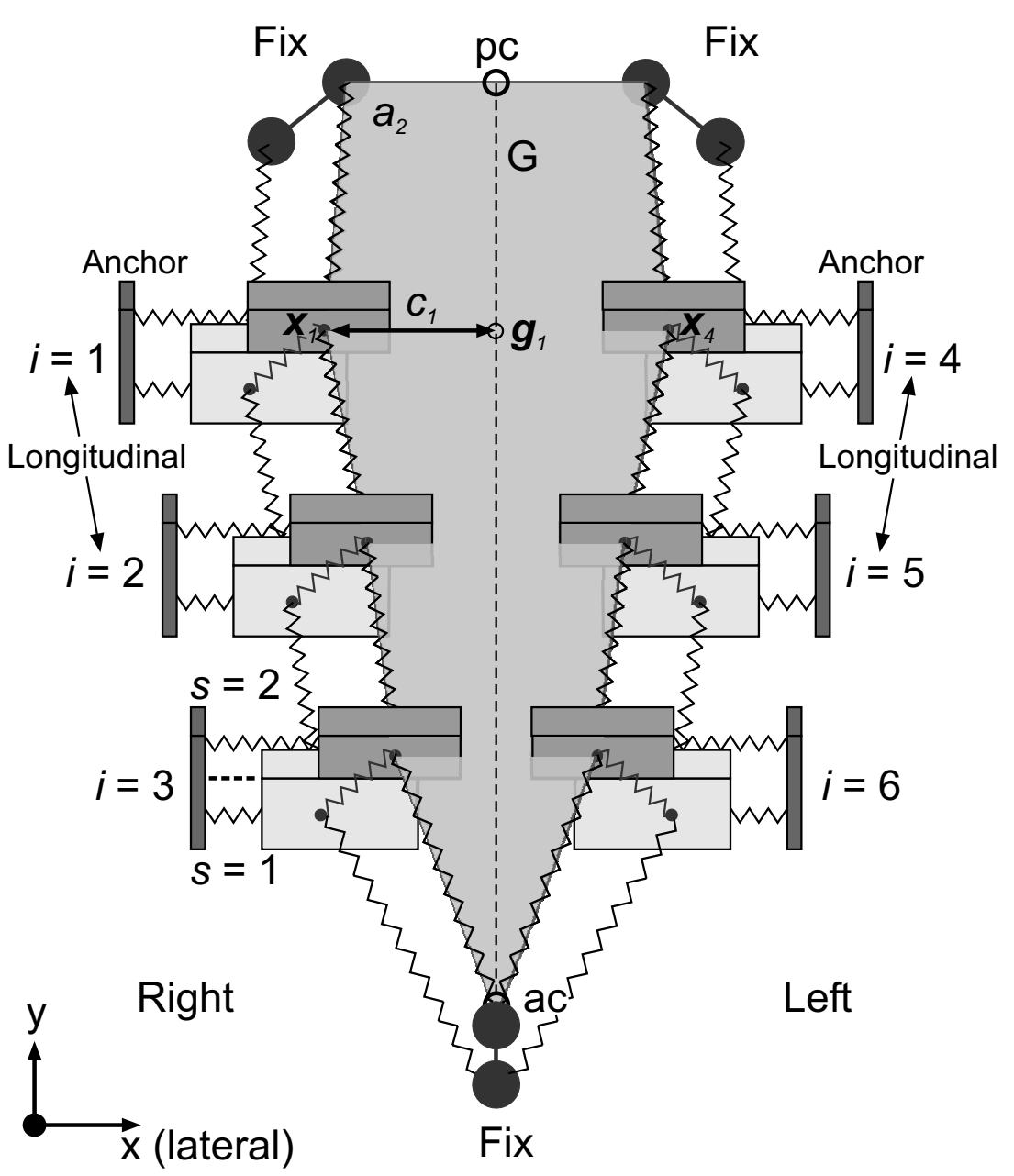

Figure 6.2: Multi-mass model of the vocal folds. The left model side represents the right vocal fold, the right side the left vocal fold. The minimum opening formed by the positions of the masses and fix positions of both planes represents the glottal area (here: $\left.a_{2}\right)$. Posterior (pc) and anterior commissure (ac) define the glottal axis $G$. 
the trajectories are calculated after

$$
\begin{aligned}
c_{j}[n] & =(-1)^{\kappa} \cdot\left\|\mathbf{x}_{j}[n]-\mathbf{g}_{j}\right\|_{2}, \\
c_{j+3}[n] & =(-1)^{\kappa-1} \cdot\left\|\mathbf{x}_{j+3}[n]-\mathbf{g}_{j}\right\|_{2},
\end{aligned}
$$

with $j=1, \ldots, 3$ and

$$
\kappa=\left\{\begin{array}{lc}
1, & \text { mass crosses glottal axis } \\
2, & \text { otherwise }
\end{array} .\right.
$$

The equation of motion for a mass element $m_{s, i}$ is defined as follows:

$$
\mathbf{0}=m_{s, i} \ddot{\mathbf{x}}_{s, i}+\mathbf{F}_{s, i}^{a}+\mathbf{F}_{s, i}^{v}+\mathbf{F}_{s, i}^{l}+\mathbf{F}_{s, i}^{c}+\mathbf{F}_{s, i}^{d}
$$

with the following forces:

$$
\begin{aligned}
& \mathbf{F}_{s, i}^{a}-\text { force due to the anchor spring, } \\
& \mathbf{F}_{s, i}^{v}-\text { vertical coupling force, } \\
& \mathbf{F}_{s, i}^{l}-\text { longitudinal coupling force, } \\
& \mathbf{F}_{s, i}^{c}-\text { force due to collision with other masses } \\
& \quad \text { or longitudinal coupling springs, } \\
& \mathbf{F}_{s, i}^{d}-\text { driving force generated by glottal flow } .
\end{aligned}
$$

Fig. 6.3 shows a free body diagram of a single oscillator element with the acting forces. Compared with the WO91 model a more general definition of the forces is required according to the two-dimensional model extensions.

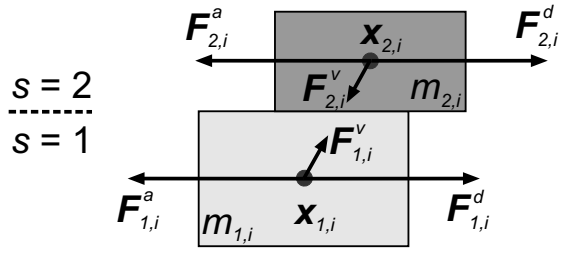

(a)

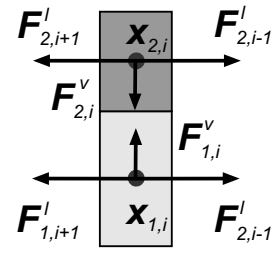

(b)

Figure 6.3: Free body diagram of an oscillating element in lateral view (a) and frontal view (b). 


\subsubsection{Anchor Force}

With stiffness $k_{s, i}^{a}$ and damping $r_{s, i}^{a}$ of the anchor spring as well as the rest position $\mathbf{x}_{s, i}^{r}$ of mass $m_{s, i}$ the anchor force $\mathbf{F}_{s, i}^{a}$ is defined as

$$
\mathbf{F}_{s, i}^{a}:=k_{s, i}^{a}\left\|\mathbf{x}_{s, i}^{r}-\mathbf{x}_{s, i}\right\|_{2} \mathbf{u}_{s, i}^{a}+r_{s, i}^{a}\left(\mathbf{u}_{s, i}^{a}\right)^{T} \dot{\mathbf{x}}_{s, i} \mathbf{u}_{s, i}^{a} .
$$

As for the 2MM, the spring constant $k_{s, i}^{a}$ represents the stiffness of the vocal fold tissue. The damping coefficient $r_{s, i}^{a}$ incorporates the viscous losses and is defined after Eq. (5.3). For the definition of the unit vector $\mathbf{u}_{s, i}^{a}$, see Fig. 6.4.

\subsubsection{Vertical Coupling Force}

The vertical coupling force $\mathbf{F}_{s, i}^{v}$ is calculated after

$$
\begin{aligned}
\mathbf{F}_{s, i}^{v}:= & k_{i}^{v}\left(\left\|\mathbf{x}_{s, i}^{r}-\mathbf{x}_{s^{*}, i}^{r}\right\|_{2}-\left\|\mathbf{x}_{s, i}-\mathbf{x}_{s^{*}, i}\right\|_{2}\right) \mathbf{u}_{s, i}^{v}+ \\
& r_{i}^{v}\left(\mathbf{u}_{s, i}^{v}\right)^{T}\left(\dot{\mathbf{x}}_{s, i}-\dot{\mathbf{x}}_{s^{*}, i}\right) \mathbf{u}_{s, i}^{v},
\end{aligned}
$$

with the stiffness and damping coefficients $k_{i}^{v}$ and $r_{i}^{v}$ of the vertical coupling spring between the masses $m_{1, i}$ and $m_{2, i}$. The index $s^{*}$ is defined as

$$
s^{*}=\left\{\begin{array}{ll}
1, & s=2 \\
2, & s=1
\end{array} .\right.
$$

For the definition of the unit vector $\mathbf{u}_{s, i}^{v}$, see Fig. 6.4.

\subsubsection{Longitudinal Coupling Force}

The force $\mathbf{F}_{s, i}^{l}$ acting on mass $m_{s, i}$ due to the longitudinal coupling to $m_{s, i-1}$ and $m_{s, i+1}$ is defined as

$$
\begin{aligned}
\mathbf{F}_{s, i}^{l}:= & k_{s, i-1}^{l}\left(\left\|\mathbf{x}_{s, i}^{r}-\mathbf{x}_{s, i-1}^{r}\right\|_{2}-\left\|\mathbf{x}_{s, i}-\mathbf{x}_{s, i-1}\right\|_{2}\right) \mathbf{u}_{s, i-1}^{l}+ \\
& r_{s, i-1}^{l}\left(\mathbf{u}_{s, i-1}^{l}\right)^{T}\left(\dot{\mathbf{x}}_{s, i}-\dot{\mathbf{x}}_{s, i-1}\right) \mathbf{u}_{s, i-1}^{l}+ \\
& k_{s, i}^{l}\left(\left\|\mathbf{x}_{s, i}^{r}-\mathbf{x}_{s, i+1}^{r}\right\|_{2}-\left\|\mathbf{x}_{s, i}-\mathbf{x}_{s, i+1}\right\|_{2}\right) \mathbf{u}_{s, i+1}^{l}+ \\
& r_{s, i}^{l}\left(\mathbf{u}_{s, i+1}^{l}\right)^{T}\left(\dot{\mathbf{x}}_{s, i}-\dot{\mathbf{x}}_{s, i+1}\right) \mathbf{u}_{s, i+1}^{l}
\end{aligned}
$$




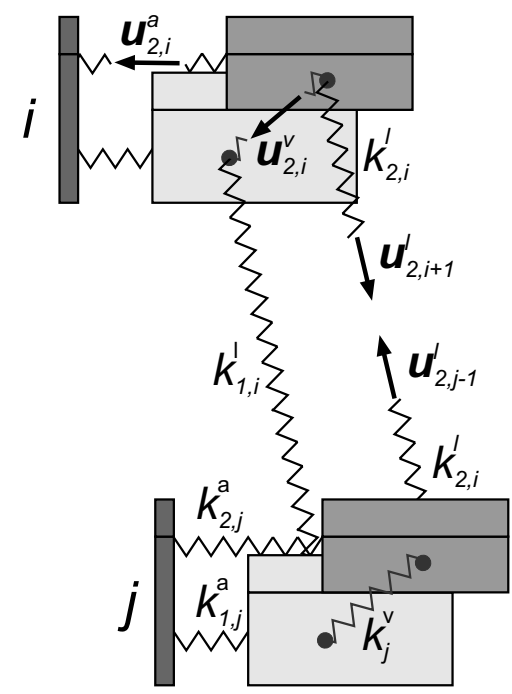

Figure 6.4: Graphical definition of the unit vectors $\mathbf{u}_{s, i}^{a}, \mathbf{u}_{s, i}^{l}$, and $\mathbf{u}_{s, i}^{v}$ for the anchor force, longitudinal and vertical coupling.

Fig. 6.4 shows the definition of the unit vectors $\mathbf{u}_{s, i-1}^{l}$ and $\mathbf{u}_{s, i+1}^{l}$. The stiffness and damping coefficients of the longitudinal coupling springs $k_{s, j}^{l}$ and $r_{s, j}^{l}$ are derived from the anchor springs of the connected masses after

$$
k_{s, j}^{l}=\xi_{k}\left(k_{s, j}^{a}+k_{s, j+1}^{a}\right),
$$

and

$$
r_{s, j}^{l}=\xi_{r}\left(r_{s, j}^{a}+r_{s, j+1}^{a}\right) .
$$

Following experiments with canine tissue, $\xi_{k}=0.2$ and $\xi_{r}=0.06$ are assumed $[26,120]$. For the coupling with fix positions, the spring values are calculated with $k_{s, j}^{a}=k_{s, j+1}^{a}$ and $r_{s, j}^{a}=r_{s, j+1}^{a}$.

\subsubsection{Collision Force}

In case of collision an additional restoring force $\mathbf{F}_{s, i}^{c}$ acts on the mass $m_{s, i}$ [107]. A collision is defined for $m_{s, i}$ if its anchor spring crosses the longitudinal coupling spring between two adjacent masses $m_{s, j}$ and $m_{s, j+1}$, as illustrated in Fig. 6.5. For the general case that $m_{s, i}$ causes more than one collision, the resulting collision force is given by

$$
\mathbf{F}_{s, i}^{c}:=\sum_{\forall j} k_{s, i, j}^{c} d_{s, i, j}^{p} \mathbf{u}_{s, i}^{a}
$$




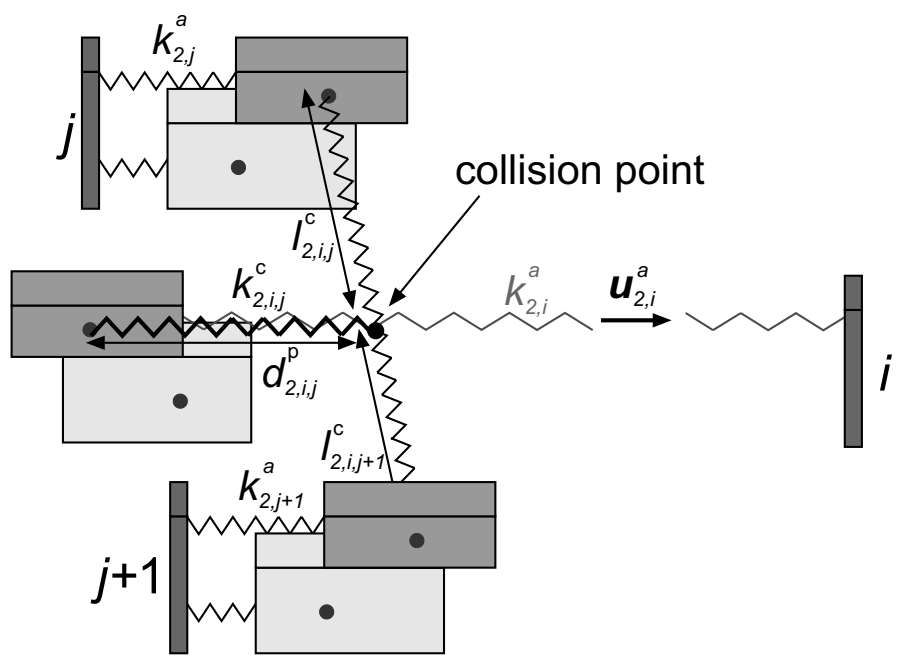

Figure 6.5: Illustration of a single impact within the multi-mass model.

with the stiffness of the restoring spring $k_{s, i, j}^{c}$ and the penetration depth $d_{s, i, j}^{p}$, defined as in Fig. 6.5. Derived from the 2MM [7] $k_{s, i, j}^{c}$ is calculated after

$$
k_{s, i, j}^{c}:=3 \cdot\left(\frac{l_{s, i, j}^{c}}{l_{s, i, j}^{c}+l_{s, i, j+1}^{c}} k_{s, j}^{a}+\frac{l_{s, i, j+1}^{c}}{l_{s, i, j}^{c}+l_{s, i, j+1}^{c}} k_{s, j+1}^{a}\right),
$$

where $l_{s, i, j}^{c}$ denotes the distance between the collision point and the position of the mass $m_{s, j}$, see Fig. 6.5. In this way, the additional spring $k_{s, i, j}^{c}$ more reflects the properties of the anchor spring $k_{s, j}^{a}$, the closer the collision point is located at mass $m_{s, j}$. If it is closer to mass $m_{s, j+1}$, the influence of $k_{s, j+1}^{a}$ prevails.

\subsubsection{Driving Force}

$\mathbf{F}_{s, i}^{d}$ is the driving force for the self-sustained MMM oscillation. It results from the pressure drop within the glottis. As the air flow is calculated for the entire model opening, the calculation of $\mathbf{F}_{s, i}^{d}$ differs from the definition in the WO91 model. Following the assumptions concerning the aerodynamic forces within the 2MM (Sec. 5.1.4) the driving force is calculated as

$$
\mathbf{F}_{s, i}^{d}=\left\{\begin{array}{cc}
P \cdot w_{i} \cdot h_{i} \cdot \mathbf{u}_{i}^{d}, & s=1 \\
\mathbf{0}, & s=2
\end{array},\right.
$$


with the height $h_{i}$ of mass $m_{1, i}$. For portioning the resulting pressure acting on the individual masses, an effective side length $w_{i}$ replaces the fixed mass length $l$ used within the $2 \mathrm{MM}$ and is defined after

$$
w_{i}=\frac{1}{2} \cdot\left\|\mathbf{x}_{s, i+1}-\mathbf{x}_{s, i-1}\right\|_{2}
$$

as shown in Fig. 6.6. The unit vector $\mathbf{u}_{i}^{d}$ indicates the direction of $\mathbf{F}_{s, i}^{d}$, see

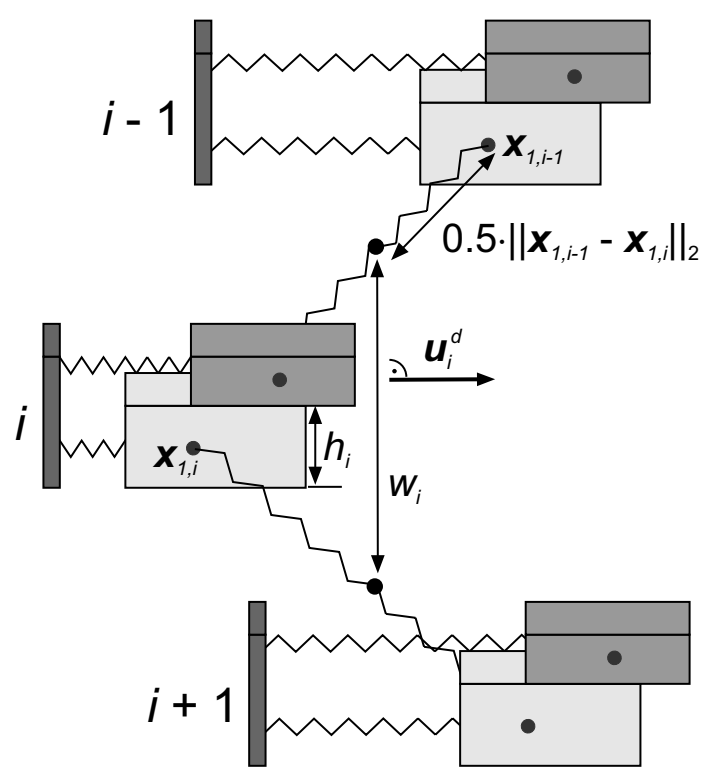

Figure 6.6: Graphical definition of the unit vector $\mathbf{u}_{s, i}^{d}$ and the effective side length $w_{i}$ for the driving force.

Fig. 6.6. The pressure $P$ within the lower plane is calculated in accordance to $[7]$ as

$$
\begin{array}{ccc}
P=P^{s} \cdot\left(1-\left(\frac{\min \left(a_{1}, a_{2}\right)}{a_{1}}\right)^{2}\right) & , & a_{1}>0, \\
P= & , & a_{1} \leq 0 .
\end{array}
$$

The driving pressure $P$ depends on the ratio of the areas $a_{s}$ and the subglottal pressure $P^{s}$.

For the integration of the equations of motion a fourth-order Runge-Kutta algorithm is used. The step size is set to $0.25 \mathrm{~ms}$. Due to the sampling frequency of the high-speed camera of $4000 \mathrm{~Hz}$ no resampling is needed. The model runs with a computing time to real time ratio of almost 1:1 (C\#, Pentium 4, $3 \mathrm{GHz}$ ). 


\subsection{Optimization Parameters}

Certain vibration patterns of the MMM can be simulated by means of modifying specific model parameters. According to [95] the variable model parameters are $P^{s}, m_{s, i}, k_{s, i}^{a}$, and $x_{s, i}^{r}$. These variable model parameters are initialized by the standard parameter values as used in the WO91 model. A set of eight optimization parameters $Q_{p}, Q_{1}, \ldots, Q_{6}$, and $Q_{r}$ is defined for modifying the standard values. By means of this set the actual model parameters $\hat{P}^{s}, \hat{m}_{s, i}, \hat{k}_{s, i}$ and rest positions $\hat{\mathbf{x}}_{s, i}^{r}$ are derived from the initial values as follows:

$$
\begin{aligned}
\hat{P}^{s} & =P^{s} \cdot Q_{p}, \\
\hat{m}_{s, i} & =m_{s, i} / Q_{i}, \\
\hat{k}_{s, i}^{a} & =k_{s, i}^{a} \cdot Q_{i}, \\
\hat{\mathbf{x}}_{s, i}^{r} & =\left(\begin{array}{c}
x_{s, i}^{r} \mp Q_{r} \cdot\left\|\mathbf{x}_{s, i}^{r}-\mathbf{g}_{i}\right\|_{2} \\
y_{s, i}^{r}
\end{array}\right) .
\end{aligned}
$$

In Equ. (6.20) the "-"-sign is used for $i=1, \ldots, 3$ and " + " for $i=$ $4, \ldots, 6$.

\subsection{Objective Function}

For evaluating the adaptation quality achieved with the parameters $\hat{P}^{s}$, $\hat{m}_{s, i}, \hat{k}_{s, i}^{a}$, and $\hat{x}_{s, i}^{r}$, the consistency between the dynamics of the MMM and the vocal folds needs to be quantitatively described. Therefore, two criteria are defined which assess different characteristics of the vibration patterns:

1. Area consistency measure. The energy $\Delta a$ of the difference between the area functions of the MMM $a[n]=\min \left(a_{1}[n], a_{2}[n]\right)$ and the vocal folds $a^{\exp }[n], n=0, \ldots, N-1$, normalized to the energy of $a^{\exp }[n]$ is calculated after

$$
\Delta a:=\frac{\sum_{n=0}^{N-1}\left|a[n]-a^{\exp }[n]\right|^{2}}{\sum_{n=0}^{N-1}\left|a^{\exp }[n]\right|^{2}} .
$$


2. Trajectory consistency measure. For each position $i$ the trajectory $c_{i}$ is compared with the trajectory of the corresponding point at the vocal fold edge $c_{i}^{e x p}$ and the energy of the difference signal is calculated after

$$
\begin{aligned}
\Delta c_{i} & :=\sum_{n=0}^{N-1}\left|c_{i}[n]-c_{i}^{e x p}[n]\right|^{2}, \\
\Delta c & :=\frac{\frac{1}{6} \sum_{i=1}^{6} \Delta c_{i}}{\frac{1}{6} \sum_{i=1}^{6} \sum_{n=0}^{N-1}\left|c_{i}^{e x p}[n]\right|^{2}},
\end{aligned}
$$

with $\Delta c$ normalized to the mean energy of the trajectories $c_{i}^{\exp }$.

For bounding the ranges of the two measures, the function $f(x)$ is introduced as

$$
f(x):=\left\{\begin{array}{cc}
x, & 0 \leq x \leq 1 \\
1, & x>1
\end{array} .\right.
$$

By means of $f(x)$ the values $\Delta a$ and $\Delta c$ are limited to values $\leq 1$. Now, the two measures are combined to the objective function $\phi$ :

$$
\phi:=(f(\Delta a))^{2}+(f(\Delta c))^{2} .
$$

The smaller the value $\phi$ the better is the fitting of the model oscillations to the vocal fold vibrations. In the following a method is introduced which uses the optimization parameters and the objective function $\phi$ for an automatic fitting of the model dynamics.

\subsection{Automatic Parameter Optimization}

The optimization procedure is constructed to simulate real vocal fold vibrations as exact as possible. For this aim, a model initialization and an automatic parameter optimization are introduced. The optimization parameters, which result into the best fitting of the model dynamics to the experimental trajectories, represent a quantitative description of the vocal fold vibration patterns. 


\subsubsection{Model Initialization}

Precondition for the parameter optimization is a proper initialization of the MMM depending on the evaluated high-speed recording. The applied image processing algorithm delivers the time-variant glottal contour but no information about the positions of the vocal processes which correspond to the fix positions near the posterior ending of the MMM. The fix positions and subsequently the rest positions $\mathbf{x}_{s, i}^{r}$ for the masses are calculated with the following procedure: A contour affiliation matrix with $256 \times 256$ entries is derived from the segmentation results. The value of each entry equals the number of time steps in which the corresponding pixel is part of the segmented glottal contour, normalized to the number of time steps $N$. For the pixel coordinates which are not passed by vocal fold edges the matrix entry is 0 . If the pixel is part of the segmented contour in exact one frame, the matrix entry amounts $1 / N$. Fig. 6.7 (a) depicts the matrix for the highspeed recording from a healthy voice subject. In regions with low dynamics as the anterior commissure or the left and right vocal process the pixels frequently belong to the segmented contour and thus result in increased values within the contour affiliation matrix. The matrix is subdivided in the regions $r_{1}$ and $r_{2}$ as shown in Fig. 6.7 (a). The pixels with minimum $y$-value for region $r_{1}$ and with maximum $y$ for $r_{2}$ and an entry $>0$ are determined. Within the $11 \times 11$-neighborhood of these two pixels the maximum matrix entry is identified. From these two values the smaller one is used as threshold value for segmentation, i.e. matrix entries smaller than this threshold are set to zero. The result is shown in Fig. 6.7 (b). The pixel with minimum $x$ within $r_{1}$ is used for the left posterior fix position and the pixel with maximum $x$ for the right one. The posterior commissure (pc) is on the half way between these two points. The pixel with maximum $y$ within $r_{2}$ defines the anterior commissure (ac). The three points $g_{j}$ are defined as in Sec. 4.1.2. The frame $n^{*}$ with the glottal area nearest to the mean opening is identified after

$$
\min _{n}\left|a^{\exp }[n]-\frac{1}{N} \sum_{k=0}^{N-1} a^{\exp }[k]\right| .
$$

Using the segmentation result of frame $n=n^{*}$, the contour points $\mathbf{p}_{j}$ (right vocal fold) and $\mathbf{p}_{j+3}$ (left vocal fold), $j=1, \ldots, 3$, are determined, see Fig. 6.7 (c). They are located at the cross section between the lines $k_{j}$ 


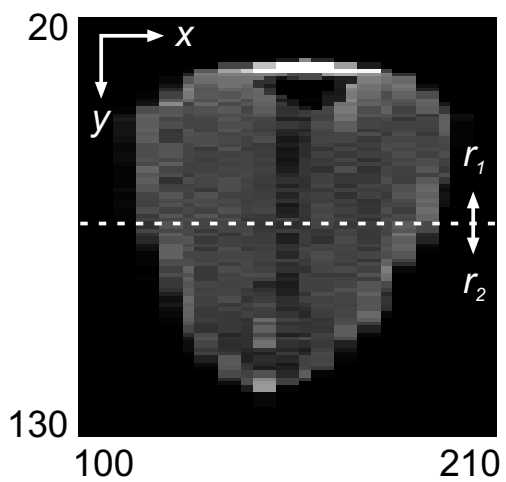

(a)

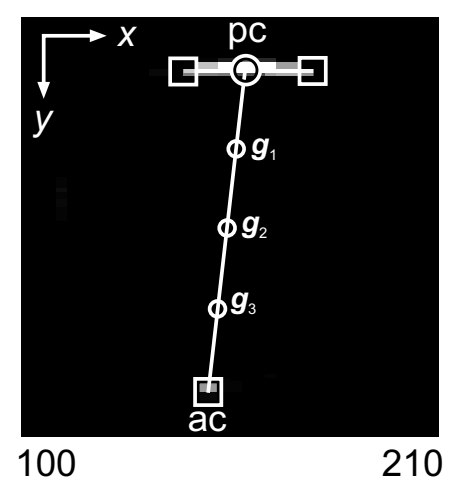

(b)

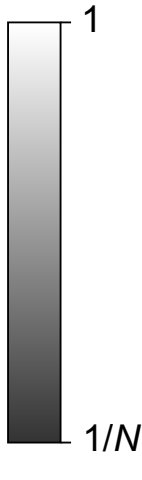

$1 / N$

100

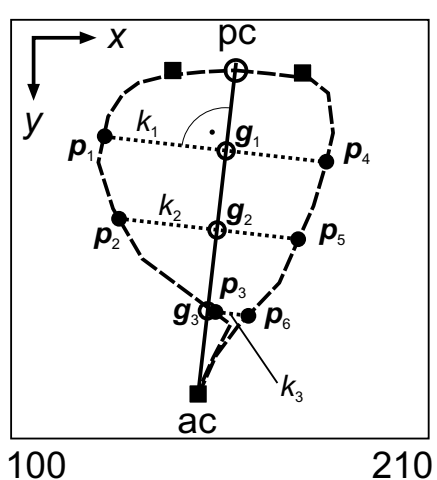

(c)

Figure 6.7: (a) Representation of the contour affiliation matrix subdivided in the areas $r_{1}$ and $r_{2}$. (b) Segmented regions at the anterior and the posterior commissure. The white squares represent the identified coordinates for the three fix positions. The points $g_{i}$ mark the dorsal, medial, and ventral position on the glottal axis. (c) The determined rest positions $\mathbf{p}_{i}$ for the oscillating elements on the glottal contour with mean opening area (dashed line).

and the glottal contour. Thereby, the lines $k_{j}$ are crossing the glottal axis perpendicularly at the points $g_{j}$. The initial rest positions of the upper plane are assigned with $\mathbf{x}_{2, i}^{r}=\mathbf{p}_{i}(i=1, \ldots, 6)$ and for the lower plane following

$$
\mathbf{x}_{1, i}^{r}=\left\{\begin{array}{cc}
\left(\begin{array}{c}
0.95 \cdot x_{2, i}^{r} \\
y_{2, i}^{r}
\end{array}\right), & i=1, \ldots, 3 \\
\left(\begin{array}{c}
1.05 \cdot x_{2, i}^{r} \\
y_{2, i}^{r}
\end{array}\right), & i=4, \ldots, 6
\end{array} .\right.
$$

\subsubsection{Optimization Procedure}

The objective function $\phi$ is a non-convex function within the search space spanned by the optimization parameters. Therefore, the procedure for the parameter optimization is based on a GA as described in Sec. 5.4.2. For the optimization of the MMM, the number of individuals $M$ is set to 25. The termination condition of the GA differs from that in Sec. 5.4.2 and is obtained in two ways: First, a fixed number of iterations is passed through. Second, all individuals of the actual population are located close 
to the fittest one. Due to the negligible diversity of the population the GA generates no more individuals with significantly differing values for the optimization parameters. Improvements for the fitness values no longer occur.

A single iteration of the GA using the objective function $\phi$ delivers no unique results, because of the non-convex behavior of the objective function. Thus, the optimization procedure consists of three parts, the pre-, the coarse, and the fine optimization. For each part the steps 1 to 5 are passed through once. The aim of the first and the second part is a sufficient limitation of the search space and part 3 determines the final result of the optimization:

1. Pre-optimization. In this step the model dynamics is fitted to frequency and amplitude of the area function $a^{\exp }$ while longitudinal vibration properties are not evaluated. Therefore, parameters $Q_{\text {left }}=Q_{1, \ldots, 3}$ and $Q_{\text {right }}=Q_{4, \ldots, 6}$ are used. All springs and masses representing one vocal fold are scaled with the same value following Eq. (6.19) and (6.18). As initial search range [0.3,3] is used for each parameter. The parameter ranges are appropriate for simulating healthy and pathologic vocal fold vibration patterns. Within the objective function it is sufficient to use only the measure $\Delta a$. The pre-optimization delivers the values $Q_{p}^{p r e}, Q_{\text {left }}^{\text {pre }}, Q_{r i g h t}^{\text {pre }}$, and $Q_{r}^{\text {pre }}$.

2. Coarse optimization. Here, the complete parameter set $Q_{p}, Q_{1}$, $\ldots, Q_{6}$, and $Q_{r}$ is used. The search ranges for the parameters are derived from the pre-optimization results: $Q \in\left[Q^{\text {pre }} / 1.2, Q^{\text {pre }} / 0.8\right]$. In consequence of the homogeneous scaling with $Q_{\text {left }}$ and $Q_{\text {right }}$ within the pre-optimization large deviations $\Delta c_{i}$ occur, if the vocal fold dynamics demands a $Q_{i}$ distinct from the other two values of the same model side. It is the aim of the coarse optimization to detect this situation as follows: The pair $\left(i^{*}, j^{*}\right)_{l}$ with the least difference between the energies of the trajectory difference signals is identified for the left $(l=1$ and $i, j=1, \ldots, 3)$ and the right model side $(l=2$ and $i, j=4, \ldots, 6)$ after

$$
\min _{i, j}\left|\Delta c_{i}^{l}-\Delta c_{j}^{l}\right|
$$

and the mean values $\Delta c_{\text {min }}^{l}=\frac{1}{2}\left(\Delta c_{i^{*}}^{l}+\Delta c_{j^{*}}^{l}\right)$ are calculated. The remaining difference energies $\Delta c_{k}, k \neq i^{*}, j^{*}$, for each side are as- 
signed to $\Delta c_{\text {max }}^{l}=\Delta c_{k}^{l}$. For $\Delta c_{\text {max }}^{l}>4 \cdot \Delta c_{\text {min }}^{l}$ the search range for the corresponding parameter $Q_{k}$ is extended to $[0.3,3]$. The factor 4 avoids an unnecessary extension of the search space in case of small deviations. Due to the local search space extension, distinct values for $Q_{k}$ compared to the remaining both vales $\left(Q_{i}, Q_{j}\right)$ of a single model side are enabled. Within the objective function, $\Delta a$ and $\Delta c$ are evaluated.

3. Fine optimization. For this step, the optimization is coupled with a regularization. Besides the model dynamics, the mass and stiffness distributions along each model side are evaluated. For this aim, a further regularization condition is introduced in addition to the objective function $\phi$.

For each model side (all masses are at rest position) a contour line $\mathbf{c}_{l}[z]=(x[z], y[z])(l=1$ for the left and $l=2$ for the right side) with the parametric domain $z \in[0,1]$ is determined as shown in Fig. 6.8. By means of approximation using cubic B-splines $q_{l}[z]$ is derived from the sampling points $Q_{i}^{g e n}$, the values for the optimization parameters delivered by the GA, see Fig. 6.8. The values at the rest positions $q_{l}\left[z=z_{i}\right]=Q_{i}$ are used for scaling the variable model parameters.

According to Eq. $(6.18,6.19)$ the function $q_{l}$ describes the mass and stiffness distributions along the model contour $\mathbf{c}_{l}$ which reveals a continuous behavior without excursive changes [126]. To take this into consideration, the local smoothness $s_{i}$ at position $z_{i}$ is calculated as

$$
s_{i}:=\sum_{z=z_{i-1}}^{z_{i+1}}\left(\frac{q_{l}[z-\Delta z]-2 q_{l}[z]+q_{l}[z+\Delta z]}{(\Delta z)^{2}}\right)^{2},
$$

the squared sum of the second order difference quotient with $\Delta z=$ 0.01. A mean value $\bar{s}$ of the $s_{i}$ is calculated, whereby positions $i$ with an extended search range during the coarse optimization are not considered:

$$
\begin{aligned}
\bar{s} & :=\frac{1}{\sum_{j=1}^{6} \kappa_{j}} \sum_{i=1}^{6} \kappa_{i} \cdot s_{i}, \quad \text { with } \\
\kappa_{i} & = \begin{cases}0, & Q_{i} \in[0.3,3] \quad \text { in coarse opt. } \\
1, & \text { else }\end{cases}
\end{aligned}
$$



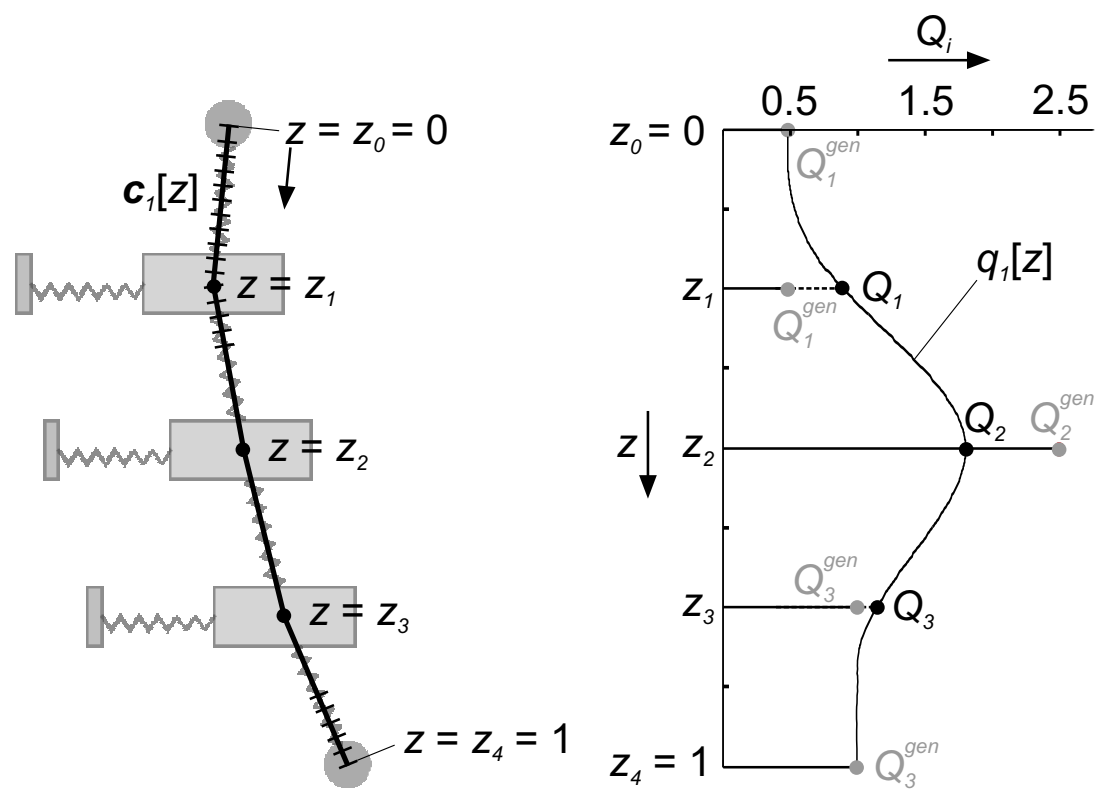

Figure 6.8: Calculation of the distribution $q_{1}[z]$ of the values $Q_{i}$ in longitudinal direction.

For the regularization, a value $\bar{s}$ as low as possible, i.e. a function $q_{l}$ as smooth as possible, is demanded. Extending the optimization procedure with the regularization, the final results $Q_{p}^{*}, Q_{1}^{*}, \ldots, Q_{6}^{*}$, and $Q_{r}^{*}$ of the parameter optimization are calculated after

$$
\min _{Q_{p}, Q_{1}, \ldots, Q_{6}, Q_{r}}\left(\phi+\frac{\bar{s}}{\max _{i}\left(s_{i}\right)}\right) .
$$

The search spaces for the optimization parameters are derived from the results of the coarse optimization after $\left[Q^{\text {coarse }} / 1.2, Q^{\text {coarse }} / 0.8\right]$.

\subsection{Validation with Synthetic Data Sets}

The reliability and performance of the optimization results are evaluated by applying the optimization procedure to synthetic data sets which are generated by simulations with predefined model configurations. Eight model configurations simulate vibration patterns as observed for healthy and pathologic voices as shown in Fig. 6.10 and 6.11. The time-series of the opening area formed by the modeled vocal fold edges are used as synthetic 
image processing results. For validation purposes, the parameter values resulting from the fitting of the MMM dynamics to the synthetic vibration patterns are compared with the predefined values.

As the genetic algorithm is random-based, besides the reliability and performance the stability of the optimization procedure is validated. For this aim, the parameter optimization is applied five times to each synthetic vibration pattern in addition to the first run. The parameters of these five iterations are compared with the first result.

\subsubsection{Validation Results}

In Fig. 6.9 the parameter values $v_{c}$ (comprising $Q_{p}^{*}, Q_{1}^{*}, \ldots, Q_{6}^{*}, Q_{r}^{*}$ ) resulting from the fitting to the eight synthetic vibration patterns are plotted over the predefined parameter values $v_{p}$. The correlation amounts $98 \%$. The mean deviation of the predefined parameters from the values determined by the optimization are summarized in Tab. 6.1. The error averaged over all eight parameters is $5.1 \%$. The smallest error is achieved for parameter $Q_{1}$ with a mean error of $3.10 \%$. The parameter $Q_{3}$ has the largest deviation with a mean error of $8.78 \%$.

For the validation of the stability, the optimization procedure is applied additionally 5 times to each synthetic vibration pattern. The results are compared with the parameter values obtained in the first processing of the synthetic data. The variation of the resulting optimization parameters facilitate an appraisal of the stability of the proposed method. The mean deviation amounts to 5.5\%, averaged across all parameters, see Tab. 6.2. The smallest deviation is achieved for parameter $Q_{4}$ with a mean error of $3.36 \%$. The greatest deviation reveals $Q_{1}$ with a mean error of $9.16 \%$.

The identification of the synthetic data values with sufficient accuracy and

Table 6.1: Error between the parameter values used for generating the synthetic data set and the optimized values averaged over all synthetic cases.

\begin{tabular}{c|c|c|c|c|c|c|c|c}
\hline & $Q_{p}$ & $Q_{1}$ & $Q_{2}$ & $Q_{3}$ & $Q_{4}$ & $Q_{5}$ & $Q_{6}$ & $Q_{r}$ \\
\hline \hline mean error [\%] & 3.54 & 3.10 & 5.23 & 8.78 & 5.21 & 3.26 & 5.04 & 6.92 \\
\hline
\end{tabular}




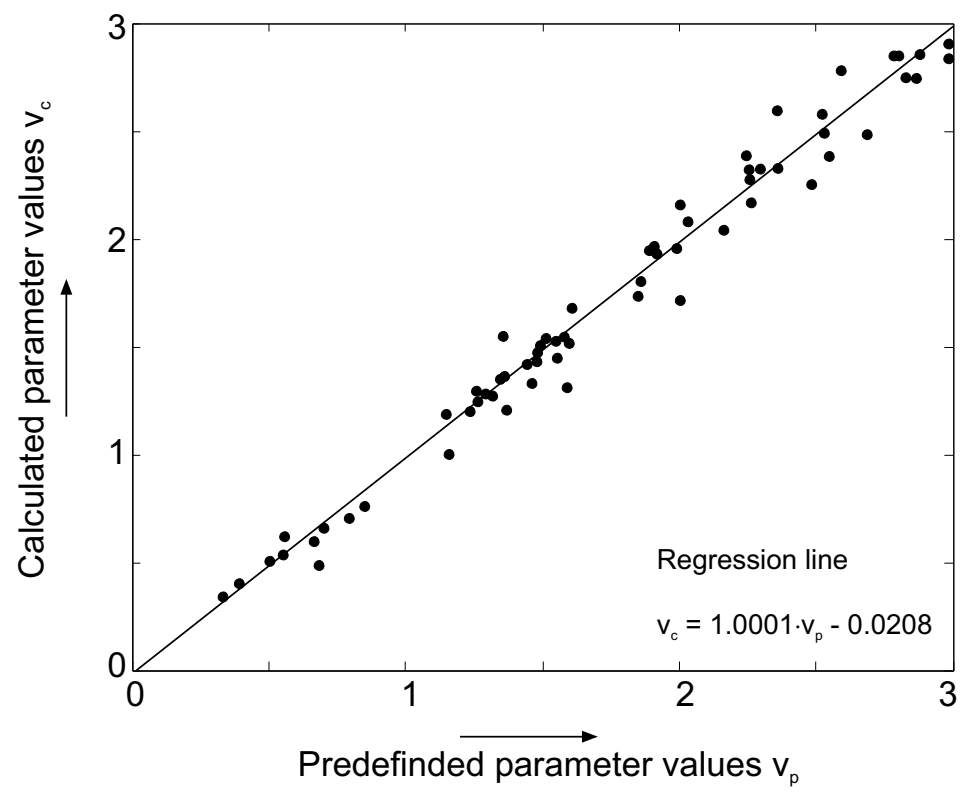

Figure 6.9: Resulting parameter values over the predefined parameter values used for generating the synthetic vibration patterns.

Table 6.2: Variation of the optimization results after additional 5 application of the optimization procedure to the same synthetic vibration patterns (averaged over all eight synthetic data sets).

\begin{tabular}{c|c|c|c|c|c|c|c|c}
\hline & $Q_{p}$ & $Q_{1}$ & $Q_{2}$ & $Q_{3}$ & $Q_{4}$ & $Q_{5}$ & $Q_{6}$ & $Q_{r}$ \\
\hline \hline mean error [\%] & 3.80 & 9.16 & 4.69 & 3.46 & 3.36 & 8.64 & 7.10 & 3.87 \\
\hline
\end{tabular}


the successful reproduction of these results demonstrate the robustness and reliability of the parameter optimization.

\subsection{Application to Real Vocal Fold Oscillations}

Within a first study high-speed recordings from 2 healthy voice subject (S1, S2) and 6 subjects (S3-S8) suffering from voice disorders are evaluated. Fig. 6.10 and 6.11 give a survey of the corresponding vibration patterns using the compact illustration, introduced in Sec. 4.1. The left columns show the opening phase for each recording. For subject S1, the construction of the trajectory $c_{2}^{e x p}$ is depicted. For $\mathrm{S} 2$ to $\mathrm{S} 8$ the point $\mathbf{g}_{2}$ on the glottal axis and the points $\mathbf{p}_{2}$ on the right medial vocal fold edge are shown. The right column depicts the closing phase. It follows a brief description of the specific vibration characteristics:

- S1. Healthy male voice. Left and right vocal fold oscillation are symmetric. The closing phase is longer $(2.5 \mathrm{~ms})$ than the opening phase $(1.5 \mathrm{~ms})$. The glottal closure starts at the ventral ending.

- S2. Healthy female voice. Left and right vocal fold oscillation are symmetric. The closing phase is slightly longer $(2.5 \mathrm{~ms})$ than the opening phase $(2.0 \mathrm{~ms})$. The glottal closure starts at the ventral ending. There is a glottal closure insufficiency at the dorsal ending.

- S3. Functional dysphonia. The vibrational amplitude of the left vocal fold is reduced. The glottal closure is insufficient.

- S4. Unilateral paralysis (right-sided). The glottal closure is insufficient and there is a phase shift between the left and right vocal fold oscillation. The left vocal fold reveals a longitudinal vibration mode.

- S5. Spasmodic dysphonia. The opening and closing phase are short $(1.0 \mathrm{~ms}$ and $0.75 \mathrm{~ms})$ compared to the duration of the glottal closure $(2.25 \mathrm{~ms})$. The glottis is closed for more than the half of the oscillation cycle.

- S6. Vocal fold scar (right-sided). The right vocal fold shows a longitudinal vibration mode. The right oscillation amplitude is decreased 

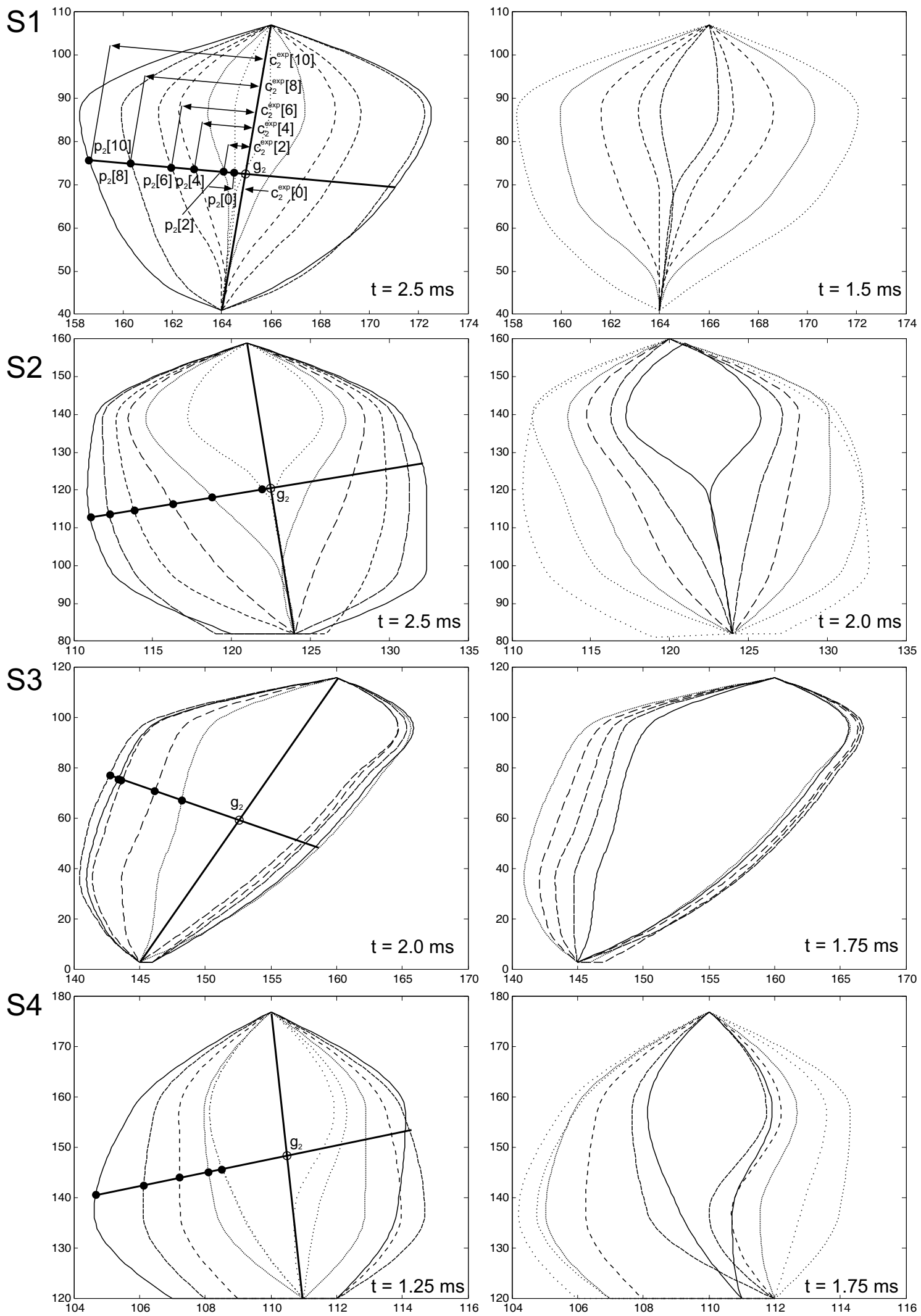

Figure 6.10: Vocal fold vibration patterns for the subjects $S 1$ to $S 4$. The left column shows the opening phase, the right column the closing phase. 

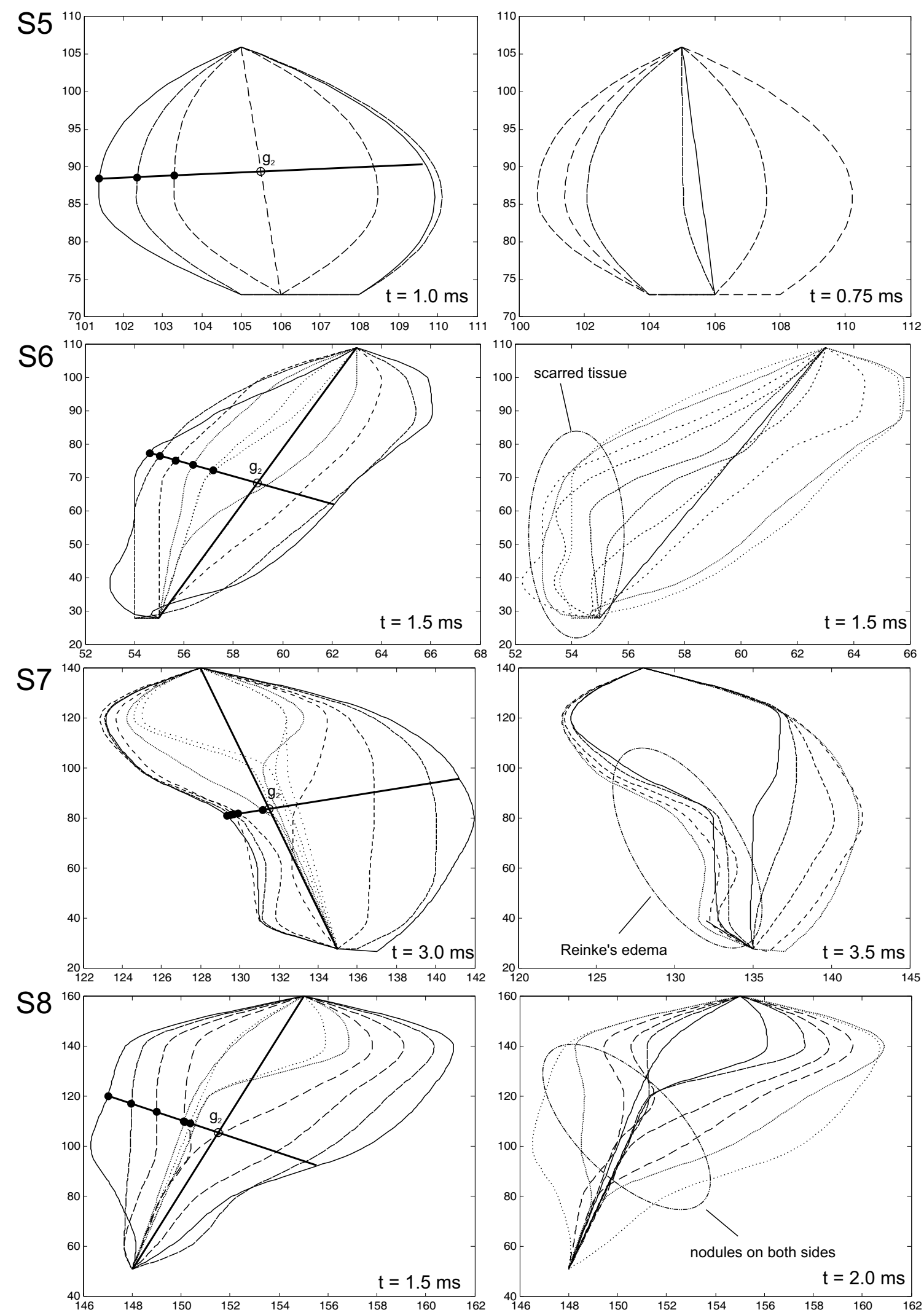

Figure 6.11: Vocal fold vibration patterns for the subjects $S 5$ to S8. The left column shows the opening phase, the right column the closing phase. 
compared to the left side. The duration of the glottal closure is short $(0.5 \mathrm{~ms})$ compared to the opening and closing phase (1.5 $\mathrm{ms}$ each).

- S7. Reinke's edema. The edema at the ventral ending of the right vocal fold decreases the right oscillation amplitude. The glottal closure at the dorsal ending is insufficient.

- S8. Nodules. The nodules are at the medial position symmetrical on both vocal folds. The glottal closure at the dorsal ending is insufficient.

The automatic optimization procedure is applied to the 8 digital high-speed recordings of the subjects S1 to S8. Fig. 6.12 shows the rest positions resulting from the described model initialization. The distance to the glottal axis along each model side is plotted. Negative values are assigned to the left side of the glottal axis, positive values to the right side. In Fig. 6.13 the vibration patterns of the optimized models are summarized. For each subject the closing phase is depicted. For comparison with the processed high-speed data, the corresponding vocal fold vibrations are also shown as gray lines.

For subject S7, Fig. 6.14 exemplarily depicts the dynamics of the optimized MMM as an overlay in the corresponding high-speed recording. The vibration pattern for one oscillation cycle of $5.25 \mathrm{~ms}$ is shown. The positions of the vibrating masses and the fix positions are marked with circles. The white line depicts the longitudinal coupling between the mass elements. The white line close to the vocal fold edge denotes the segmentation result. The frequency and amplitude of the vocal fold dynamics, as well as the time-varying shape of the glottis are reproduced by the MMM.

For giving a survey over the achieved fitting quality in all 8 subjects, Fig. 6.15 summarizes the correlations between the area functions $a$ and $a^{e x p}$ as well as the individual trajectories $c_{i}$ and $c_{i}^{e x p}$. Concerning the area functions a correlation of at least $89 \%$ is achieved. The correlation between the individual trajectories $c_{i}$ of the model masses and the vocal fold edge points $c_{i}^{e x p}$ amounts to (mean \pm standard deviation (sd), averaged across all positions and subjects) $87 \% \pm 9 \%$. The worst correlation is obtained at the position $i=3$ for $\mathrm{S} 1$ and at $i=5$ for S7, each with $63 \%$. 


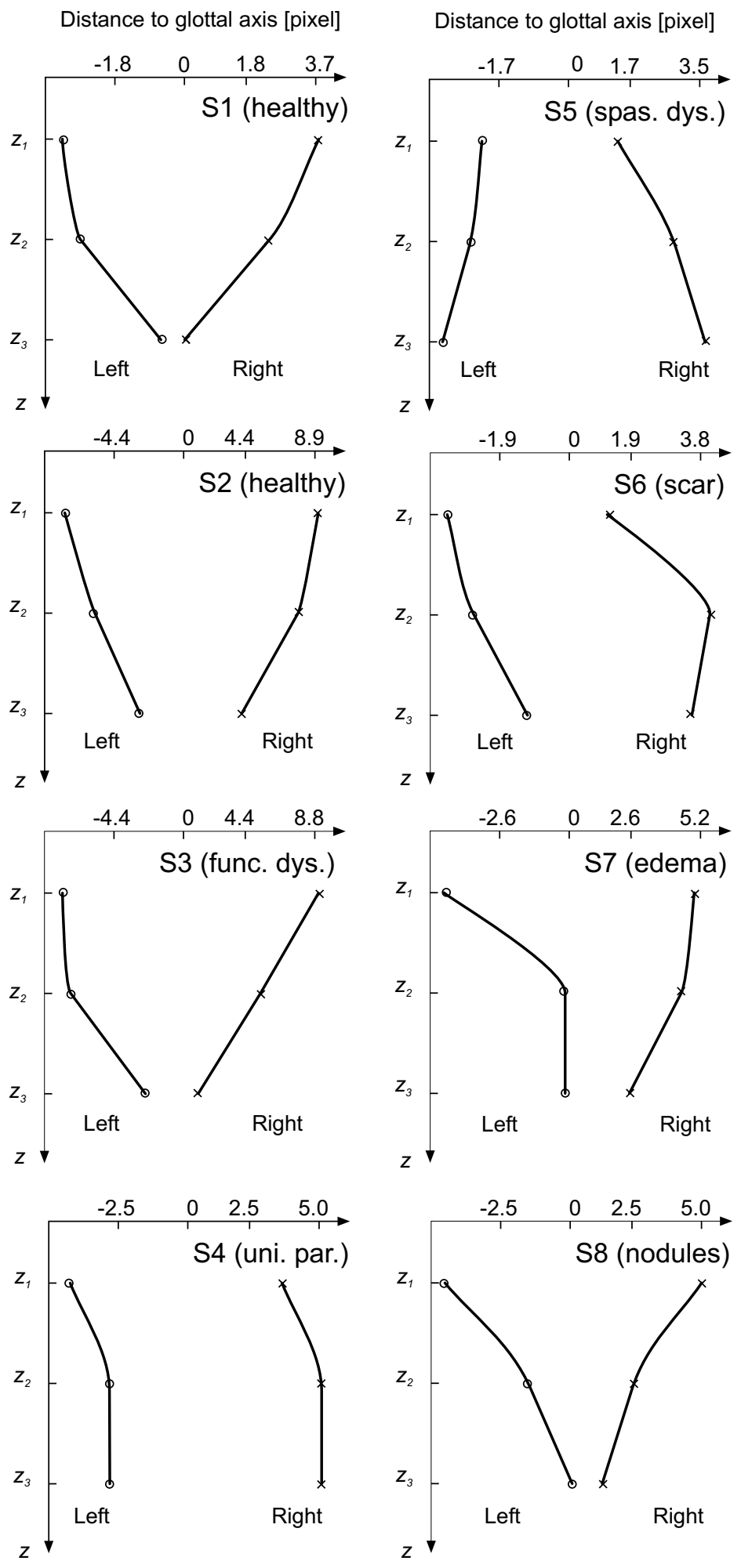

Figure 6.12: Rest position used for the model initialization. The values for the right side are marked with crosses, the values for the left side with circles. 

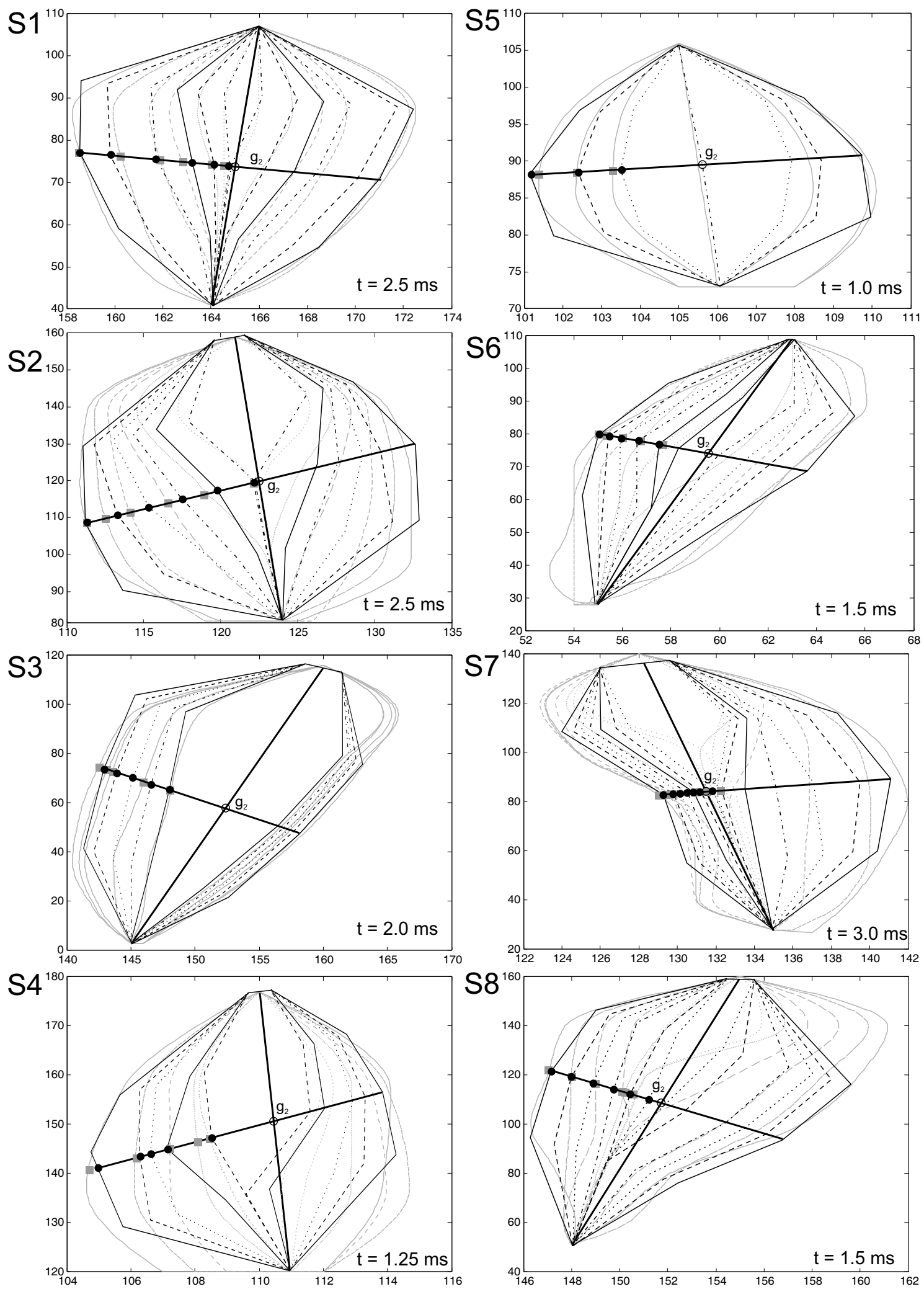

Figure 6.13: Resulting vibration patterns for the optimized parameter values. The closing phase for the eight subjects is shown. The vibrations extracted from the high-speed recordings are shown as gray lines. 


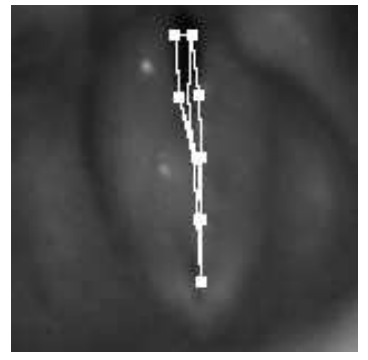

$t=0 \mathrm{~ms}$

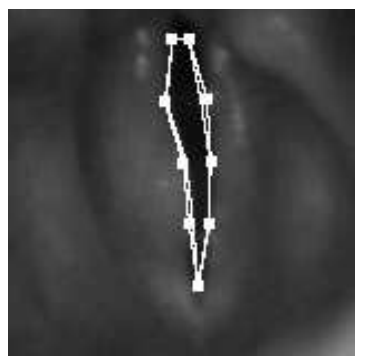

$t=3.0 \mathrm{~ms}$

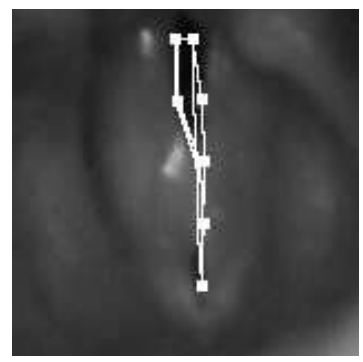

$t=0.75 \mathrm{~ms}$

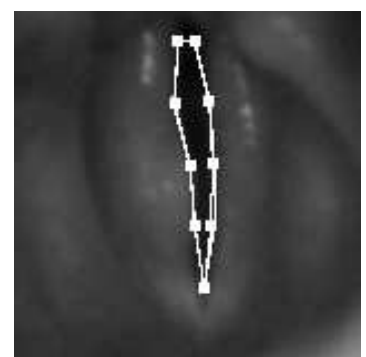

$t=3.75 \mathrm{~ms}$

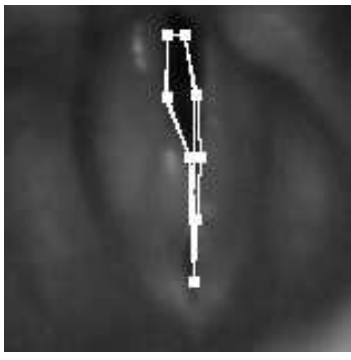

$t=1.5 \mathrm{~ms}$

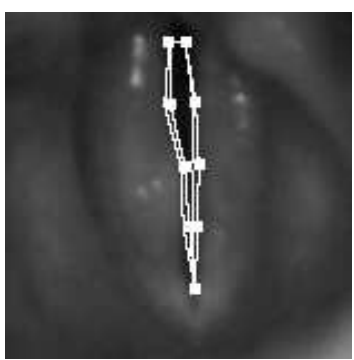

$t=4.5 \mathrm{~ms}$

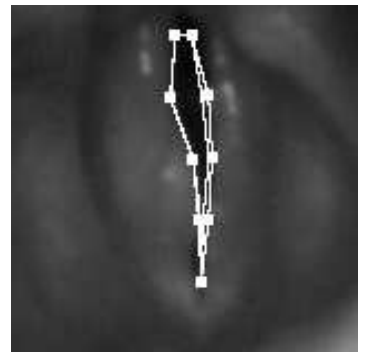

$t=2.25 \mathrm{~ms}$

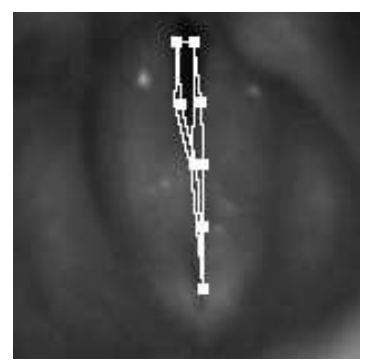

$t=5.25 \mathrm{~ms}$

Figure 6.14: Dynamics of the multi-mass model fitted to the vocal fold vibrations for the subject $S 7$. The positions of the oscillating elements are marked with white filled squares. The two most upper squares denote the posterior fix positions, the lowest one the anterior fix position. The white line next to the vocal folds represents the segmentation result.

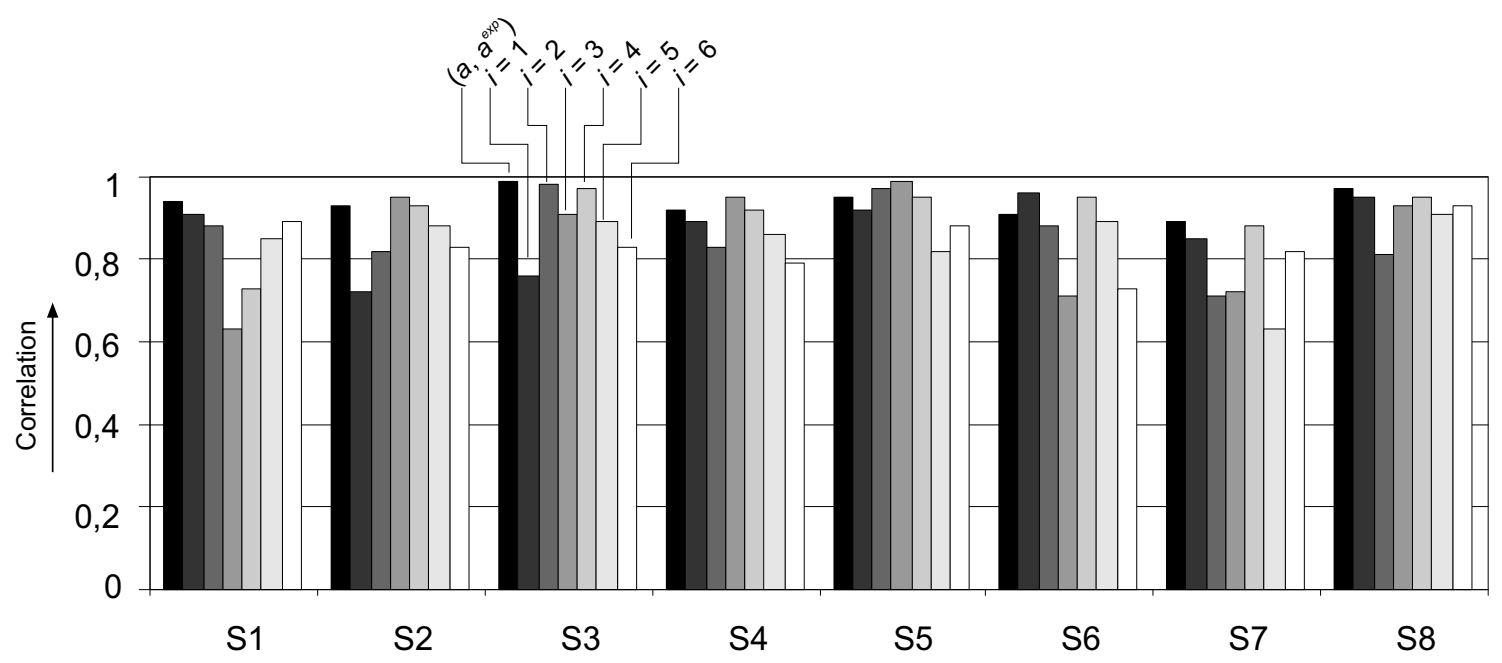

Figure 6.15: Correlation between the area functions from the model $a$ and the high-speed recordings $a^{e x p}$ as well as the model trajectories $c_{i}$ and the trajectories from the vocal fold edge points $c_{i}^{e x p}$. 

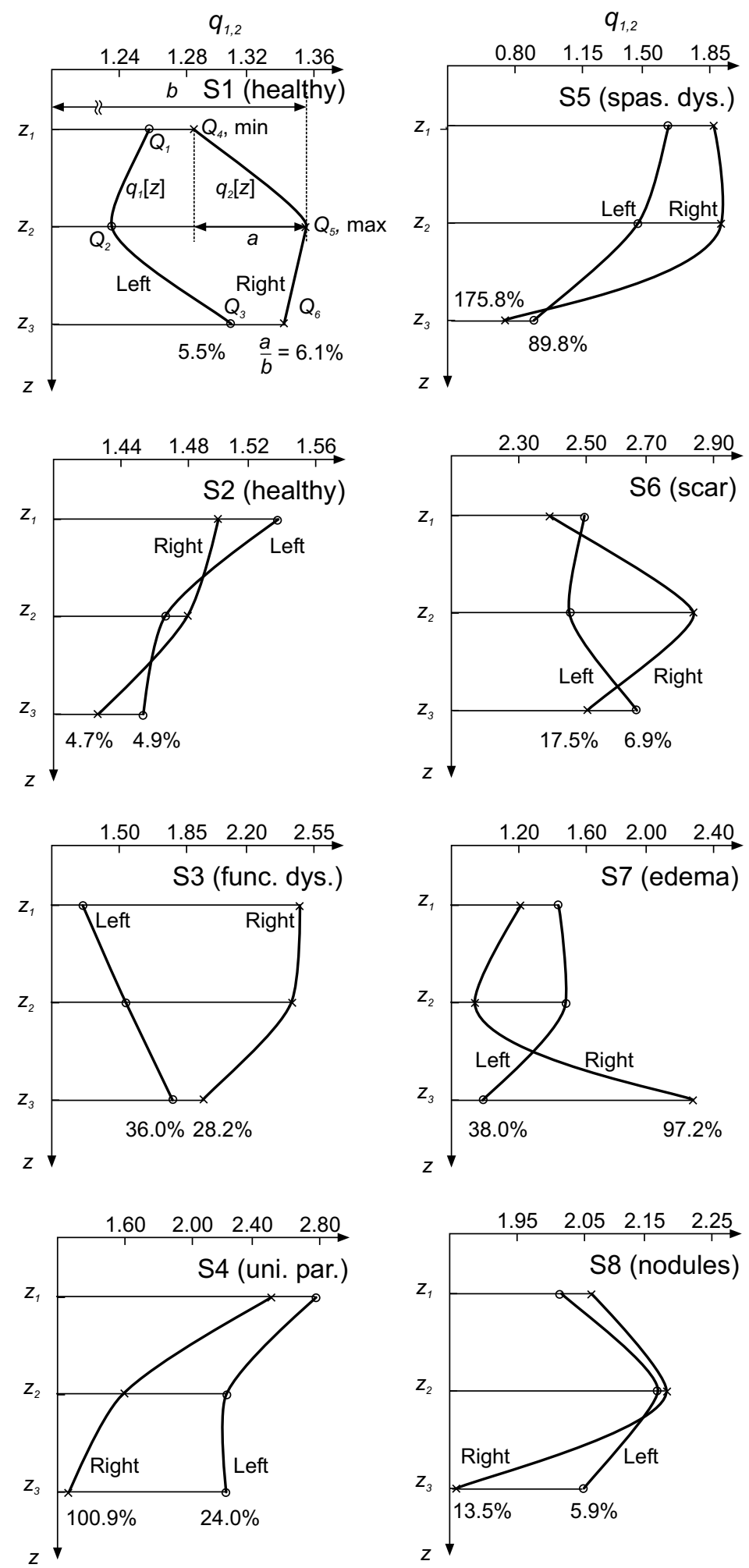

Figure 6.16: Distribution of $Q_{1}$ to $Q_{3}$ and $Q_{4}$ to $Q_{6}$ along the left (circles) and right model side (crosses) as defined Fig. 6.8. The difference between the maximum and minimum value normalized to the maximum is assigned to each curve. 
Table 6.3: Results for the optimization parameters $Q_{p}$ and $Q_{r}$.

\begin{tabular}{c|c|c}
\hline$\#$ & $Q_{p}^{*}$ & $Q_{r}^{*}$ \\
\hline \hline S1 & 2.52 & 0.55 \\
\hline S2 & 2.87 & 0.70 \\
\hline S3 & 2.35 & 0.50 \\
\hline S4 & 2.25 & 0.38 \\
\hline S5 & 2.98 & 0.66 \\
\hline S6 & 1.90 & 0.55 \\
\hline S7 & 2.85 & 0.79 \\
\hline S8 & 2.35 & 0.32 \\
\hline
\end{tabular}

The optimization results are summarized in Tab. 6.3 and Fig. 6.16. Tab. 6.3 shows the values for the parameters $Q_{p}$ and $Q_{r}$. Fig. 6.16 shows the distribution of the values $Q_{1}$ to $Q_{3}$ (circles) and $Q_{4}$ to $Q_{6}$ (crosses) along the left and right model side. As a quantification for the variabilities within the values $Q_{i}$ of a single model side, the differences between the maximum and minimum value related to the maximum are assigned to each distribution. For both healthy subjects S1 and S2 all four values are smaller than $10 \%$. For the remaining pathologic subjects for at least one model side the difference between the minimum and the maximum value is above $10 \%$.

\subsection{Interpretation of the Clinical Results}

Using the optimization procedure in combination with the MMM, the vocal fold vibrations extracted from digital high-speed recordings of 8 subjects (2 healthy voice subjects and 6 with different voice disorders) are evaluated. The considered subjects reveal distinct vibration patterns. The vibration patterns range from almost symmetric and regular oscillations for the healthy subjects S1 and S2 to clearly asymmetric vibrations concerning the left and the right vocal fold (e.g., S3 and S4) and irregular shapes as for subject S6 and S7. Although the subjects show this high variability, the optimization procedure is capable to generate MMM oscillations and corresponding area functions with a mean correlation of $94 \%$ 
to the area functions extracted from the high-speed recordings (Fig. 6.15). In addition, the correlations between the individual model trajectories $c_{i}$ and $c_{i}^{e x p}$ from the corresponding vocal fold edge points have a mean value of $87 \%$. These results account for a sufficient accuracy of the model fitting.

Following Fig. 6.12 and Fig. 6.16, the shapes of the plotted curves are distinct from each other. For a further application of the determined parameters it is necessary, that the shapes are plausible concerning the evaluated voice disorder. Besides the vibrating masses and spring stiffnesses, the rest positions of the masses influence the model dynamics and have to be taken into account for the following discussion. The data sets can be categorized in three groups: healthy voice subjects, subjects with functional or paralytic voice disorders and voice disorders which result in local organic changes on one or both vocal folds.

\section{Healthy Voice Subjects}

For the healthy voice subjects $\mathrm{S} 1$ and $\mathrm{S} 2$ the distances of the rest positions to the glottal axis (Fig. 6.12) as well as the values for $Q_{i}$ (Fig. 6.16) are almost symmetric for the left and the right side with a low variability. Symmetric model configurations reflect no pathologic changes within the vocal fold constitution.

\section{Functional and Paralytic Voice Disorders}

For the subjects with functional and paralytic voice disorders (S3, S4, S5), i.e., no local changes of the organic constitution of one or both vocal folds, the distributions of the $Q_{i}$ values are smooth along each model side. The variability of the values for the $Q_{i}$ is significantly increased compared to the healthy subjects. For S4 and S5 asymmetric rest positions are observable. Especially for S4 this reflects the disturbed positioning of the vocal folds due to the paralysis $[96,127]$.

\section{Organic Voice Disorders}

For the subjects S6, S7, and S8 with organic voice disorders, the distributions of the values $Q_{i}$ along the pathologic vocal folds reflect the local changes of the organic constitutions of the vocal folds. In case of the scar on the right vocal fold at ventral position (see Fig. 6.11, S6), the corresponding value for $Q_{i}$ is increased compared to the adjacent values. The edema at ventral position for subject S7 corresponds to a clearly increased $Q_{i}$ and the symmetrical nodules of subject $\mathrm{S} 8$ result in increased values 
for $Q_{i}$ at medial position. For the subjects $\mathrm{S} 6$ and $\mathrm{S} 7$ with a one-sided organic disorders the determined rest positions are asymmetric between left and right side. In case of subject S8 with the symmetric placed nodules, symmetric rest positions are obtained.

The resulting model parameters and optimization parameters reflect individual properties of the vocal fold vibrations. The different voice disorders are mapped to different domains within the parameter space. Thereby, the obtained parameter combinations are comprehensible by accounting the specific characteristics of the regarded voice disorder. 


\section{Spatio-Temporal Quantification of PE Segment Vibrations}

The intelligibility of the tracheoesophageal substitute voice and thus the quality of life in case of laryngectomy is reduced compared to normal voice [128]. In addition, the vibration patterns and substitute voice qualities among different laryngectomees reveal a significant variability $[9,85]$. The surgical intervention during laryngectomy is not optimized so far concerning the resulting vibration characteristics of the PE segment and the substitute voice quality $[55,59]$. Thus, regarding the excision procedure improvements of the voice rehabilitation are possible. For improving laryngectomy with the aim of obtaining a substitute voice quality as good as possible, the interrelation between the PE dynamics and voice quality has to be analyzed. One precondition for this aim is an objective quantification of the PE segment vibration patterns. In this chapter, the applicability of a modified multi-mass model for this purpose is examined.

\subsection{Multi-Mass Model of the PE Segment}

The modeling of the PE segment is based on the MMM used for vocal folds as the basic myoelastic principles of tracheoesophageal and laryngeal phonation are identical [129]. The upper esophageal sphincter can be regarded approximately as a circular flexible tube. This is modeled by multiple coupled oscillating elements as used in the MMM circularly placed in a horizontal plane, hereafter referred to as the PE-MMM. Fig. 7.1 shows the PE-MMM composed of six oscillators. In analogy to the MMM each mass is capable to move within the whole horizontal plane. The $M$ oscillating elements numbered with $i=1, \ldots, 6$ are oriented towards the common central point $\mathbf{p}$. As the esophagus is a closed elastic tube, adjacent oscillators are connected to each other with longitudinal coupling 


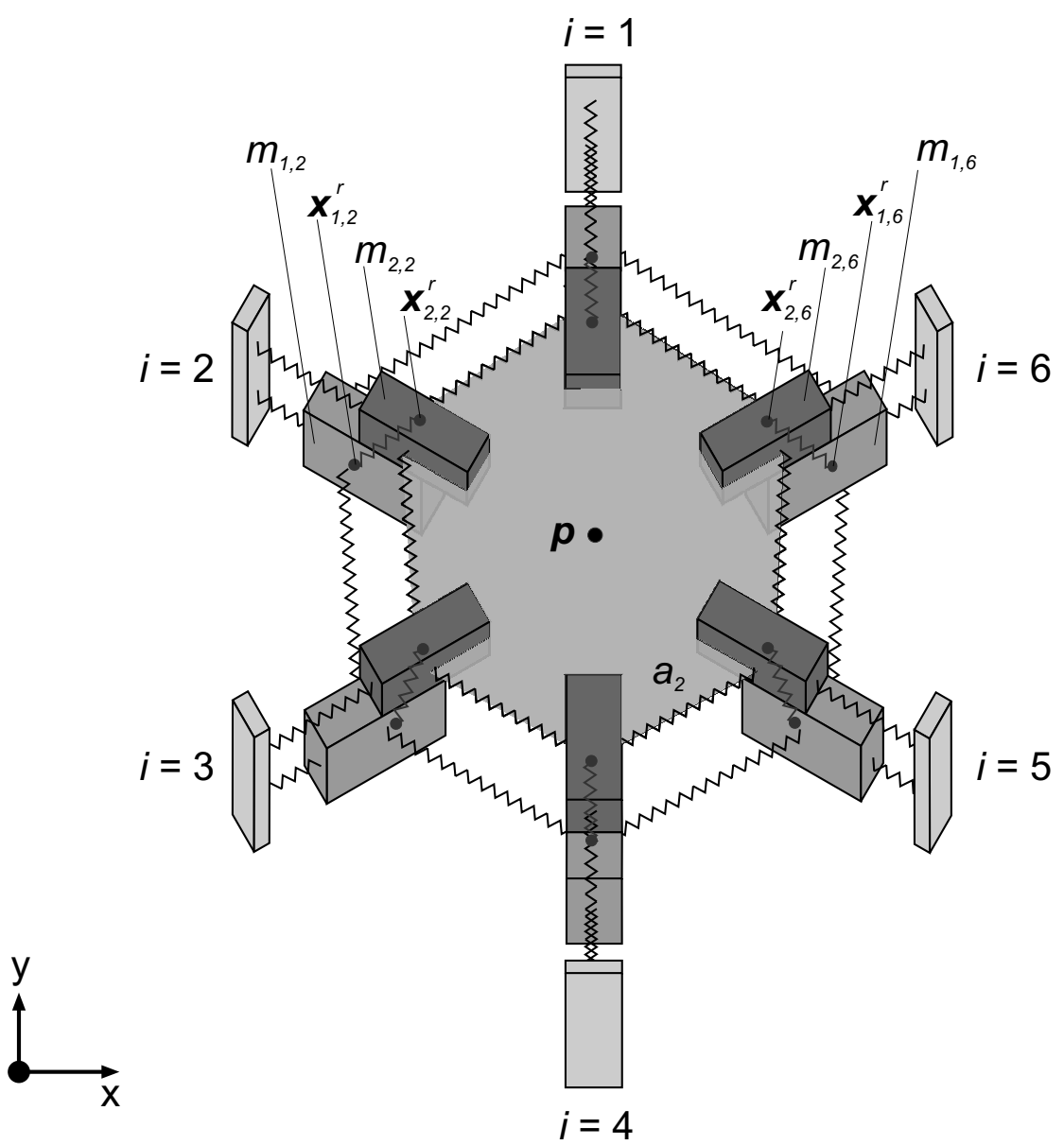

Figure 7.1: Schematic representation of the MMM of the PE segment comprising six coupled oscillators numbered with index $i$. The pseudoglottis is represented by the minimum opening (here: $a_{2}$ ) enclosed by the masses of the lower plane $(s=1)$ or upper plane $(s=2)$. 
springs and damping elements. Compared to the MMM of the vocal folds the PE-MMM possesses no fix positions. As for the MMM, the vector $\mathbf{x}_{s, i}[n]=\left(x_{s, i}[n], y_{s, i}[n]\right)^{T}$ denotes the position of mass $m_{s, i}$ for the $n^{\text {th }}$ time step with velocity $\dot{\mathbf{x}}_{s, i}[n]$ and acceleration $\ddot{\mathbf{x}}_{s, i}[n]$. The mass positions define the model opening area $a_{s}[n]$ in the lower $(s=1)$ and the upper $(s=2)$ horizontal plane for the $n^{\text {th }}$ time step. In accordance to the time-variant experimental contours $\mathbf{c}^{\exp }[z, n](z \in[0,1])$ for describing the PE dynamics (see Sec. 4.2), the model dynamics is defined by the polygon formed by the positions $\left(\mathbf{x}_{1}[n], \ldots, \mathbf{x}_{6}[n]\right)$. Thereby, $\mathbf{x}_{i}[n]=\mathbf{x}_{1, i}$ for $a_{1}[n]<a_{2}[n]$, otherwise $\mathbf{x}_{i}[n]=\mathbf{x}_{2, i}$.

The equation of motion for the mass element $m_{s, i}$ follows Equ. (6.5). The vertical and longitudinal coupling forces $\mathbf{F}_{s, i}^{v}$ and $\mathbf{F}_{s, i}^{l}$, the collision force $\mathbf{F}_{s, i}^{c}$ and the driving force $\mathbf{F}_{s, i}^{d}$ are defined as for the MMM, see Sec. 6.1 and Eq. (6.7) - (6.14). Due to the missing of fix positions, circular vibration modes occur for model configurations which are not absolutely symmetric concerning the parameter arrangement (spring stiffnesses, masses) or rest positions. As a result, the PE-MMM performs rotary motions which are not observable in PE segment oscillations $[8,61,83]$. For such vibration patterns, the movement of the masses can be regarded as nearly perpendicular to the anchor spring direction. As a consequence, for strongly elongated anchor springs, there is a significantly decreased damping of the circular vibration mode. To solve this problem, an additional anchor spring perpendicular to the original one is introduced for the calculation of the anchor force $\mathbf{F}_{s, i}^{a}$ :

$$
\begin{aligned}
\mathbf{F}_{s, i}^{a}:= & \overbrace{k_{s, i}^{a}\left\|\mathbf{x}_{s, i}^{r}-\mathbf{x}_{s, i}\right\|_{2} \mathbf{u}_{s, i}^{a}+r_{s, i}^{a}\left(\mathbf{u}_{s, i}^{a}\right)^{T} \dot{\mathbf{x}}_{s, i} \mathbf{u}_{s, i}^{a}}^{\text {fraction as within the MMM }} \\
& +\underbrace{\underbrace{a}_{s, i}\left\|\mathbf{x}_{s, i}^{r}-\mathbf{x}_{s, i}\right\|_{2} \mathbf{u}_{s, i}^{p}+r_{s, i}^{a}\left(\mathbf{u}_{s, i}^{p}\right)^{T} \dot{\mathbf{x}}_{s, i} \mathbf{u}_{s, i}^{p}}_{\text {additional, perpendicular fraction }},
\end{aligned}
$$

with

$$
\mathbf{u}_{s, i}^{p}:=\left(\begin{array}{cc}
0 & -1 \\
1 & 0
\end{array}\right) \mathbf{u}_{s, i}^{a}
$$




\subsection{Automatic Parameter Optimization}

With the objective of reproducing the time-variant contours of the pseudoglottis as exact as possible, the automatic parameter optimization introduced in Sec. 6.4 is extended to the application to PE segment vibrations. In the following, the optimization parameters, the objective function, the modified model initialization, and the optimization procedure are explained.

\subsubsection{Optimization Parameters}

Specific vibration patterns of the PE-MMM are produced by means of an appropriate adjustment of certain model parameters. According to the previous chapter, the variable model parameters are $P^{s}, m_{s, i}$ and $k_{s, i}^{a}$. The optimization parameters for the optimization of the PE-MMM $Q_{p}, Q_{1}, \ldots$, $Q_{M}$ and $Q_{r}$ are defined as for the MMM. By means of this set the actual model parameters $\hat{P}^{s}, \hat{m}_{s, i}$ and $\hat{k}_{s, i}^{a}$ are derived from the standard values as shown in Eq. (6.17) to (6.19). The rest positions are adapted with the parameter $Q_{r}$ with

$$
\hat{\mathbf{x}}_{s, i}^{r}=\mathbf{p}+\left(\mathbf{x}_{s, i}^{r}-\mathbf{p}\right) \cdot Q_{r},
$$

where $\mathbf{p}$ denotes the centroid of the polygon formed by the $M$ rest positions $\mathbf{x}_{s, i}^{r}$, see Fig. refpmmm.

\subsubsection{Objective Function}

For evaluating the adaptation quality achieved with the parameters $\hat{P}^{s}$, $\hat{m}_{s, i}$ and $\hat{k}_{s, i}^{a}$, the dynamics of the PE-MMM and the PE segment have to be compared with each other. Three criteria are defined which assess different characteristics of the vibration patterns. Due to the complex and highly variable PE morphology, the used image processing delivers the time variant contour of the pseudoglottal opening but not the distinct trajectories of discrete contour points. Therefore, the trajectory conistency measure defined in Sec. 6.3 has to be replaced by other adequate criteria.

1. Area consistency measure. Following Sec. 6.3, the energy $\Delta a$ of the difference signal between the area function of the PE-MMM 
$a[n]=\min \left(a_{1}[n], a_{2}[n]\right)$ and the PE segment $a^{\exp }[n], n=0, \ldots, N-$ 1 , normalized to the energy of $a^{\exp }[n]$ is calculated after

$$
\Delta a:=\frac{\sum_{n=0}^{N-1}\left|a[n]-a^{\exp }[n]\right|^{2}}{\sum_{n=0}^{N-1}\left|a^{\exp }[n]\right|^{2}} .
$$

2. Intersection area consistency measure. This measure compares the time variant contours of the PE segment and the PE model. Besides the opening area also the shape is taken into consideration. For this aim the intersection area $a^{\sec }[n]$ between $a^{\exp }[n]$ and $a[n]$ is determined, see Fig. 7.2. The deviation of model opening and the pseudoglottal area is quantified with

$$
\Delta s:=\frac{\sum_{n=0}^{N-1}\left(\left|a[n]-a^{\sec }[n]\right|+\left|a^{\exp }[n]-a^{\sec }[n]\right|\right)}{\sum_{n=0}^{N-1}\left(a[n]+a^{\exp }[n]\right)} .
$$

3. Time-averaged distance measure. For every mass the timeaveraged distance $d_{i}$ to the contour of the PE segment, see Fig. 7.3, is determined after

$$
d_{i}[n]:=\min _{z}\left\|\mathbf{x}_{i}[n]-\mathbf{c}^{e x p}[z, n]\right\|_{2} .
$$

For normalization, the radius $r$ of a circle with the same area as the orifice of the PE segment is calculated using

$$
r[n]=\sqrt{a^{\exp }[n] / \pi} .
$$

For the objective function the values $d_{i}$ are normalized as well as averaged over all masses and time steps following

$$
d:=\frac{1}{6 N} \sum_{i=1}^{6} \sum_{n=0}^{N-1} \frac{d_{i}[n]}{r[n]} .
$$

For the optimization procedure, these criteria are combined in the objective function $\phi_{P E}$ :

$$
\phi_{P E}:=(f(\Delta a))^{2}+(f(\Delta s))^{2}+(f(d))^{2},
$$

with $f(x)$ after Eq. (6.23). 


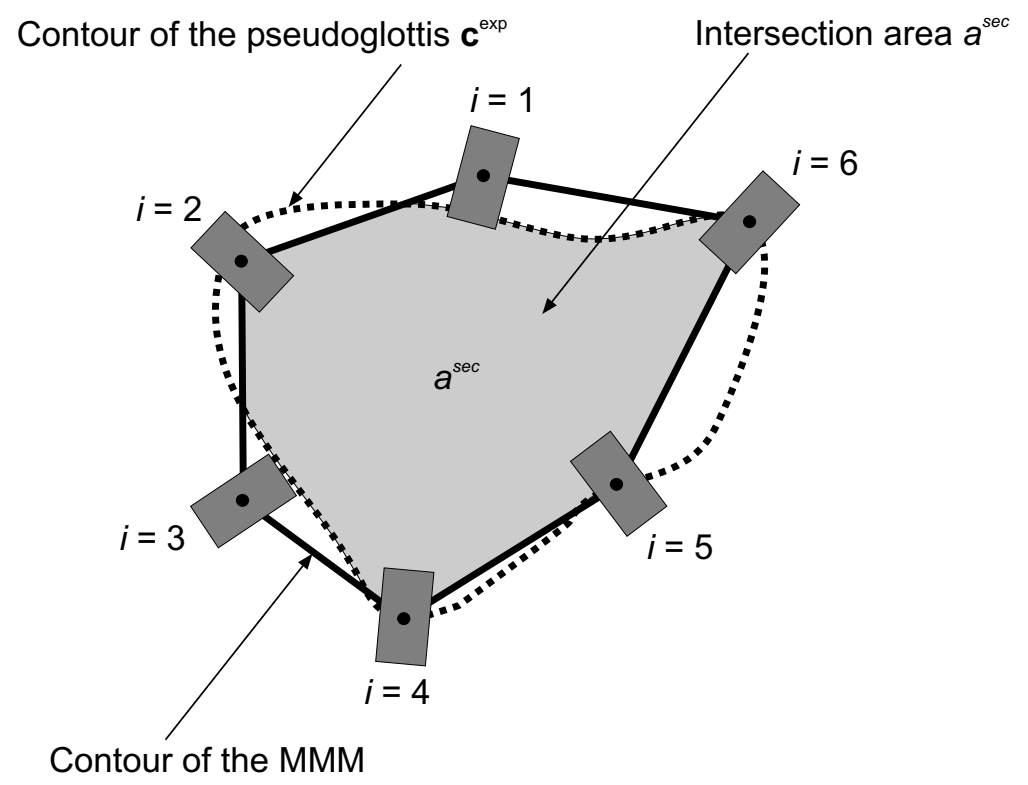

Figure 7.2: Intersection area between the contours of the multi-mass model and the segmented pseudoglottis.

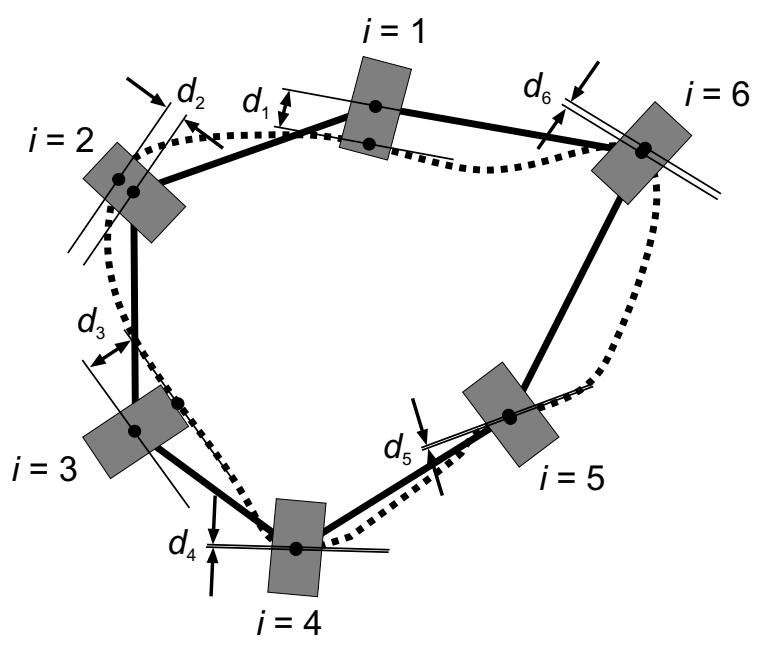

Figure 7.3: Minimum distances $d_{i}$ of the masses to the contour of the pseudoglottis.

\subsubsection{Model Initialization and Optimization Procedure}

For the aim of rebuilding the irregular shapes of PE segments, the rest positions $\mathbf{x}_{s, i}^{r}$ of the masses differ from the initial circular configuration. As for the MMM initialization, the contour with mean opening area is used for the model initialization. The oscillating elements are manually placed along this contour. The anchors are placed perpendicular to local 
contour section with a fixed distance of $1.2 \mathrm{~cm}$.

Concerning the automatic parameter optimization the procedure as introduced in Sec. 6.4.2 is applied. Consequently, the optimization is also subdivided into the three steps pre-, coarse, and fine optimization. The regularization within the fine optimization needs a continuous transition for the $q$-function between $Q_{6}$ and $Q_{1}$ which is achieved with a periodical continuation as shown in Fig. 7.4.
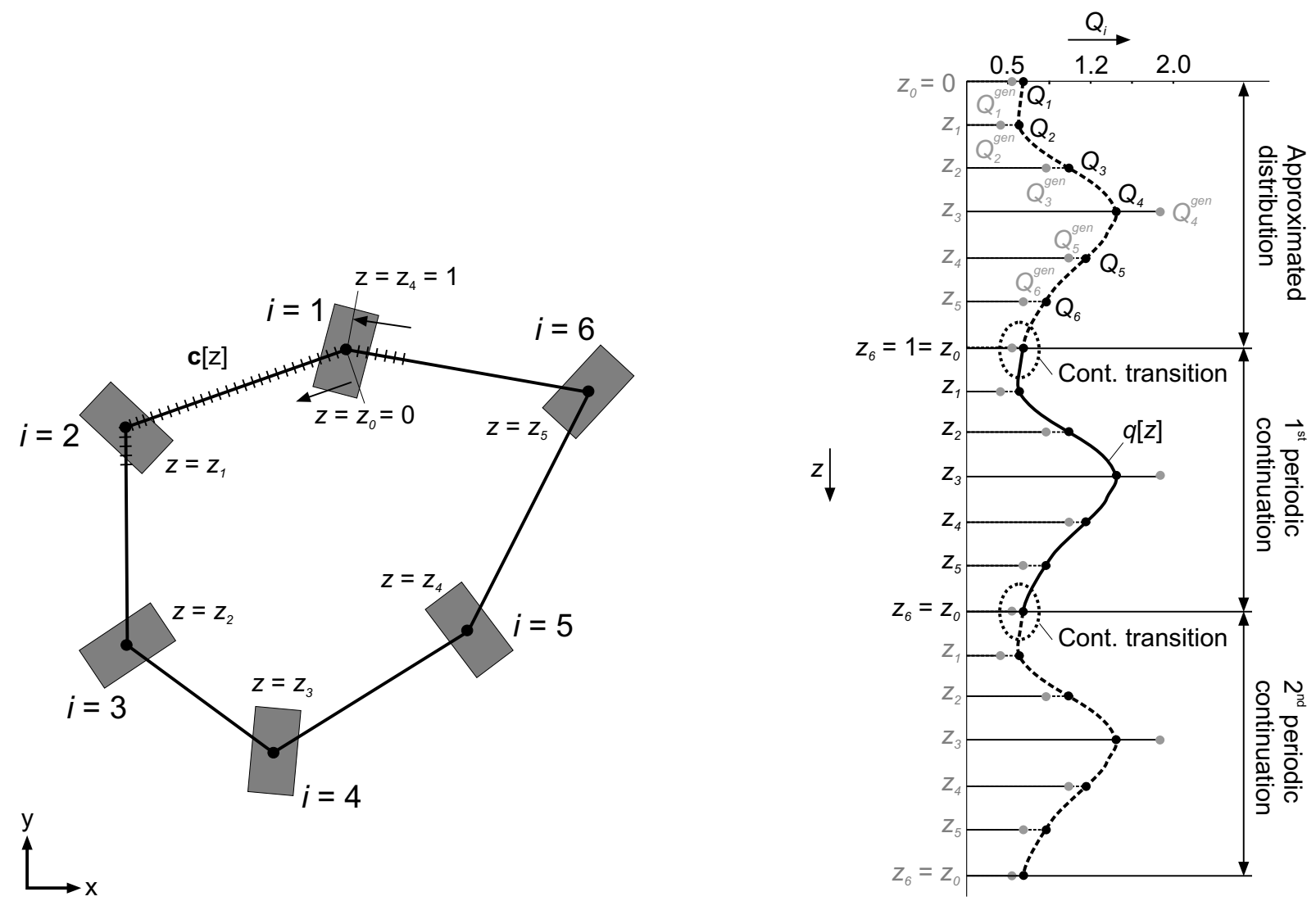

Figure 7.4: Left: Definition of the parameterized contour c $[z]$. Right: Approximated distribution of the values $Q_{i}$ using cubic B-splines and the $1^{\text {st }}$ and $2^{\text {nd }}$ periodical continuation. For the fine optimization the medial section (solid line) is used.

\subsubsection{Validation with Synthetic Data Sets}

As in the MMM approach, the reliability and performance of the optimization is validated with 10 synthetic data sets. In accordance to the prior 
validation, the stability of the random-based search algorithm is evaluated additionally by applying the procedure five times to each data set.

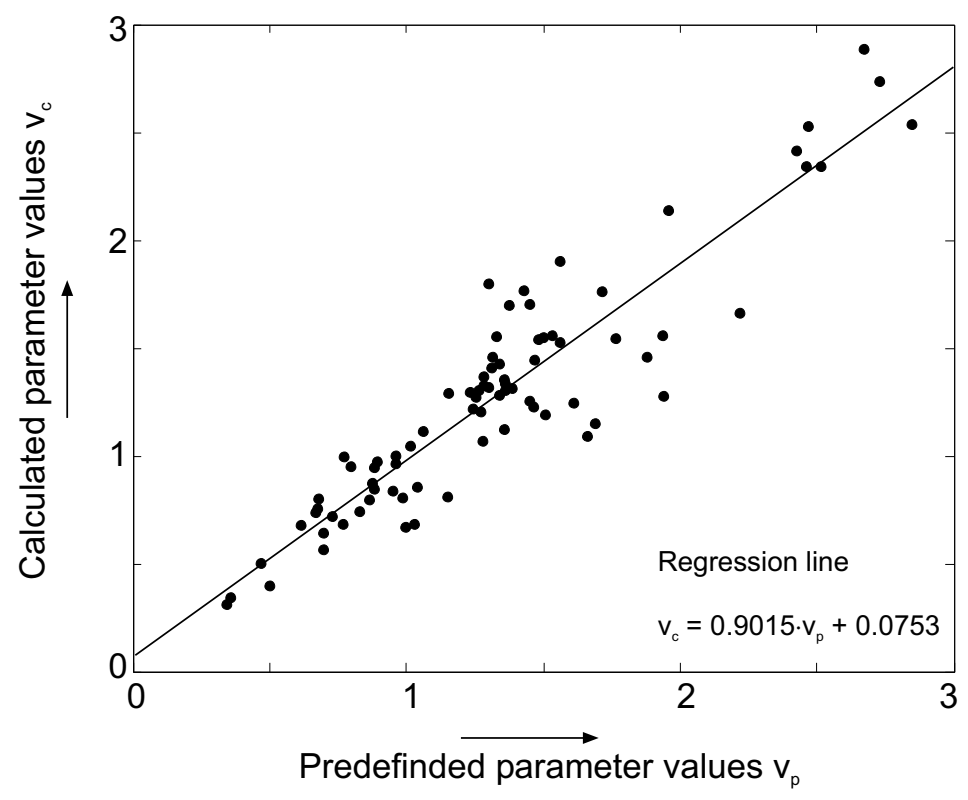

Figure 7.5: Resulting parameter values over the predefined parameter values used for generating the synthetic vibration patterns.

In Fig. 7.5 the calculated parameter values $v_{c}$ (comprising $Q_{p}^{*}, Q_{1}^{*}, \ldots, Q_{6}^{*}$, $\left.Q_{r}^{*}\right)$ resulting from the fitting to ten synthetic vibration patterns are plotted over the predefined parameter values $v_{p}$. The correlation amounts $84 \%$. The mean deviation of the predefined parameters from the values deter-

Table 7.1: Error between the parameter values used for generating the synthetic data set and the optimized values averaged over all ten synthetic cases.

\begin{tabular}{c|c|c|c|c|c|c|c|c}
\hline & $Q_{p}$ & $Q_{1}$ & $Q_{2}$ & $Q_{3}$ & $Q_{4}$ & $Q_{5}$ & $Q_{6}$ & $Q_{r}$ \\
\hline \hline mean error [\%] & 6.32 & 7.78 & 12.32 & 7.82 & 7.53 & 12.10 & 7.18 & 4.85 \\
\hline
\end{tabular}

mined by the optimization are summarized in Tab. 7.1. The error averaged over all eight parameters is $8.24 \%$. The smallest error is achieved for parameter $Q_{r}$ with a mean error of $4.85 \%$. The parameter $Q_{2}$ has the largest deviation with a mean error of $12.32 \%$. 
For the validation of the stability, the optimization procedure is applied additionally 5 times to each synthetic vibration pattern. For each parameter, the mean deviation of the optimization result to the value obtained within the first run is summarized in Tab. 7.2. The grand average (across

Table 7.2: Variation of the optimization results after additional 5 application of the optimization procedure to the same synthetic vibration patterns (averaged over all ten synthetic data sets).

\begin{tabular}{c|c|c|c|c|c|c|c|c}
\hline & $Q_{p}$ & $Q_{1}$ & $Q_{2}$ & $Q_{3}$ & $Q_{4}$ & $Q_{5}$ & $Q_{6}$ & $Q_{r}$ \\
\hline \hline mean error [\%] & 4.66 & 6.02 & 8.14 & 6.70 & 15.69 & 7.93 & 5.72 & 1.80 \\
\hline
\end{tabular}

all parameters) amounts to $7.08 \%$, see Tab. 7.2. The smallest deviation is achieved for parameter $Q_{r}$ with a mean error of $1.80 \%$. The greatest deviation reveals $Q_{4}$ with a mean error of $15.69 \%$.

The accuracy for the identification of the predefined parameter values and the stability in reproducing the achieved results demonstrate the robustness and reliability of the parameter optimization.

\subsection{Application to Real PE Segment Oscillations}

For six high-speed recordings R1-R6 (male subjects S1 to S6, mean age 61.2) the time-variant contour of the pseudoglottis is extracted by image processing. Subsequently, the introduced optimization procedure is applied to these six data sets. For a visualization of the optimization results, the model oscillations are shown as overlay in the high-speed recordings. Within the appendix, Fig. A.1 and A.2 show the segmentation results of the image processing together with the dynamics of the adapted PE-MMM. The vibration pattern for one oscillation cycle is shown. The positions of the six oscillators are marked with white squares. The frequency of the model dynamics is equal to the frequency of the PE segment vibration for the six recordings. The area enclosed by the oscillators rebuilds the 
segmented pseudoglottis. The irregular shape of the pseudoglottis is reproduced by the adapted PE-MMM. For the recording R1-R3 the circular contour of the PE segment is well approximated. Within the recordings $\mathrm{R} 4$-R6 the shape is more irregular and thus the reproduction with the 6 oscillating elements is less accurate.

Tab. 7.3 summarizes the optimization parameter results for the six highspeed recordings. The correlation $C$ between the area functions of the

Table 7.3: Results for the optimization parameters due to the adaptation of the PE-MMM dynamics to the PE segment vibrations extracted from 6 high-speed recordings. The last column denotes the achieved correlations between the area functions of the PE-MMM and the PE segment.

\begin{tabular}{c|c|c|c|c|c|c|c|c|c}
\hline$\#$ & $Q_{p}$ & $Q_{1}$ & $Q_{2}$ & $Q_{3}$ & $Q_{4}$ & $Q_{5}$ & $Q_{6}$ & $Q_{r}$ & $C$ \\
\hline \hline R1 & 1.86 & 1.09 & 1.06 & 1.45 & 1.27 & 1.21 & 1.37 & 1.04 & 0.69 \\
\hline R2 & 0.98 & 0.87 & 1.36 & 0.90 & 1.64 & 0.89 & 1.36 & 1.15 & 0.95 \\
\hline R3 & 1.71 & 0.59 & 1.23 & 1.10 & 0.94 & 0.96 & 1.02 & 0.78 & 0.76 \\
\hline R4 & 1.73 & 0.91 & 1.34 & 0.84 & 1.01 & 1.09 & 1.08 & 0.63 & 0.90 \\
\hline R5 & 0.93 & 0.64 & 0.84 & 0.72 & 1.32 & 0.79 & 0.62 & 0.82 & 0.76 \\
\hline R6 & 1.40 & 0.59 & 0.85 & 0.94 & 1.29 & 1.18 & 0.98 & 0.67 & 0.83 \\
\hline
\end{tabular}

PE-MMM and the PE segment varies between 0.69 for R1 and 0.95 for R2. The results from the previous section demonstrate the basic applicability of the PE-MMM and the introduced parameter optimization for an objective quantification of $\mathrm{PE}$ segment vibrations. Obviously, the reproduction of vocal fold vibration patterns using the MMM achieves better results even for irregular oscillation schemes (see Fig. 6.13). This may be due to the difference in capturing the dynamics of the PE segment and the vocal folds. Whereas discrete trajectories are available for fitting the MMM dynamics, only the contour itself is used for the parameter optimization of the PEMMM. An extension of the image processing by means of registration of subsequent PE segment contours enables the tracking of two-dimensional trajectories for single contour points. This may be useful for improving the adaptation quality $[86,130]$.

In following works, the method has to be applied to a larger quantity of 
high-speed recordings. This enables a more comprehensive evaluation of the parameter optimization. In addition to the evaluated quality of the substitute voice the resulting optimization parameters constitute the basis for an objective classification of the PE segment vibration concerning voice quality. This step facilitates a substantiated basis for analyzing the relationship between the vibration patterns of the PE segment and the quality of the substitute voice. From a medical point of view the knowledge from these investigations can help to improve voice rehabilitation and therefore the quality of life in case of laryngectomy. In particular an improvement of the surgical intervention resulting in an optimized scarring of the PE segment tissue concerning the vibration characteristics is an important issue. For this aim, the objective of the medical substitute voice assessment is the development of a surgical intervention which causes PE segment tissue properties resulting in vibration patterns producing a sufficient voice quality. 


\section{Summary and Outlook}

The interpersonal verbal communication is based on production and perception of speech using the voice as carrier signal. Voice arises from vocal fold oscillations within the larynx. Healthy voice is a precondition for the production of intelligible speech and thus efficient verbal communication. As speech communication becomes more and more important, especially for different occupational fields, the investigation and medical treatment of voice disorders gain in economic importance.

The production of healthy voice requires coordinated interaction between several laryngeal muscles as described in Chapter 2. Due to functional or organic disorders the voice generating process is disturbed. The consequences are irregular vocal fold oscillations and thus hoarse voice. One of the most extrem forms of voice disorder occurs due to laryngeal cancer. Depending on the state and position of the carcinoma, the only adequate oncological therapy may be the entire excision of the larynx, a so-called total laryngectomy. In this case, the patient loses the ability to speak. The state-of-the-art voice rehabilitation technique, the tracheoesophageal substitute voice, was also explained in Chapter 2. Here, tissue in the upper part of the esophagus (PE segment) is used as substitute voice generator to enable speech communication after laryngectomy.

The quality of voice depends on the vibration characteristics of the voice generating element. This holds for both, the laryngeal and the tracheoesophageal voice. In Chapter 3, endoscopic high-speed recording techniques were explained for imaging the vibrating voice generator with sufficient temporal resolution for observing irregular vibrations of the vocal folds and the PE segment. The image processing algorithms described in Chapter 4 delivered the dynamics: 1.) The opening formed by the vocal fold edges (glottis) or the contour of the PE segment were segmented, respectively. 2.) The vocal fold dynamics was described as the deflection of the vocal fold edges from the glottal axis. The PE dynamics was defined as 
the segmented contour of the time-varying opening area.

The present work focused on the model-based objective quantification of the dynamics of the voice generators. Biomechanical models of the voice generating elements were introduced. Their parameters were optimized automatically for fitting the model dynamics to the dynamics extracted from clinical recordings.

In Chapter 5, the two-mass model of the vocal folds was used for the classification of healthy and pathologic vocal fold vibrations in case of one-sided paralyses. Within this model, each vocal fold is represented by a pair of coupled mass-spring oscillators. The Bernoulli-type air flow along the opposing masses is driven by the subglottal pressure. Two optimization parameters were defined for varying the standard values for the masses, spring constants and the subglottal pressure for fitting amplitude and frequency of the model oscillation. For reproducing the left-right oscillation asymmetries due to the one-sided paralyses and the specific waveforms of the oscillation, two further optimization parameters $Q_{k 1}$ and $Q_{k c}$ were introduced for defining asymmetric model configurations. The proposed parameter optimization is subdivided into an knowledge-based initial value search procedure and a genetic search algorithm. By means of synthetically vocal fold oscillations, the reliability of the optimization procedure was proven. From results of the parameters $Q_{k 1}$ and $Q_{k c}$ for the application to the clinical data a scheme for classifying healthy and paralytic voice by subdivision of the parameter space was derived. Besides the identification of a one-sided paralysis the degree of voice disorder was classified as well. The proposed model-based quantification and classification represents the basis for developing medical applications for supporting therapy selection and quantification of therapy outcome. The next step towards this aim will be the evaluation of further high-speed data.

The two-mass model approach was augmented in Chapter 6 to enable a spatio-temporal assessment of vocal fold oscillations. For this aim, the two-mass model was extended to a two-dimensional multi-mass model approach, i.e. the two-mass model is subdivided in several coupled oscillators in longitudinal direction. For fitting the multi-mass model to vocal fold oscillations optimization parameters and an automatic optimization procedure were proposed. As for the two-mass model, the stability and reliability of the method was validated by the application to synthetic data. Finally, 
the method was applied to clinical data. The obtained optimization parameters reflected individual properties of the vocal fold oscillations. The different voice disorders evaluated in this study were mapped to different domains within the parameter space. The calculated parameter combinations were comprehensible by accounting the specific characteristics of the voice disorders.

A further useful extension of the biomechanical vocal fold model will be the introduction of time-dependent model parameters. For historical reasons, the conventional clinical examination of vocal fold vibrations is done during stationary, sustained phonation. However, the conclusions drawn from a stationary phonation are restricted to the observed steady-state vocal fold vibrations and cannot be generalized to voice mechanisms during running speech. Recently, high-speed recordings of non-stationary vocal fold oscillations were successfully classified with a time-dependent one-dimensional model [131].

In Chapter 7 a biomechanical model of the PE segment is derived from the multi-mass model. Compared to the extracted vocal fold dynamics used for fitting the two-mass model and the multi-mass model, the PE dynamics is described by a time-variant contour and not by one-dimensional trajectories. Therefore, an objective function was defined which accounts for the frequency and amplitude as well as the time-varying shape of the PE segment oscillations. The proposed model-based quantification was successfully validated with a synthetic data set and applied to six highspeed recordings in a first study. In all cases frequency and amplitude of the PE segment vibration as well as the time-variant contour were reproduced with sufficient accuracy. These results demonstrate the potential of the model-based approach for an objective quantification of the substitute voice generation.

The further intention of evaluating high-speed recordings of the PE segment with the model-based approach is the classification of PE segment vibration patterns concerning the resulting substitute voice quality. Together with recordings of the acoustic substitute voice signal the optimization parameters calculated by the optimization procedure constitute the basis for this aim. Using the classification results, methods for improving the voice rehabilitation concerning the quality of the substitute voice can be developed. 


\section{Zusammenfassung und Ausblick}

Die zwischenmenschliche lautsprachliche Kommunikation basiert auf der Erzeugung und Wahrnehmung von Sprache. Dabei dient das Stimmsignal als Träger für das Sprachsignal. Erzeugt wird das Stimmsignal durch Stimmlippenschwingungen im Kehlkopf. Eine gesunde Stimme ist die Voraussetzung für die Produktion verständlicher Sprache und damit einer effizienten verbalen Kommunikation. Da die sprachliche Verständigung besonders auf dem beruflichen Sektor zunehmend wichtiger wird, gewinnt die Erforschung und Behandlung von Stimmstörungen an wirtschaftlicher Bedeutung.

Die Erzeugung eines gesunden Stimmsignals erfordert wie in Kapitel 2 beschrieben ein koordiniertes Zusammenspiel zwischen verschiedenen Kehlkopfmuskeln um ein reguläres Schwingungsmuster der Stimmlippen zu erhalten. Aufgrund verschiedener Pathologien kann dieser Vorgang gestört sein. Die Folge sind irreguläre Schwingungen der Stimmlippen und damit eine heisere Stimme. Im extremsten Fall muss aufgrund eines Kehlkopfkarzinoms der gesamte Kehlkopf zusammen mit den stimmgebenden Stimmlippen entfernt werden und der Mensch verliert zunächst die Fähigkeit zu sprechen. Nach heutigem Stand der Technik dient die tracheo-esophageale Ersatzstimme für eine Rehabilitation der Stimmgebung. Deren Prinzip wurde ebenfalls in Kapitel 2 vorgestellt. Gewebe im oberen Bereich der Speiseröhre (PE-Segment) wird als neuer Tongenerator verwendet. Diese Ersatzstimmtechnik ermöglicht dem Patienten eine eingeschränkte lautsprachliche Kommunikation.

Die Qualität der Stimme hängt von den Schwingungseigenschaften des stimmgebenden Elements ab. Dies gilt sowohl für die normale Stimme als auch für die tracheo-esophageale Ersatzstimme. In Kapitel 3 wurde die en- 
doskopische Aufnahmetechnik mittels digitalen Hochgeschwindigkeitskameras erläutert. Sie ermöglicht eine Aufnahme der Schwingungen des Tongenerators mit ausreichender zeitlicher Aufösung. Die Bildverarbeitungsalgorithmen wie sie in Kapitel 4 beschrieben wurden, liefern die Dynamik des Tongenerators: 1.) Die Öffnung, welche die Stimmlippen bzw. das PE-Segment bilden, wird segmentiert. 2.) Die Stimmlippendynamik ist definiert als die Abweichung der Stimmlippenkante von der glottalen Achse. Die PE-Dynamik wird durch den zeitvarianten Flächeninhalt der segmentierten Kontur beschrieben.

Die vorliegende Arbeit beschäftigte sich mit der modellbasierten objektiven Quantifizierung der Dynamik des Tongenerators während der Stimmgebung. Für diese Aufgabe wurden biomechanische Modelle der stimmgebenden Elemente eingeführt. Unter Verwendung hierfür entwickelter Prozeduren zur Parameteroptimierung wurde die Modelldynamik automatisch an die Schwingungsmuster der Stimmlippen bzw. des PE-Segments angepasst.

In Kapitel 5 fand das sogenannte Zwei-Massen-Modell der Stimmlippen Anwendung zur Klassifizierung von gesunden und pathologischen Stimmlippenschwingungen bei einseitigen Stimmlippenlähmungen. Innerhalb dieses Modells wird jede Stimmlippe durch ein Paar gekoppelter Masse-FederOszillatoren repräsentiert. Durch einen subglottalen Überdruck entsteht ein Luftstrom der die Massen des Models zu Schwingungen anregt. Beschrieben wurde der Luftstrom mit Hilfe der Bernoulligleichung. Zwei Optimierungsparameter wurden definiert um die Standardwerte für die Massen, der Federsteifigkeiten und des subglottalen Überdrucks zu variieren. Auf diese Weise wird die Amplitude und Frequenz der Modellschwingung an die der tatsächlichen Bewegungsmuster angepasst. Die Einführung zwei weiterer Parameter $Q_{k 1}$ und $Q_{k c}$ ermöglicht asymmetrische Modellkonfigurationen. Damit wurde die Reproduktion der spezifischen Wellenformen und der Links-Rechts-Asymmetrien als Folge einseitiger Stimmlippenlähmungen ermöglicht. Die vorgeschlagen Prozedur zur Parameteroptimierung ist unterteilt in eine wissensbasierte Startwertsuche und einem genetischen Suchalgorithmus. Mit Hilfe synthetisch generierter Schwingungskurven wurde die Zuverlässigkeit der Optimierung belegt. Die Auswertung der Ergebnisse für die Parameter $Q_{k 1}$ und $Q_{k c}$ ermöglichte die Definition eines Schemas zur Klassifizierung von gesunden und pathologischen Stimmlippenschwingungen anhand einer Unterteilung des Param- 
eterraums. Neben der Identifizierung einseitiger Paresen konnte ebenso der Grad der Stimmstörung klassifiziert werden. Die vorgeschlagene modellbasierte Quantifizierung und Klassifizierung repräsentiert die Basis für die weitere Entwicklung von medizinischen Methoden zur Unterstützung von Therapieauswahl und Quantifizierung des Therapieergebnisses. Der nächste Schritt in diese Richtung ist die Auswertung größerer klinischer Datensätze.

Kapitel 6 behandelte die Erweiterung des Ansatzes basierend auf dem ZweiMassen-Modell um neben der zeitlichen auch die räumliche Information für die Bewertung von Stimmlippenschwingungen zu nutzen. Hierfür wurde das Zwei-Massen-Modell zweidimensional auf das Mehr-Massen-Modell erweitert. Mehrere longitudinal gekoppelten Masse-Feder-Oszillatoren werden entlang der Stimmlippe positioniert. Zur Anpassung der Modelldynamik an Stimmlippenschwingungen wurden Optimierungsparameter und ein Algorithmus zur automatischen Parameteroptimierung eingeführt. Wie für das Zwei-Massen-Modell dienten synthetische Datensätze für den Nachweis der Stabilität und Verlässlichkeit der Optimierungsergebnisse. Die Ergebnisse für die Optimierungsparameter aufgrund der Auswertung von klinischen Datensätzen geben die individuellen Schwingungseigenschaften der Stimmlippen wieder. Unterschiedliche Stimmstörungen dieser Studie wurden auf unterschiedliche Parameterbereiche abgebildet. Die erzielten Parameterkombinationen waren plausibel hinsichtlich der charakteristischen Merkmale der Stimmstörungen.

Eine sinnvolle Erweiterung des Mehr-Massen-Modells wäre die Einführung zeitabhängiger Modellparameter. Aus historischen Gründen wird die konventionelle klinische Untersuchung von Stimmlippenschwingungen anhand stationärer Stimmlippenschwingungen bei gehaltener Phonation durchgeführt. Allerdings sind die Schlussfolgerungen welche durch Auswertung der stationären Phonation möglich sind auf den beobachteten eingeschwungenen Zustand beschränkt und können nicht auf die Mechanismen der Alltagssprache verallgemeinert werden. In einer aktuellen Arbeit konnten Hochgeschwindigkeitsaufnahmen instationärer Stimmlippenschwingungen mit einem zeitabhängigen Zwei-Massen-Modell klassifiziert werden [131].

Ein biomechanisches Modell des PE-Segments wurde in Kapitel 7 vom Mehr-Massen-Modell abgeleitet. Im Gegensatz zur Stimmlippendynamik dienten zur Beschreibung der Dynamik des PE-Segments keine diskreten 
Bewegungskurven sondern die segmentierte zeitveränderliche Kontur der Öffnung des PE-Segments. Daher wurde eine Zielfunktion definiert, welche neben Frequenz und Amplitude ebenso die Form der schwingenden Kontur berücksichtigt. Die vorgeschlagene modellbasierte Quantifizierung wurde erfolgreich mit synthetischen Datensätzen verifiziert und in einer ersten Studie auf sechs Hochgeschwindigkeitsaufnahmen des PE-Segments angewendet. In allen Fällen konnten sowohl Frequenz und Amplitude der Schwingung des PE-Segments als auch die Form der zeitveränderlichen Öffnung mit ausreichender Genauigkeit reproduziert werden. Dieses Ergebnis zeigt die Anwendbarkeit des modellbasierten Ansatzes zur objektiven Quantifizierung des ersatzstimmgebenden Prozesses.

Weitere Zielsetzung der modellbasierten Auswertung von Hochgeschwindigkeitsaufnahmen des PE-Segments ist die Klassifizierung der Schwingungsmuster hinsichtlich der resultierenden Qualität der Ersatzstimme. Zusammen mit Aufnahmen des akustischen Ersatzstimmsignals bilden die berechneten Optimierungsparameter die hierfür erforderliche Basis. Die Auswertung der Klassifizierungsergebnisse ermöglicht die Entwicklung medizinischer Methoden zur Verbesserung der Stimmrehabilitation bezüglich der erreichbaren Stimmqualität und damit der Lebensqualität der betroffenen Patienten. 
A PE-MMM Fitting Results 
S1, male, age 64, Recording R1
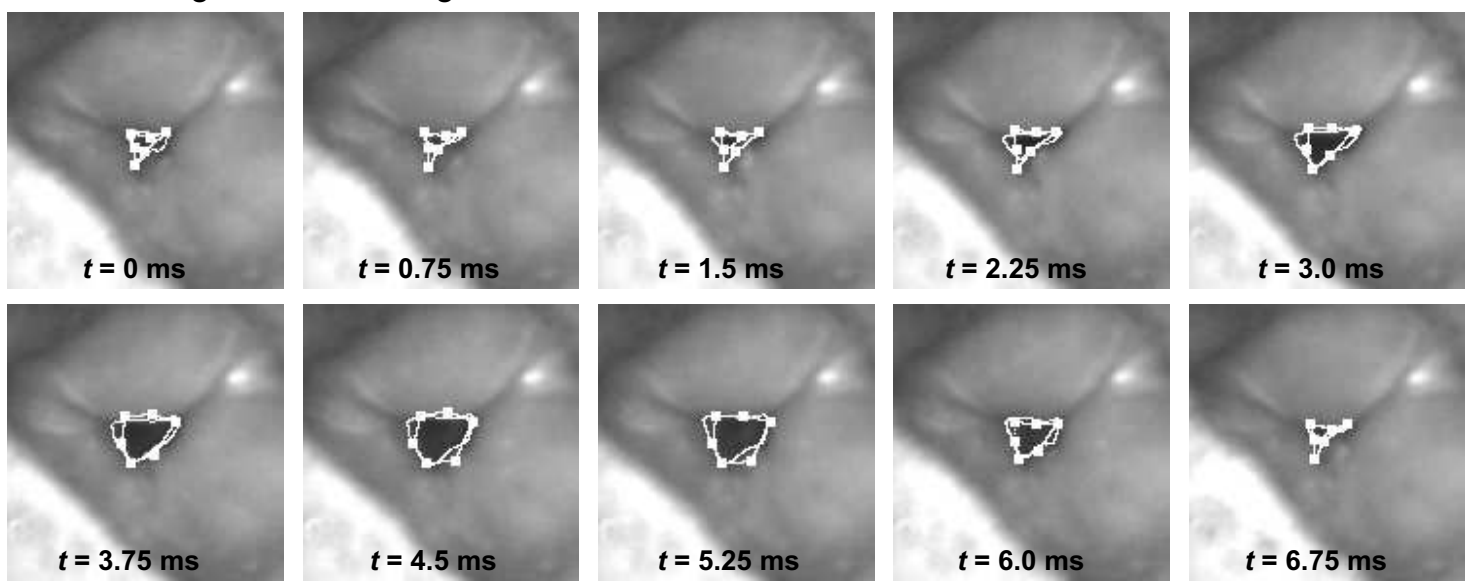

S2, male, age 56, Recording R2
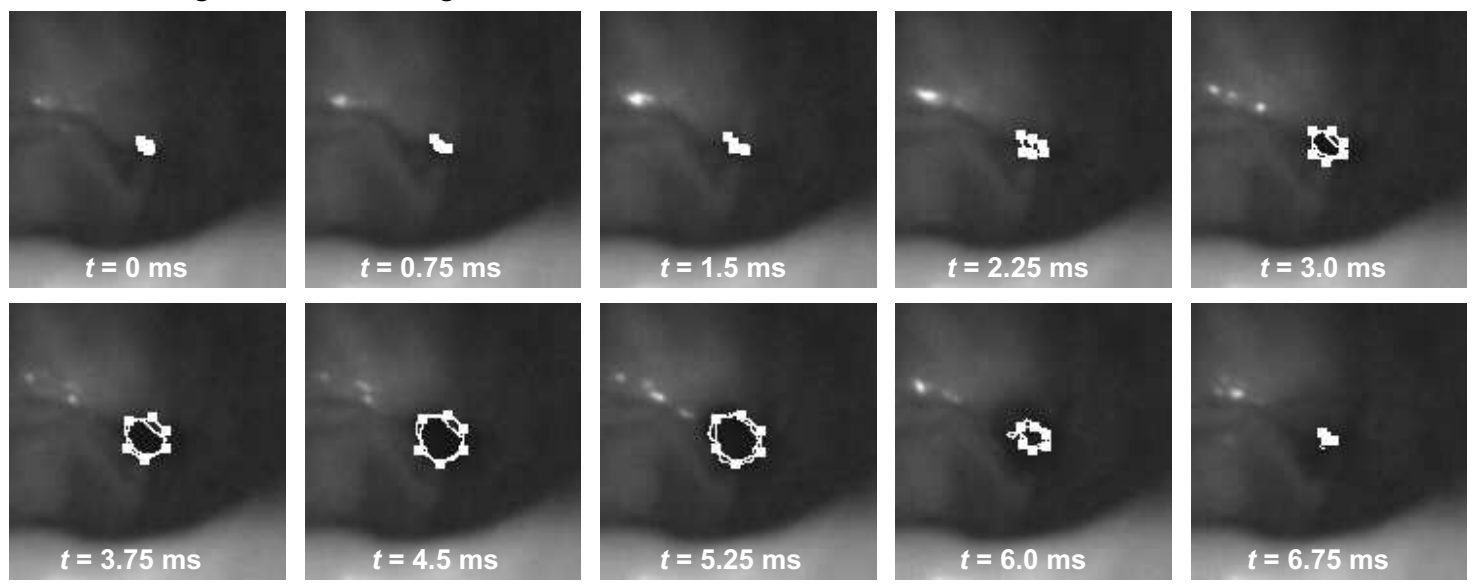

S3, male, age 57, Recording R3
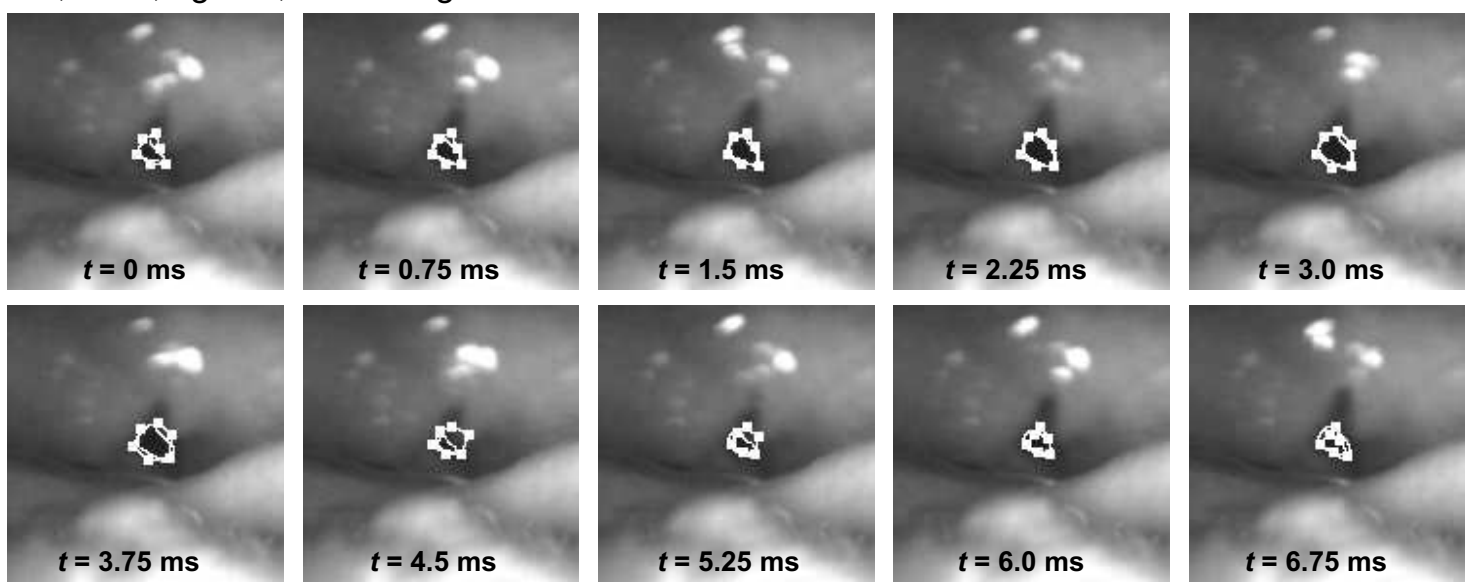

Figure A.1: Fitting of the PE-MMM to recording $R 1$ to $R 3$. In each frame the segmentation result of the image processing (white line near the tissue of the PE segment) and the actual state of the PE-MMM (white lines with white squares, indicating the position of the oscillating elements) is shown. 
S4, male, age 63 , Recording R4
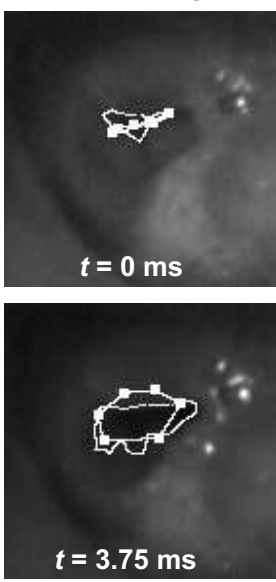
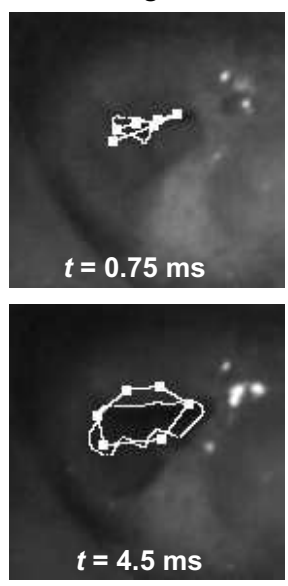

$t=4.5 \mathrm{~ms}$
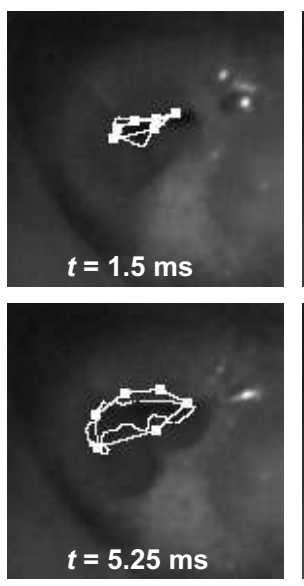

$\boldsymbol{t}=\mathbf{5 . 2 5} \mathrm{ms}$

S5, male, age 68, Recording R5
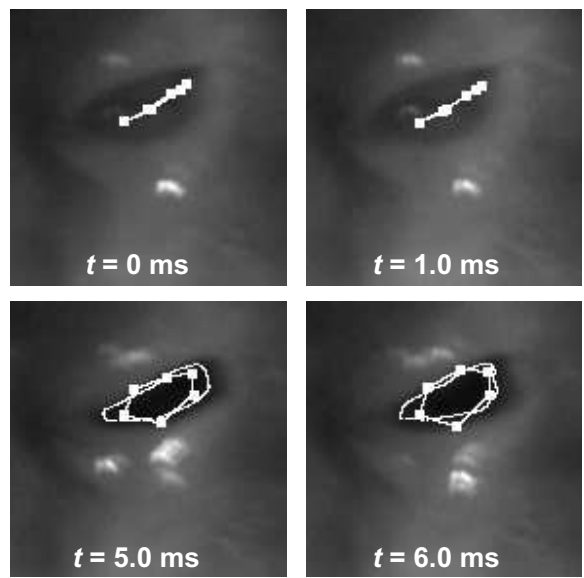

$t=6.0 \mathrm{~ms}$
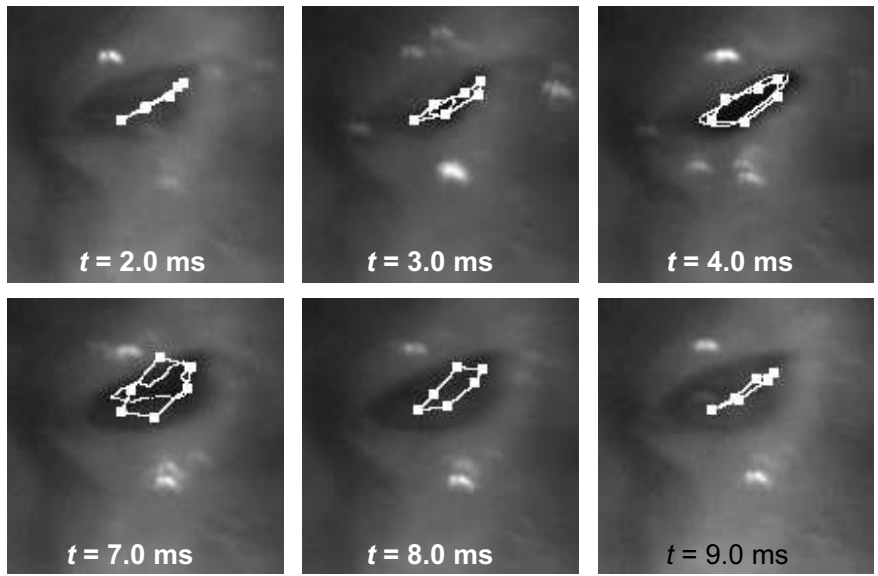

S6, male, age 59, Recording R6
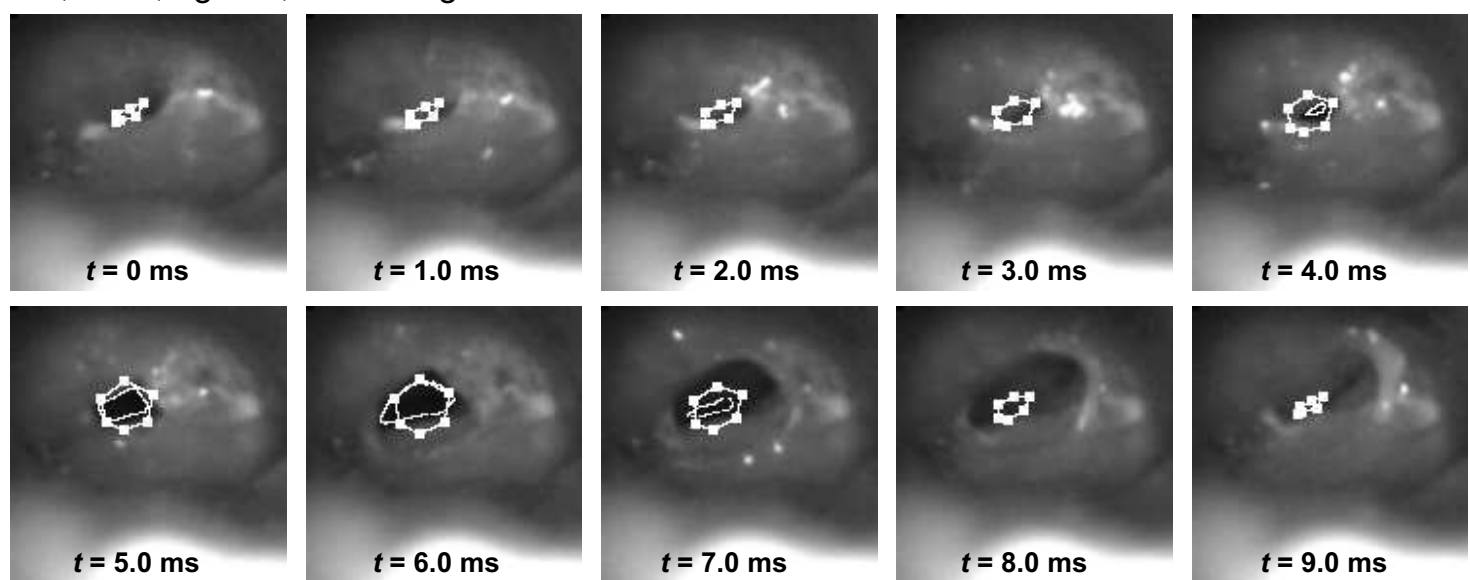

Figure A.2: Fitting of the PE-MMM to recording $R_{4}$ to $R 6$. 


\section{List of Abbreviations}

$\begin{array}{ll}2 \mathrm{MM} & \text { Two-Mass Model } \\ \text { ac } & \text { Anterior Commissure } \\ \text { CNS } & \text { Central Nervous System } \\ \text { GA } & \text { Genetic Algorithm } \\ \text { HNR } & \text { Harmonic-to-Noise Ratio } \\ \text { J } & \text { Jitter } \\ \text { MMM } & \text { Multi-Mass Model } \\ \text { NNE } & \text { Normalized Noise Energy } \\ \text { pc } & \text { Posterior Commissure } \\ \text { PE } & \text { Pharyngeal-Esophageal } \\ \text { RLNP } & \text { Recurrent Laryngeal Nerve Paralysis } \\ \text { ROI } & \text { Region of Interest } \\ \text { S } & \text { Shimmer }\end{array}$




\section{Bibliography}

[1] J. Wendler, W. Seidner, G. Kittel, and U. Eysholdt, Lehrbuch der Phoniatrie und Pädaudiologie. Stuttgart, New York: Georg Thieme Verlag, 1996.

[2] S. Pollack, Statistical forecasts of the United States. New York: Gale Research, 1995.

[3] I. R. Titze, J. Lemke, and D. Montequin, "Populations in the U.S. workforce who rely on voice as a primary tool of trade: A preliminary report," J Voice, vol. 11, pp. 254-259, 1997.

[4] R. J. Ruben, "Redefining the survival of the fittest: Communication disorders in the 21st century," Laryngoscope, vol. 110, pp. 241-245, 2000 .

[5] D. Kruse, "Employment and Disability: Characteristics of employed and non-employed people with disabilities," US Department of Labor, Washington, DC, Tech. Rep., 1997.

[6] K. Ishizaka and J. L. Flanagan, "Synthesis of voiced sounds from a two-mass model of the vocal cords," Bell Syst. Techn. J., vol. 51, pp. 1233-1268, 1972.

[7] I. Steinecke and H. Herzel, "Bifurcations in an asymmetric vocal fold model," J. Acoust. Soc. Am., vol. 97, pp. 1571-1578, 1995.

[8] C. van As, M. Tigges, T. Wittenberg, B. op de Coul, and U. Eysholdt, "High-speed digital imaging of neoglottic vibration after total laryngectomy," Arch. Otolaryngol. Head Neck Surg., vol. 125, pp. 891-897, 1999. 
[9] M. Schuster, F. Rosanowski, R. Schwarz, U. Eysholdt, and J. Lohscheller, "Quantitative detection of substitute voice generator during phonation in patients undergoing laryngectomy," Arch. Otolaryngol. Head Neck Surg., vol. 131, pp. 945-952, 2005.

[10] I. R. Titze, "Measurements for the assessment of voice disorders," in Proceedings of the 1990 NIDCD Conference, J. Cooper, Ed., 1991, pp. $42-47$.

[11] M. Tigges, T. Wittenberg, F. Rosanowski, and U. Eysholdt, "Highspeed imaging and image processing in voice disorders," in Optical and imaging techniques for biomonitoring II, H.-J. Foth, R. Marchesini, and H. Podbieslska, Eds. Wien: Proc. SPIE 2927, 1996, pp. 209-215.

[12] S. Niimi and M. Miyai, "Vocal fold vibration and voice quality," Folia Phoniatr. Logop., vol. 52, pp. 32-38, 2000.

[13] U. Hoppe, Mechanism of hoarseness - visualization and interpretation by means of nonlinear dynamics. Aachen: Shaker Verlag, 2001.

[14] S. McCoy, Your voice: An inside view. Rider: Rider University, 2002 .

[15] I. R. Titze, Principles of voice production. Englewood Cliffs: Prentice-Hall, 1994.

[16] E. Schönhärl, Die Stroboskopie in der Laryngologie. Stuttgart: Thieme Verlag, 1960.

[17] A. Smit, L. Hand, J. Freilinger, and J. Bernthal, "The Iowa articulation norms project and its Nebraska replication," J. Speech Hear. Disord., vol. 55, pp. 779-798, 1990.

[18] N. Isshiki, M. Tanabe, K. Ishizaka, and D. Broad, "Clinical significance of asymmetrical vocal cord tension," Ann. Otol. Rhinol. Laryngol., vol. 86, pp. 58-66, 1977.

[19] M. Hermann-Röttgen and E. Miethe, Unsere Stimme. Idstein: Schulz-Kirchner Verlag, 2006. 
[20] R. J. Baken and R. F. Orlikoff, Clinical measurement of speech and voice. San Diego: Singular Publishing Group, 2000.

[21] C. A. Rosen and T. Murry, "Nomenclature of voice disorders and vocal pathology," Otolaryngol. Clin. North Am., vol. 33, pp. 10351046, 2000.

[22] P. Dejonckere, P. Bradley, P. Clemente, G. Cornut, L. CrevierBuchman, G. Friedrich, P. V. D. Heyning, M. Remacle, and V. Woisard, "A basic protocol for functional assessment of voice pathology, especially for investigating the efficacy of (phonosurgical) treatments and evaluating new assessment techniques," Eur. Arch. Otorhinolaryngol., vol. 258, pp. 77-82, 2001.

[23] G. Böhme, Sprach-, Sprech-, Stimm- und Schluckstörungen. Stuttgart: Gustav Fischer Verlag, 1997, vol. 1.

[24] B. H. Story, "Physical modeling of voice and voice quality," in Proceedings of VOQUAL03, Geneva, Switzerland, 2003.

[25] I. R. Titze and B. H. Story, "Rules for controlling low-dimensional vocal fold models with muscle activation," J. Acoust. Soc. Am., vol. 112, pp. 1064-1076, 2002.

[26] M. Hirano, "Structure and vibratory behavior of the vocal folds," in Dynamic aspects of speech production, M. Sawashima and S. C. Franklin, Eds. Tokyo: University of Tokyo Press, 1977, pp. 13-30.

[27] K. N. Stevens, "Physics of laryngeal behavior and larynx modes," Phonetica, vol. 34, pp. 264-279, 1977.

[28] M. Hirano, "Morphological structure of the vocal cord as a vibrator and its variations," Folia Phoniatr. Logop., vol. 26, 1974.

[29] M. Hirano, S. Kurita, and T. Nakashima, "The structure of the vocal folds," in Vocal fold physiology, K. Stevens and M. Hirano, Eds. Tokyo: University of Tokyo Press, 1981, pp. 33-41.

[30] O. Fujimura, "Body-cover theory of the vocal fold and its phonetic implications," in Vocal fold physiology, K. Stevens and M. Hirano, Eds. University of Tokyo Press, 1981, ch. 19, pp. 271-288. 
[31] M. Hirano and Y. Kakita, "Cover-body theory of vocal cord vibration," in Speech science, R. Daniloff, Ed. San Diego: College Hill Press, 1985, pp. 1-46.

[32] M. Hirano and K. Sato, Histological color atlas of the human larynx. San Diego: Singular Publishing, 1993.

[33] I. R. Titze and E. J. Hunter, "Normal vibration frequencies of the vocal ligament," J. Acoust. Soc. Am., vol. 115, pp. 2264-2269, 2004.

[34] W. Tonndorf, "Die Mechanik bei der Stimmlippenschwingung und beim Schnarchen," Z. Hals-, Nasen- u. Ohrenheilk., vol. 12, pp. 214$245,1925$.

[35] J. van den Berg, "Myoelastic-aerodynamic theory of voice production," J. Speech Hear. Res., vol. 1, pp. 227-244, 1958.

[36] G. Fant, Acoustic theory of speech production. Hague Mouton, 1960.

[37] S. Krischke, S. Weigelt, and U. Hoppe, "Quality of life in dysphonic patients," J. Voice, vol. 19, pp. 132-137, 2005.

[38] S. M. Cohen, W. D. Dupont, and M. S. Courey, "Quality-of-life impact of non-neoplastic voice disorders: A meta-analysis," Ann. Oto. Rhinol. Laryn., vol. 115, pp. 128-134, 2006.

[39] R. T. Sataloff, Professional Voice - the science and art of clinical care. San Diego, London: Singular Publishing Group Inc., 1997.

[40] R. Matthesius, K. Jochheim, and G. Barolin, Eds., ICIDH, international classification of impairements, dissabilities, and handicaps. Bern: Verlag Huber, 1999.

[41] International statistical classification of diseases and related health problems, 10th revision (ICD-10), 2nd ed., World Health Organization, Geneva, 2005.

[42] M. Schuntermann, Einführung in die ICF. Landsberg: Ecomed Verlag, 2007. 
[43] U. Eysholdt, M. Tigges, T. Wittenberg, and U. Proeschel, "Direct evaluation of high-speed recordings of vocal fold vibrations," Folia Phoniatr. Logop., vol. 48, pp. 163-170, 1996.

[44] J. Svec and H. K. Schutte, "Videokymography: High-speed line scanning of vocal fold vibrations," J. Voice, vol. 10, pp. 201-205, 1996.

[45] H. Tucker, Surgery for phonatory disorders. New York: Churchill Livingstone, 1981.

[46] F. Klingholz, "Zur Fragwürdigkeit der Diagnose der weiblichen hypofunktionellen Dysphonie primären Typs," Sprache - Stimme - Gehör, vol. 14, pp. 179-180, 1990.

[47] D. M. Parkin, P. Pisani, and J. Ferlay, "Global cancer statistics," CA Cancer J. Clin., vol. 49, pp. 33-64, 1999.

[48] D. DeRienzo, S. Greenberg, and A. Fraire, "Carcinoma of the larynx. Changing incidence in women." Arch. Otolaryngol. Head Neck Surg., vol. 117, pp. 681-684, 1991.

[49] J. Shah, Ed., Cancer of the head and neck. Hamilton: BC Decker Inc., 2001.

[50] W. J. Blot, J. K. McLaughlin, and D. M. Winn, "Smoking and drinking in relation to oral and pharyngeal cancer," Cancer Res., vol. 48, pp. 3282-3287, 1988.

[51] J. D. Dahm, D. G. Sessions, R. C. Paniello, and J. Harvey, "Primary subglottic cancer," Laryngoscope, vol. 108, pp. 741-746, 1998.

[52] H. Maier and H. Johannsen, Eds., Stimmrehabilitation nach Laryngektomie. Ulm: Verlag Phoniatrische Ambulanz der Universität Ulm, 1995.

[53] P. Holinger, "The historical development of laryngectomy. A century of progress of laryngectomies in the northern hemisphere," Laryngoscope, vol. 85, pp. 322-332, 1975.

[54] H. Luckhaupt, "Geschichte der Kehlkopf- und Trachealchirurgie im 19. Jahrhundert," Laryngo. Rhino. Otol., vol. 79, pp. 657-658, 2000. 
[55] H. A. J. Brok, R. J. Stroeve, M. P. Copper, and P. F. Schouwenburg, "The treatment of hypertonicity of the pharyngo-oesophageal segment after laryngectomy," Clin. Otolaryngol., vol. 23, pp. 302-307, 1998.

[56] M. Schuster, H. Toy, J. Lohscheller, U. Eysholdt, and F. Rosanowski, "Lebensqualität und Stimmbeeinträchtigung Laryngektomierter mit Stimmventilprothese," Laryngo. Rhino. Otol., vol. 84, pp. 101-107, 2005 .

[57] H. Choi, Y. Park, S. Lee, and K. Kim, "Functional characteristics of a new electrolarynx 'eveda' having a force sensing resistor sensor," J. Voice, vol. 15, pp. 592-599, 2001.

[58] S. Salmon, "Methods of air intake for esophageal speech and their associated problems," in Laryngectomee Rehabilitation, R. Keith and F. Darley, Eds. Austin, Texas: Pro-ed, 1994.

[59] E. Blom, "Tracheoesophageal voice restoration: origin - evolution state of the art," Folia Phoniatr. Logop., vol. 52, pp. 14-23, 2000.

[60] J. Dworkin, R. Meleca, M. Zormeier, M. Simpson, I. Garfield, J. Jacobs, and R.Mathog, "Videostroboscopy of the pharyngoesophageal segment in total laryngectomy," Laryngoscope, vol. 108, pp. 17731781, 1998.

[61] C. K. Oh, R. J. Meleca, M. L. Simpson, and J. P. Dworkin, "Fiberoptic examination of the pharyngoesophageal segment in tracheoesophageal speakers," Arch. Otolaryngol. Head Neck Surg., vol. 128, pp. 692-697, 2002.

[62] D. Z. Huang, F. D. M. H. Kasuya, and S. X. Lin, "Measures of vocal function during changes in vocal effort level," J. Voice, vol. 9, pp. 429-438, 1995.

[63] S. Hadjitodorov and P. Mitev, "A computer system for acoustic analysis of pathological voices and laryngeal diseases screening," Med. Eng. Phys., vol. 21, pp. 419-429, 2002. 
[64] J. Godino-Llorente and P. Gomez-Vilda, "Automatic detection of voice impairments by means of short-term cepstral parameters and neural network based detectors," IEEE Trans. Biomed. Eng., vol. 51, pp. 380-384, 2004.

[65] S. Fleischer and M. Hess, "The significance of videostroboscopy in laryngological practice," HNO, vol. 54, pp. 628-634, 2006.

[66] U. Eysholdt, F. Rosanowski, and U. Hoppe, "Vocal fold vibration irregularities caused by different types of laryngeal asymmetry," Eur. Arch. Otorhinolaryngol., vol. 260, pp. 412-417, 2003.

[67] P. Kitzing, "Stroboscopy - a pertinent laryngological examination," J. Otolaryngol, vol. 14, pp. 151-157, 1985.

[68] H. Hirose, "High-speed digital imaging of vocal fold vibrations," Acta Otolaryngol., vol. 458, pp. 151-153, 1988.

[69] R. T. Sataloff, J. R. Spiegel, and M. J. Hawkshaw, "Strobovideolaryngoscopy: Results and clinical value," Anal. Otorhinolaryngol., vol. 100, pp. 725-727, 1991.

[70] M. Hirano and D. M. Bless, Videostroboscopic examination of the larynx. San Diego: Singular Publishing, 1993.

[71] M. Tigges, T. Wittenberg, P. Mergell, and U. Eysholdt, "Imaging of vocal fold vibration by digital multi-plane kymography," Comput. Med. Imag. Grap., vol. 23, pp. 323-330, 1999.

[72] J. Neubauer, P. Mergell, U. Eysholdt, and H. Herzel, "Spatiotemporal analysis of irregular vocal fold oscillations: Biphonation due to desynchronization of spatial modes," J. Acoust. Soc. Am., vol. 110, pp. 3179-3192, 2001.

[73] D. Farnsworth, "High-speed motion pictures of the human vocal cords," Bell Lab. Rec., vol. 18, pp. 203-208, 1940.

[74] R. Luchsinger, "Der zeitliche Ablauf der Stimmritzveränderung bei Zeitlupenaufnahmen der Stimmlippenbewegung," Folia Phoniatr., vol. 6, pp. 14-19, 1954. 
[75] J. R. Booth and D. G. Childers, "Automated analysis of ultra highspeed laryngeal films," IEEE Trans. Biomed. Eng., vol. 26, pp. 185192, 1979.

[76] M. Moser and G. Kittel, "Darstellung der Stimmlippenbewegung mittels digitaler Hochgeschwindigkeitserfassung," Sprache-StimmeGehör, pp. 74-77, 1990.

[77] S. Kiritani, H. Hirose, and H. Imagawa, "High-speed digital image analysis of vocal fold vibration in diplophonia," Speech Communication, vol. 13, pp. 23-32, 1993.

[78] U. Eysholdt, "Vocal fold pathophysiology and clinical practice - new developments," in Advances in Quantitative Laryngoscopy, T. Wittenberg, P. Mergell, M. Tigges, and U. Eysholdt, Eds. Göttingen: Verlag Abteilung Phoniatrie, 1997, pp. 1-4.

[79] M. Döllinger, Parameter estimation of vocal fold dynamics by inversion of a biomechanical model. Aachen: Shaker Verlag, 2002.

[80] J. Lohscheller, H. Toy, F. Rosanowski, U. Eysholdt, and M. Döllinger, "Clinically evaluated procedure for the reconstruction of vocal fold vibrations from endoscopic digital high-speed videos," Med. Image Anal., 2006, accepted 02/2007.

[81] T. Wittenberg, Wissensbasierte Bewegungsanalyse von Stimmlippenschwingungen anhand digitaler Hochgeschwindigkeitsaufnahmen. Aachen: Shaker Verlag, 1998.

[82] T. Wittenberg, M. Moser, M. Tigges, and U. Eysholdt, "Recording, processing and analysis of digital high-speed sequences in glottography," Mach. Vision Appl., vol. 8, no. 12, pp. 399-404, 1995.

[83] M. Tigges, C. van As, T. Wittenberg, F. Hilgers, and U. Eysholdt, "Direkte Beobachtung der tracheoösophagealen Phonation bei 46 Laryngektomierten," in Aktuelle phoniatrisch-pädaudiologische Aspekte 1989/1999, M. Gross, Ed., Heidelberg, 1999, pp. 131-133.

[84] S. Hirano, H. Kojima, K. Shoji, K. Kaneko, I. Tateya, R. Asato, and K. Omori, "Vibratory analysis of the neoglottis after surgical 
intervention of cricopharyngeal myotomy and implantation of tracheal cartilage," Arch. Otolaryngol. Head Neck Surg., vol. 125, pp. 1335-1340, 1999.

[85] J. Lohscheller, M. Döllinger, M. Schuster, R. Schwarz, U. Eysholdt, and U. Hoppe, "Quantitative investigation of the vibration pattern of the substitute voice generator," IEEE Trans. Biomed. Eng., vol. 51, no. 8, pp. 1394-1400, 2004.

[86] A. K. Saadah, N. P. Galatsanos, D. M. Bless, and C. A. Ramos, "Deformation analysis of the vocal folds from videostroboscopic image sequences of the larynx," J. Acoust. Soc. Am., vol. 103, pp. 36273641, 1998.

[87] S. Allin, J. Galeotti, G. D. Stetten, and S. H. Dailey, "Enhanced snake-based segmentation of vocal folds," in IEEE International Symposium on Biomedical Imaging, Washington, DC, 2004, pp. 812815 .

[88] Y. Yan, K. Ahmad, M. Kunduk, and D. M. Bless, "Analysis of vocal fold vibrations from high-speed laryngeal images using a Hilbert transform based methodology," J. Voice, vol. 19, pp. 161-175, 2005.

[89] Q. J. Qiu, H. K. Schutte, L. Gu, and Q. L. Yu, "An automatic method to quantify the vibration properties of human vocal folds via videokymography," Folia Phoniatr. Logop., vol. 55, pp. 128-136, 2003.

[90] M. Döllinger, T. Braunschweig, J. Lohscheller, U. Eysholdt, and U. Hoppe, "Normal voice production: Computation of driving paramters from endoscopic digital high-speed images," Methods Inf. Med., vol. 42, pp. 271-6, 2003.

[91] J. Lohscheller, Dynamics of the laryngectomee substitute voice production. Aachen: Shaker Verlag, 2003.

[92] T. McInerney and D. Terzopoulos, "Deformable models in medical image analysis: A survey," Med. Image Anal., vol. 1, pp. 91-108, 1996. 
[93] G. Schade and F. Müller, "Hochgeschwindigkeitsglottographische Diagnostik in der Laryngologie," HNO, vol. 53, pp. 1085-1091, 2005.

[94] G. E. Woodson, "Configuration of the glottis in laryngeal paralysis. I: Clinical study," Laryngoscope, vol. 103, pp. 1227-1234, 1993.

[95] M. Döllinger, U. Hoppe, F. Hettlich, J. Lohscheller, S. Schubert, and U. Eysholdt, "Vibration parameter extraction from endoscopic image series of the vocal folds," IEEE Trans. Biomed. Eng., vol. 49, pp. 773-81, 2002.

[96] H. Jung and B. Schlager, "Recurrent laryngeal nerve paralysis after thyroidectomy," Laryng. Rhino. Otol., vol. 79, pp. 297-303, 2000.

[97] E. Yumoto, R. Minoda, M. Hyodo, and T. Yamagata, "Causes of recurrent laryngeal nerve paralysis," Auris. Nasus. Larynx, vol. 29, pp. 41-45, 2002.

[98] J. Müller, "Die palliativ-chirurgische Behandlung des Karzinoms der Speiseröhre," Med. Klinik, vol. 86, pp. 24-31, 1992.

[99] N. Bhattacharyya and M. P. Fried, "Assessment of the morbidity and complications of total thyroidectomy," Arch. Otolaryngol. Head Neck Surg., vol. 128, pp. 389-392, 2002.

[100] C. Y. Lo, K. F. Kwok, and P. W. Yuen, "A prospective evaluation of recurrent laryngeal nerve paralysis during thyroidectomy," Arch. Surg., vol. 135, pp. 204-207, 2000.

[101] J. Flanagan and L. Landgraf, "Self-oscillating source for vocal-tract synthesizers," IEEE Trans. Audio Electroacoustics, vol. 16, pp. 5764, 1968.

[102] K. Ishizaka and T. Kaneko, "On equivalent mechanical constants of the vocal cords," J. Acoust. Soc. Japan, vol. 24, pp. 312-313, 1968.

[103] K. Ishizaka and M. Matsudaira, "What makes the vocal cords vibrate," in The 6th International Congress on Acoustics, Tokyo, 1968, pp. 9-12. 
[104] I. R. Titze, "Comments on the myoelastic-aerodynamic theory of phonation," J. Speech Hear. Res., vol. 23, pp. 495-510, 1980.

[105] I. Titze, "The importance of vocal tract loading in maintaining vocal fold oscillations," in Proceedings of the Stockholm Musical Acoustics Conference, SMAC 1983, A. Askenfeld, S. Felicette, E. Jansson, J. Sundberg, and W. Savage, Eds. Royal Swedish Academy of Music, 1985, pp. 61-71.

[106] I. Bronstein, K. Semendjajew, G. Musiol, and H. Mühlig, Taschenbuch der Mathematik. Thun, Frankfurt am Main: Verlag Harri Deutsch, 1993.

[107] H. E. Gunter, "A mechanical model of vocal fold collision with high spatial and temporal resolution," J. Acoustic. Soc. Am., vol. 37, pp. 1119-1124, 2004.

[108] M. Döllinger, D. A. Berry, and G. S. Berke, "A quantitative study of the medial surface dynamics of an in vivo canine vocal fold during phonation," Laryngoscope, vol. 115, pp. 1646-1654, 2005.

[109] G. C. J. Hofmans, G. Groot, M. Ranucci, G. Graziani, and A. Hirschberg, "Unsteady flow through in-vitro models of the glottis," J. Acoust. Soc. Am., vol. 113, pp. 1658-1675, 2003.

[110] P. Mergell, Nonlinear dynamics of phonation - high-speed glottography and biomechanical modeling of vocal fold oscillations. Aachen: Shaker Verlag, 1998.

[111] B. H. Story and I. R. Titze, "Voice simulation with a body-cover model of the vocal folds," J. Acoust. Soc. Am., vol. 97, pp. 12491260, 1995.

[112] W. H. Press, S. A. Teukolsky, W. T. Vetterling, and B. P. Flannery, Numerical recipes in $C$. Cambridge: Cambridge University Press, 1994.

[113] P. Mergell, I. R. Titze, and H. Herzel, "Irregular vocal-fold vibration - high speed observation and modeling," J. Acoust. Soc. Am., vol. 108, pp. 2996-3002, 2000. 
[114] M. P. de Vries, H. K. Schutte, A. Veldmann, and G. J. Verkerke, "Glottal flow through a two-mass model: Comparison of NavierStokes solutions with simplified models," J. Acoust. Soc. Am., vol. 11, pp. 1847-1853, 2002.

[115] I. Tokuda and H. Herzel, "Detecting synchronizations in an asymmetric vocal fold model from time series data," Chaos, vol. 15, pp. 137-148, 2005.

[116] Y. Zhang and J. J. Jiang, "Chaotic vibrations of a vocal fold model with a unilateral polyp," J. Acoust. Soc. Am., vol. 115, pp. 1266$1269,2004$.

[117] C. Manfredi, Ed., Non-modal voice synthesis by low-dimensional physical models. Firenze University Press, 2003.

[118] D. Goldberg, Genetic algorithms in search, optimization and machine learning. Massachusetts: Addison-Wesley, 1989.

[119] C. R. Houck, J. A. Joines, and M. G. Kay, "A genetic algorithm for function optimization: A matlab implementation," NCSU-IE, Technical Report 09-95, 1995.

[120] D. Wong, M. Ito, N. Cox, and I. R. Titze, "Observation of perturbations in a lumped-element model of the vocal folds with application to some pathological cases," J. Acoust. Soc. Am., vol. 89, pp. 383-394, 1991.

[121] L. Meiteles, P. Lin, and E. Wenk, "An anatomic study of the external laryngeal framework with surgical implications," Otolaryngol. Head Neck Surg., vol. 106, pp. 235-240, 1992.

[122] Z. Milutinovic and J. Vasiljevic, "Contribution to the understanding of the etiology of vocal fold cysts: A functional and histologic study," Laryngoscope, vol. 102, pp. 568-571, 1992.

[123] U. Reker and H. Rudert, "Die modifizierte posteriore Chordektomie nach Dennis und Kashima bei der Behandlung beidseitiger Rekurrensparesen," Laryngo. Rhino. Otol., vol. 77, pp. 213-218, 1998. 
[124] G. Schade, M. Hess, M. Bubenheim, and J. Berger, "Gibt es ein einheitliches Vorgehen bei der Einteilung der Stimmlippen in Drittel?" Laryngo. Rhino. Otol., vol. 83, pp. 236-242, 2004.

[125] I. R. Titze, "Control of fundamental frequency with a body-cover model of the vocal folds," Bull. Audiophonologie. Ann. Sc. Univ. Franche-Comté, vol. 10, pp. 57-72, 1994.

[126] M. Hess, F. Mueller, J. B. Kobler, S. M. Zeitels, and E. Goodyer, "Measurements of vocal fold elasticity using the linear skin rheometer," Folia Phoniatr. Logop., vol. 58, pp. 207-216, 2006.

[127] J. Rigau, R. Farré, X. Trepat, D. Shusterman, and D. Navajas, "Oscillometric assessment of airway obstruction in a mechanical model of vocal cord dysfunction," J. Biomech., vol. 37, pp. 37-43, 2004.

[128] M. Schuster, P. Kummer, U. Eysholdt, and F. Rosanowski, "Quality of life in laryngectomees after prosthetic voice restoration," Folia Phoniatr. Logop., vol. 55, pp. 211-219, 2003.

[129] J. Lohscheller, M. Döllinger, R. Schwarz, U. Eysholdt, and U. Hoppe, "Modeling of the laryngectomee substitute voice," in Models and Analysis of Vocal Emissions for Biomedical Applications, C. Manfredi, Ed. Firenze University Press, 2003, pp. 19-22.

[130] M. Stiglmayr, R. Schwarz, K. Klamroth, G. Leugering, and J. Lohscheller, "Registration for high speed video sequences of the PE segment using assignment problems," in Proceedings of EURO XXI, Reykjavik, Iceland, 2006.

[131] T. Wurzbacher, R. Schwarz, M. Doellinger, U. Hoppe, U. Eysholdt, and J. Lohscheller, "Model-based classification of nonstationary vocal fold vibrations," J. Acoust. Soc. Am., vol. 120, pp. 1012-1027, 2006 . 


\section{List of Figures}

2.1 Schematic cross section of the head . . . . . . . . 7

2.2 Anatomy of the larynx . . . . . . . . . . . . 8

2.3 Transverse section of the larynx . . . . . . . . . . 8

2.4 Coronal section of the vocal folds . . . . . . . . . . 10

2.5 Cross section of the head after a laryngectomy . . . . . . 16

2.6 Respiration and voice production after laryngectomy . . . 18

3.1 Recording situation . . . . . . . . . . . . . 20

3.2 High-speed sequence . . . . . . . . . . . . . . . . . . . 21

3.3 Recording situation in case of laryngectomy . . . . . . . 22

3.4 High-speed sequence of the vibrating PE segment . . . . . 23

4.1 Illustration of the vocal fold dynamics . . . . . . . 26

4.2 Single-line extraction . . . . . . . . . . . . . . 27

4.3 Experimental curves . . . . . . . . . . . . . . . . . . . . 28

4.4 Multi-line extraction . . . . . . . . . . . . . . . . 29

4.5 Multi-line trajectories . . . . . . . . . . . . . 30

4.6 Segmented contours of the pseudoglottis . . . . . . . . 31

4.7 Description of the PE dynamics . . . . . . . . . . . 32

5.1 Trajectories of two subjects . . . . . . . . . . 34

5.2 Representation of the two-mass model . . . . . . . . 36

5.3 Phase difference $\Delta \phi$ as a function of $Q_{k 1}$ and $Q_{k c} \ldots \ldots .42$

5.4 Theoretical curves . . . . . . . . . . . . . . . 44

5.5 The non-convex objective function $\eta \ldots \ldots \ldots$

5.6 Flow chart of the initial value search procedure . . . . . 47

5.7 Convergence behavior of the fitness $-\eta \ldots \ldots \ldots$

5.8 Optimization parameters and predefined values $\ldots \ldots . \quad 52$

5.9 Optimization results within the parameter space $\left(Q_{k 1}^{*}, Q_{k c}^{*}\right) \quad 59$ 
5.10 Results of the subjects S2, S12, and S4 . . . . . . 61

6.1 Vocal fold vibration characteristics . . . . . . . . . 63

6.2 Representation of the multi-mass model . . . . . . . . . . 66

6.3 Free body diagram of an oscillating element . . . . . . . 67

6.4 Illustration of the anchor force as well as longitudinal and vertical coupling . . . . . . . . . . . . . . 69

6.5 Illustration of a single impact within the multi-mass model 70

6.6 Illustration of the driving force . . . . . . . . . . . 71

6.7 Model initialization . . . . . . . . . . . . . . . 75

6.8 Approximation using cubic B-splines . . . . . . . . . 78

$\begin{array}{ll}6.9 \text { Optimization results over the predefined parameter values } & 80\end{array}$

6.10 Vocal fold vibration patterns for the subjects S1 to S4 . . 82

6.11 Vocal fold vibration patterns for the subjects S5 to S8 . . 83

6.12 Rest positions used for the model initialization . . . . . . 85

6.13 Resulting vibration patterns for the optimized parameter values ................... 86

6.14 Dynamics of the fitted multi-mass model . . . . . . . 87

6.15 Correlation of the area functions . . . . . . . . . 87

6.16 Distribution of the values $Q_{i} \ldots \ldots \ldots$

7.1 The multi-mass model of the PE segment . . . . . . . . . 94

7.2 Intersection area between the contours of the multi-mass model and the segmented pseudoglottis. . . . . . . . . 98

7.3 Minimum distances $d_{i}$ of the masses to the contour of the pseudoglottis. . . . . . . . . . . . . . 9 98

7.4 Parameterized contour and approximation using cubic Bsplines . . . . . . . . . . . . . . . . 99

7.5 Optimization results over the predefined parameter values 100

A.1 Fitting of the PE-MMM to recording R1 to R3 . . . . 110

A.2 Fitting of the PE-MMM to recording R4 to R6 . . . . . 111 


\section{List of Tables}

5.1 Standard parameters of the two-mass model . . . . . . . 37

5.2 Experimental data of healthy voice subjects . . . . . . 54

5.3 Experimental data of paralytic voice subjects . . . . . 55

5.4 Optimization results of the healthy voice subjects . . . 56

5.5 Optimization results of the paralytic voice subjects . . . 58

6.1 Error between the optimization results and the predefined values . . . . . . . . . . . . . . . . . . . 79

6.2 Variation of the optimization results . . . . . . 80

6.3 Results for the optimization parameters $Q_{p}$ and $Q_{r} \ldots \ldots$

7.1 Error between the optimization results and the predefined

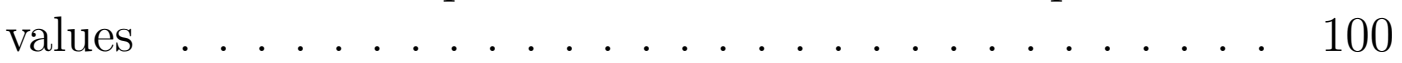

7.2 Variation of the optimization results . . . . . . . . 101

7.3 Results for the optimization parameters . . . . . . . . . . 102 


\section{Abbildungsverzeichnis}

2.1 Querschnitt des Kopfes und des Halses $\ldots . \ldots \ldots \ldots \ldots \ldots \ldots \ldots 7$

2.2 Anatomie des Kehlkopfes $\ldots \ldots \ldots \ldots \ldots \ldots \ldots \ldots \ldots \ldots \ldots$

2.3 Querschnitt des Kehlkopfes $\ldots \ldots \ldots \ldots \ldots \ldots \ldots \ldots \ldots \ldots \ldots$

2.4 Koronaler Schnitt der Stimmlippen $\ldots \ldots \ldots \ldots \ldots \ldots \ldots \ldots \ldots \ldots$

2.5 Querschnitt des Halses nach einer Laryngektomie ........... 16

2.6 Atmung und Stimmgebung nach einer Laryngektomie.......... 18

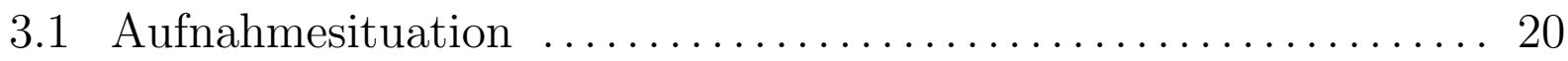

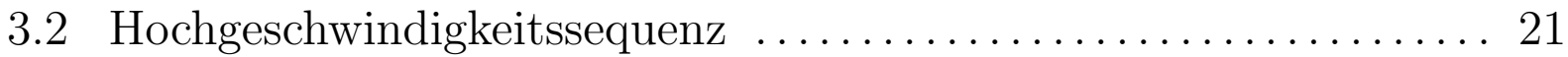

3.3 Aufnahmesituation bei Laryngektomierten $\ldots \ldots \ldots \ldots \ldots \ldots 22$

3.4 Aufnahme des schwingenden PE-Segments ............... 23

4.1 Darstellung der Stimmlippenschwingungen $\ldots \ldots \ldots \ldots \ldots \ldots \ldots$

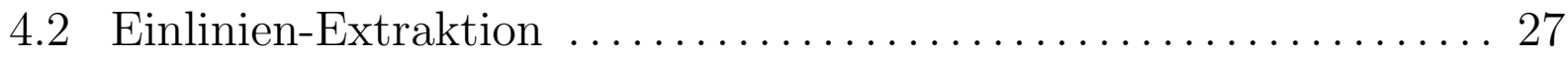

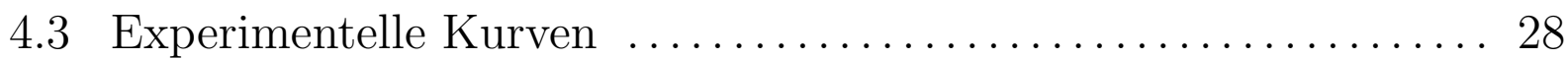

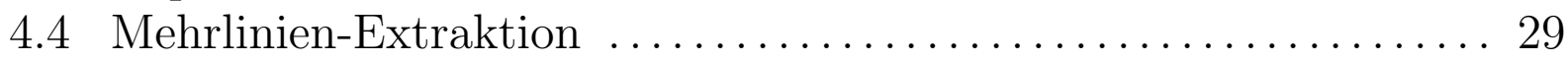

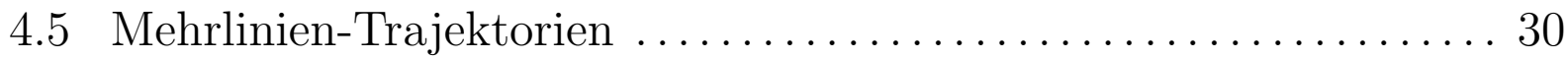

4.6 Segmentierte Konturen der Pseudoglottis $\ldots \ldots \ldots \ldots \ldots \ldots \ldots . \ldots 31$

4.7 Beschreibung der PE-Dynamik . ....................... 32

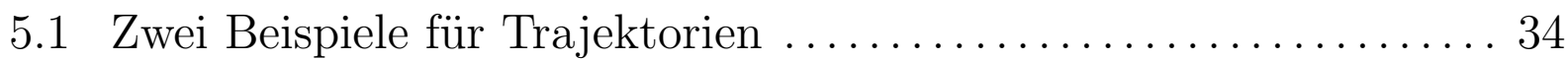

5.2 Darstellung des Zwei-Massen-Modells $\ldots \ldots \ldots \ldots \ldots \ldots \ldots \ldots$

5.3 Phasendifferenz $\Delta \phi$ als Funktion von $Q_{k 1}$ und $Q_{k c} \ldots \ldots \ldots \ldots 42$

5.4 Theoretische Kurven .............................. 44

5.5 Die nicht-konvexe Zielfunktion $\eta \ldots \ldots \ldots \ldots \ldots \ldots \ldots \ldots \ldots$

5.6 Flussdiagram der Startwertsuche $\ldots \ldots \ldots \ldots \ldots \ldots \ldots \ldots \ldots . \ldots 4$

5.7 Gesamtmittelwert des Konvergenzverhaltens der Fitness $-\eta \ldots . .51$

5.8 Berechnete über vordefinierte Werte der Optimierungsparameter 52

5.9 Optimierungsergebnisse im Parameterraum $Q_{k 1}^{*}, Q_{k c}^{*} \ldots \ldots \ldots .59$ 
5.10 Ergebnisse der Probanden S2, S12 und S4 .............. 61

6.1 Eigenschaften der Stimmlippenschwingung $\ldots \ldots \ldots \ldots \ldots \ldots 63$

6.2 Darstellung des Mehr-Massen-Modells .................. 66

6.3 Freikörperbild des schwingenden Elements $\ldots \ldots \ldots \ldots \ldots \ldots 67$

6.4 Darstellung von Ankerkraft, longitudinaler und vertikaler

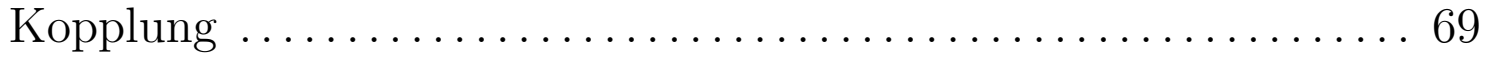

6.5 Darstellung einer einzelnen Kollision .................... 70

6.6 Darstellung der antreibenden Kraft ..................... 71

6.7 Initialisierung des Modells .......................... 75

6.8 Approximation mit kubischen B-Splines ............... 78

6.9 Berechnete und vordefinierte Werte der Optimierungsparameter . 80

6.10 Schwingungsmuster der Stimmlippen der Probanden S1 bis S4 . . 82

6.11 Schwingungsmuster der Stimmlippen der Probanden S5 bis S8 .. 83

6.12 Ruhepositionen nach der Modellinitialisierung ............. 85

6.13 Resultierend Schwingungsmuster nach der Optimierung ....... 86

6.14 Dynamik des angepassten Mehr-Massen-Modells ............ 87

6.15 Korrelation der Flächenfunktionen .................... 87

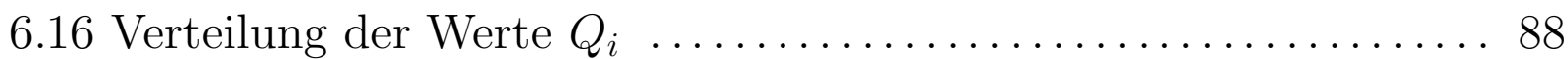

7.1 Das Mehr-Massen-Modell des PE-Segments ................. 94

7.2 Schnittflächen zwischen den Konturen des PE-Segments und des Mehr-Massen-Modells ........................... 98

7.3 Minimaler Abstand $d_{i}$ der Massen zur Kontur der Pseudoglottis . 98

7.4 Parametrisierte Kontur und Approximation mit kubischen

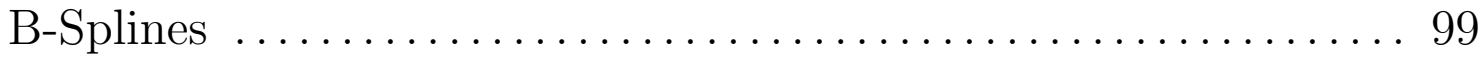

7.5 Berechnete und vordefinierte Werte der Optimierungsparameter 100

A.1 Anpassung des PE-MMM an die Aufnahmen R1 bis R3 ..... 110

A.2 Anpassung des PE-MMM an die Aufnahmen R4 bis R6 ..... 111 


\section{Tabellenverzeichnis}

5.1 Standardwerte des Zwei-Massen-Modells $\ldots \ldots \ldots \ldots \ldots \ldots \ldots . \ldots 37$

5.2 Experimentelle Daten der gesunden Probanden ............ 54

5.3 Experimentelle Daten der Probanden mit paralytischer

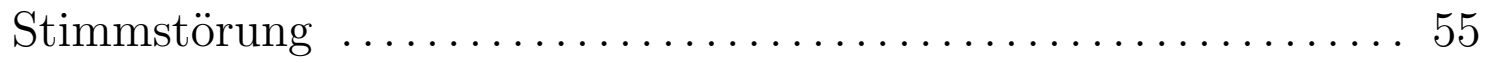

5.4 Optimierungsergebnisse der gesunden Probanden $\ldots \ldots \ldots \ldots \ldots 56$

5.5 Optimierungsergebnisse der Probanden mit paralytischer

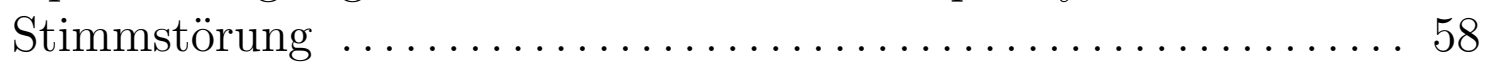

6.1 Fehler zwischen den Optimierungsergebnissen und den vordefinierten Werten ................................. 79

6.2 Streuung der Optimierungsergebnisse $\ldots \ldots \ldots \ldots \ldots \ldots \ldots \ldots$

6.3 Ergebnisse der Optimierungsparameter $Q_{p}$ and $Q_{r} \ldots \ldots \ldots . . . .89$

7.1 Fehler zwischen den Optimierungsergebnissen und den

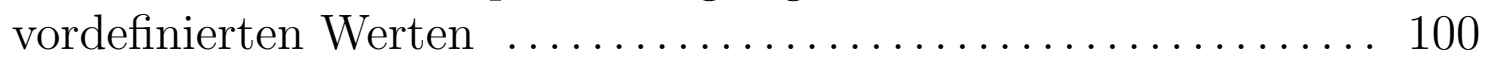

7.2 Streuung der Optimierungsergebnisse .................... 101

7.3 Ergebnisse der Optimierungsparameter $\ldots . \ldots \ldots \ldots \ldots \ldots \ldots . \ldots . \ldots . \ldots 2$ 


\section{Lebenslauf}

$\begin{array}{ll}\text { Name: } & \text { Schwarz } \\ \text { Vorname: } & \text { Raphael Richard } \\ \text { Geburtsdatum: } & \text { 16.02.1977 } \\ \text { Geburtsort: } & \text { München } \\ \text { Staatsangehörigkeit: } & \text { deutsch } \\ \text { Familienstand: } & \text { ledig, keine Kinder } \\ & \\ 1983-1985 & \text { Grundschule Hannberg } \\ 1985-1987 & \text { Grundschule Heroldsberg } \\ 1987-1996 & \text { Labenwolf-Gymnasium Nürnberg } \\ 09 / 1996-09 / 1997 & \text { Zivildienst }\end{array}$

11/1997 - 03/2003 Elektrotechnikstudium an der

Friedrich-Alexander-Universität Erlangen-Nürnberg

09/2002 - 03/2003 Diplomarbeit am Lehrstuhl

für Informationsübertragung der

Friedrich-Alexander-Universität Erlangen-Nürnberg

Thema: "Vorcodierung für dezentrale Empfänger"

seit 05/2003 Wissenschaftlicher Mitarbeiter an der Abteilung für Phoniatrie und Pädaudiologie der HNO-Klinik an der Friedrich-Alexander-Universität Erlangen-Nürnberg

$05 / 2007$ Promotion zum Doktor der Ingenieurwissenschaften Technischen Fakultät der an der

Friedrich-Alexander-Universität Erlangen-Nürnberg 